\title{
Biosynthesis of Nonimmunosuppressive FK506 Analogues with Antifungal Activity
}

Ji Yoon Beom, ${ }^{\dagger}, \|$ Jin A Jung, ${ }^{\dagger,} \|$ Kyung-Tae Lee,,$"$, Areum Hwangbo,,$"$, Myoung Chong Song, ${ }^{\dagger}$ Yeonseon Lee, ${ }^{\ddagger}$ Soo Jung Lee,${ }^{\ddagger}$ Ji Hoon Oh, ${ }^{\S}$ Sang-Jun Ha, ${ }^{\S}$ Sang-Jip

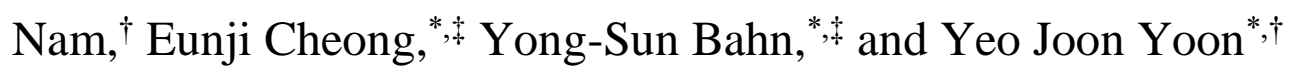

${ }^{\dagger}$ Department of Chemistry and Nano Science, and Institute of Nano-Biotechnology, Ewha Womans University, Seoul 120-750, Republic of Korea

Department of Biotechnology, College of Life Science and Biotechnology, Yonsei University, Seoul 03722, Republic of Korea

${ }^{\S}$ Department of Biochemistry, College of Life Science and Biotechnology, Yonsei University, Seoul 03722, Republic of Korea

"These authors contributed equally.

${ }^{*}$ Corresponding Author

Tel: +82-2-3277-4446. Fax: +82-2-3277-3419. E-mail: joonyoon@ewha.ac.kr

Tel: +82-2-2123-5558. Fax: +82-2-362-7265. E-mail: ysbahn@yonsei.ac.kr

Tel: +82-2-2123-5885. Fax: +82-2-2123-8284. E-mail: eunjicheong@yonsei.ac.kr 


\section{Table of Contents}

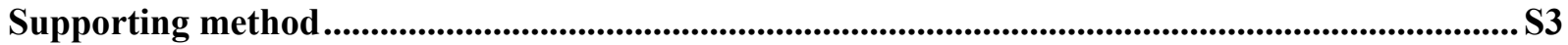

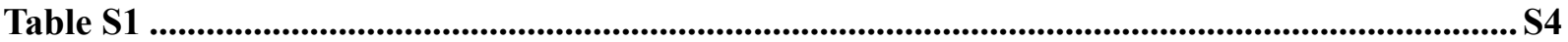

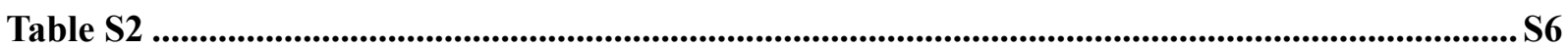

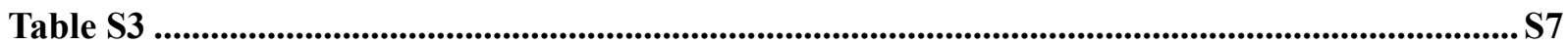

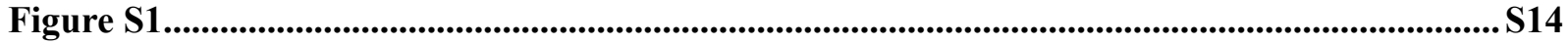

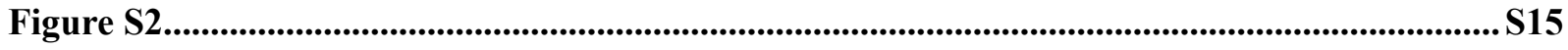

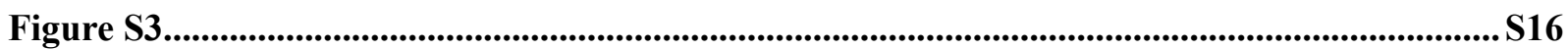

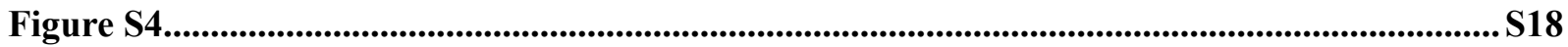

Figure S5

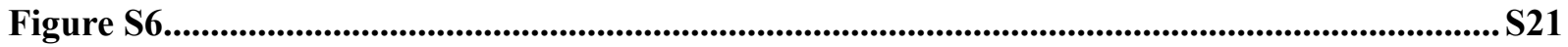

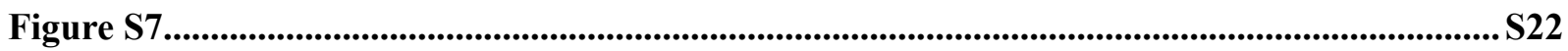

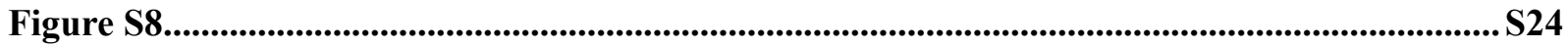

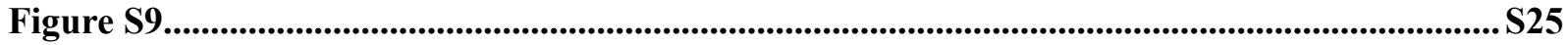

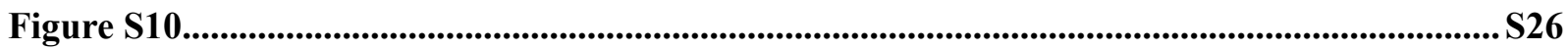

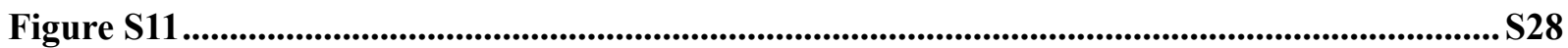

Figure S12

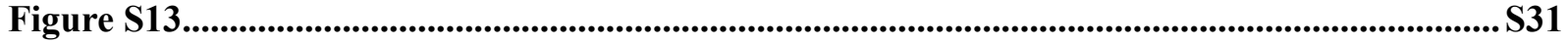

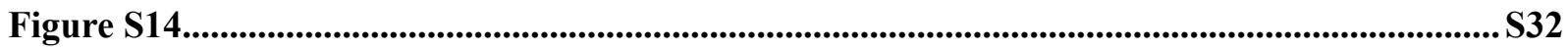

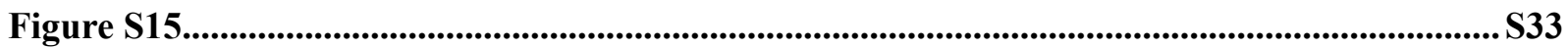

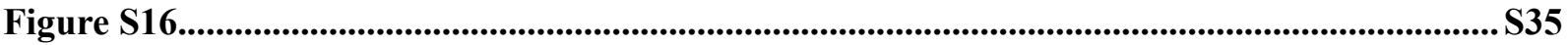

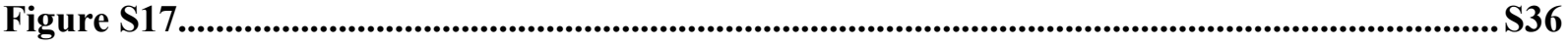

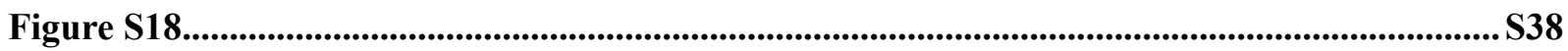

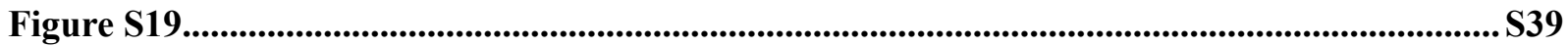

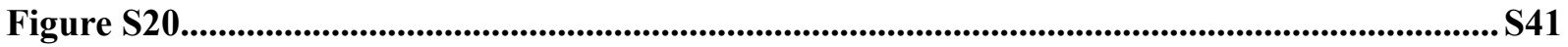

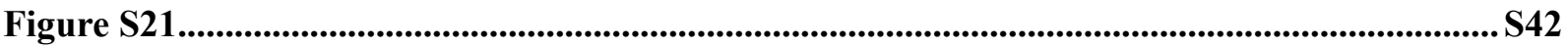

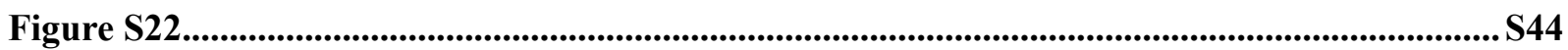

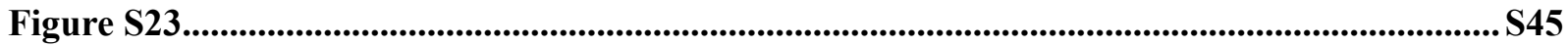

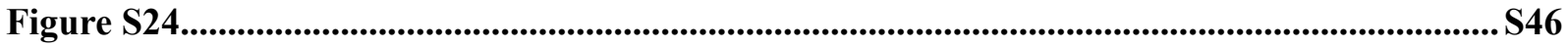

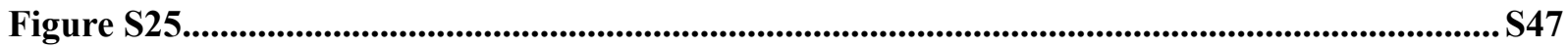

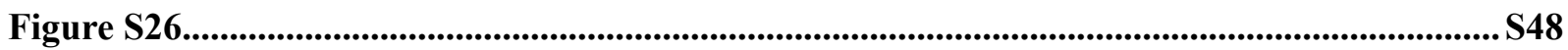

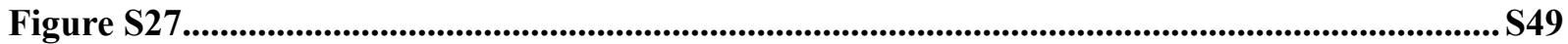

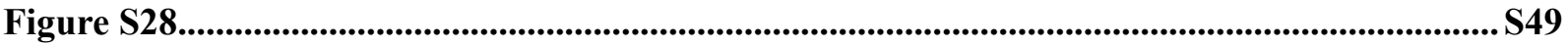

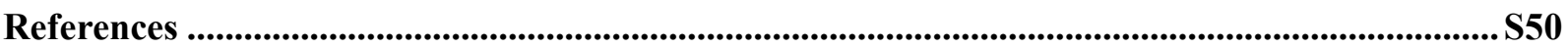




\section{Materials and bacterial strains}

Polymerase chain reactions (PCR) were carried out using Prime STAR GXL polymerase from Takara. Restriction endonucleases and T4 DNA ligase were purchased from New England Biolabs. Ampicillin, apramycin, chloramphenicol, kanamycin, and nalidixic acid were purchased from Sigma.

Bacterial strains used in this study are listed in Table S1. Escherichia coli $\mathrm{DH} 5 \alpha^{1}$ was used for routine subcloning, while E. coli ET12567/pUZ8002 (nonmethlyating plasmid donor strain) ${ }^{2}$ was used for intergenic conjugation with mutant of Streptomyces sp. KCTC 11604BP.

\section{Gene inactivation by in-frame deletion}

For in-frame deletion, the construction of recombinant plasmids was carried out by PCR amplification of the left- and right- flanking fragments from genomic DNA derived from Streptomyces sp. KCTC 11604BP. The primers fkbMLF and fkbMLR were designed for amplification of left-flanking fragments of target genes, whereas the primers fkbMRF and fkbMRR were used for amplification of right-flanking fragments (Table S2). The two PCR fragments were separately cloned in pGEM-T Easy vector (Promega) and sequenced. After digestion with appropriate restriction enzymes, the fragments were cloned into E. coli-Streptomyces shuttle vector pKC1139³ digested with HindIII-XbaI or XbaIEcoRI, to construct two different in-frame deletion plasmids. The plasmids used for in-frame gene deletion are summarized in Table S1. They were transferred by conjugation from E. coli ET12567/pUZ8002 ${ }^{2}$ to mutant of Streptomyces sp. KCTC 11604BP, and then target genes were deleted by homologous recombination. The eight desired double crossover mutants, $\Delta \mathrm{fkbM}, \Delta \mathrm{fkbDM}$, $\Delta \mathrm{tcsB}-\Delta \mathrm{fkbD}, \Delta \mathrm{tcsB}-\Delta \mathrm{fkbM}, \Delta \mathrm{tcsB}-\Delta \mathrm{fkbDM}, \Delta \mathrm{tcsD}-\Delta \mathrm{fkbD}, \Delta \mathrm{tcsD}-\Delta \mathrm{fkbM}$, and $\Delta \mathrm{tcsD}-\Delta \mathrm{fkbDM}$, were selected as described previously, ${ }^{4}$ and verified by PCR or Southern blot analysis. 
Table S1. Strains and plasmids used in this study

\begin{tabular}{llc}
\hline \multicolumn{1}{c}{ Strain/vector } & Relevant characteristics & Reference \\
\hline \hline Bacterial stains & & \\
Escherichia coli & & New England \\
DH5 $\alpha$ & Host for general cloning & Biolabs \\
& & \\
ET12567/pUZ8002 & Donor strain for intergeneric conjugation between E. coli and \\
& Streptomyces
\end{tabular}

$\underline{\text { Streptomyces }}$

$\Delta \mathrm{fkbD} \quad$ Mutant of KCTC 11604BP with an in-frame deletion of $f k b D$, produces $\mathbf{2}$ and $\mathbf{3}$

$\Delta \mathrm{fkbM} \quad$ Mutant of KCTC 11604BP with an in-frame deletion of $f k b M$, produces 4 and 31-O-demethyl-prolylFK506

This study

$\Delta \mathrm{fkbDM} \quad$ Mutant of KCTC 11604BP with an in-frame deletion of $f k b D$ and $f k b M$, produces $\mathbf{5}$ and $\mathbf{1 1}$

This study

$\Delta \mathrm{tcsB}-\Delta \mathrm{fkbD} \quad$ Mutant of KCTC $11604 \mathrm{BP}$ with an in-frame deletion of tcsB and $f k b D$, produces $\mathbf{7}$ and $\mathbf{8}$

This study

$\Delta \mathrm{tcsB}-\Delta \mathrm{fkbM} \quad$ Mutant of KCTC $11604 \mathrm{BP}$ with an in-frame deletion of $t c s B$ and $f k b M$, produces 10 and 31-O-demethylFK523

This study

$\Delta \mathrm{tcsB}-\Delta \mathrm{fkbDM} \quad$ Mutant of KCTC 11604BP with an in-frame deletion of $t c s B, f k b D$ and $f k b M$, produces $\mathbf{1 3}$ and $\mathbf{1 4}$

This study

$\Delta \mathrm{tcsD}-\Delta \mathrm{fkbD} \quad$ Mutant of KCTC 11604BP with an in-frame deletion of $t c s D$ and $f k b D$, produces 6 .

This study

$\Delta \mathrm{tcsD}-\Delta \mathrm{fkbM} \quad$ Mutant of KCTC 11604BP with an in-frame deletion of $t c s D$ and $f k b M$, produces 9 .

This study 
$\Delta \mathrm{tcsD}-\Delta \mathrm{fkbDM} \quad$ Mutant of KCTC 11604BP with an in-frame deletion of $t c s D, f k b D$ and $f k b M$, produces $\mathbf{1 2}$ and $\mathbf{1 3}$

\section{Fungals}

H99

Cryptococcus neoformans (ATCC number: 208821)

SC5314

Candida albicans (ATCC number: MYA2876)

Af293

Aspergillus fumigatus (ATCC number: MYA4609)

\section{Plasmid}

$\begin{array}{lll}\text { pGEM-Teasy } & \text { PCR fragment cloning vector } & \text { Promega } \\ \mathrm{pKC1139} & \text { High-copy-number temperature-sensitive } \quad \text { E. coli-Streptomyces } & (3) \\ & \text { shuttle vector } & \\ \mathrm{p} \Delta \mathrm{FkbD} & \text { Deletion plasmid with in-frame deletion of 53-bp internal fkbD } \\ & \text { fragment } \\ \mathrm{p} \Delta \mathrm{FkbM} & \text { Deletion plasmid with in-frame deletion of 509-bp internal fkbM } & \text { This study } \\ \mathrm{p} \Delta \mathrm{FkbDM} & \text { fragment } & \\ & \text { Deletion plasmid with in-frame deletion of 1,165-bp internal fkbD } \\ \mathrm{p} \Delta \mathrm{TcsB} & \text { and fkbM fragment } & \text { This study } \\ \mathrm{p} \Delta \mathrm{TcsD} & \text { Deletion plasmid with in-frame deletion of 2,088-bp internal tcsB } \\ & \text { fragment } \\ & \text { Deletion plasmid with in-frame deletion of 1,152-bp internal tcsD } \\ & \text { fragment }\end{array}$


Table S2. Primers used in this study

\begin{tabular}{crc}
\hline Primer Sequence & $\mathbf{5}^{\prime}$ to 3' (restriction site underlined) & $\begin{array}{c}\text { Restriction } \\
\text { enzyme }\end{array}$ \\
\hline \hline FkbMLF & TACG $\underline{\text { AAGCTT TCTGTTCGGCATCCAGCA }}$ & HindIII \\
FkbMLR & TAGC $\underline{\text { TCTAGA GTCACCCGGGAGCAGTTC }}$ & XbaI \\
FkbMRF & TATA $\underline{\text { TCTAGA GACACCGAAGGCGCGCTC }}$ & XbaI \\
FkbMRR & TTAA GAATTC GAACACCGAGGCCGTCCA & EcoRI \\
\hline
\end{tabular}


Table S3. NMR data of FK506 analogues

\begin{tabular}{|c|c|c|c|c|c|c|c|c|}
\hline & \multicolumn{2}{|c|}{$\begin{array}{c}\text { 9-deoxo-36,37-dihydroFK506 } \\
\text { (6) }\end{array}$} & \multicolumn{2}{|r|}{ 9-deoxoFK523 (8) } & \multicolumn{2}{|c|}{$\begin{array}{c}\text { 31- } O \text {-demethyl- } \\
\text { 36,37-dihydroFK506 (9) } \\
\end{array}$} & \multicolumn{2}{|c|}{$\begin{array}{c}\text { 9-deoxo-31- } O \text {-demethyl- } \\
\text { prolylFK506 (11) } \\
\end{array}$} \\
\hline & $\delta_{\mathrm{C}}$ & $\delta_{\mathrm{H}},(J$ in $\mathrm{Hz})$ & $\delta_{\mathrm{C}}$ & $\delta_{\mathrm{H}},(J$ in $\mathrm{Hz})$ & $\delta_{\mathrm{C}}$ & $\delta_{\mathrm{H}},(J$ in $\mathrm{Hz})$ & $\delta_{\mathrm{C}}$ & $\delta_{\mathrm{H}},(J$ in $\mathrm{Hz})$ \\
\hline 1 & 169.4 & & 169.6 & & 169.4 & & 170.1 & \\
\hline 2 & 52.6 & 4.85, brd $(5.0)$ & 52.6 & 4.85, brd $(5.0)$ & 56.6 & 4.58, brd $(5.0)$ & 59.1 & $4.36, \mathrm{dd}(10.5,3.5)$ \\
\hline \multirow[t]{2}{*}{3} & 26.6 & $1.70, \mathrm{~m}$ & 26.9 & $1.70, \mathrm{~m}$ & 27.9 & $2.05, \mathrm{~m}$ & 29.4 & $1.97, \mathrm{~m}$ \\
\hline & & $2.24, \mathrm{~m}$ & & $2.24, \mathrm{~m}$ & & $1.90, \mathrm{~m}$ & & $2.19, \mathrm{~m}$ \\
\hline \multirow[t]{2}{*}{4} & 20.7 & $1.31, \mathrm{~m}$ & 20.7 & $1.31, \mathrm{~m}$ & 21.4 & $1.38, \mathrm{~m}$ & 24.9 & $1.96, \mathrm{~m}$ \\
\hline & & $1.72, \mathrm{~m}$ & & $1.72, \mathrm{~m}$ & & $1.74, \mathrm{~m}$ & & $1.98, \mathrm{~m}$ \\
\hline \multirow[t]{2}{*}{5} & 24.4 & $1.51, \mathrm{~m}$ & 24.4 & $1.51, \mathrm{~m}$ & 24.8 & $1.51, \mathrm{~m}$ & & \\
\hline & & $1.68, \mathrm{~m}$ & & $1.68, \mathrm{~m}$ & & $1.68, \mathrm{~m}$ & & \\
\hline \multirow[t]{2}{*}{6} & 42.7 & $3.19, \mathrm{~m}$ & 42.7 & $3.19, \mathrm{~m}$ & 39.6 & $3.03, \mathrm{~m}$ & 47.6 & $3.55, \mathrm{~m}$ \\
\hline & & $3.69, \mathrm{~m}$ & & $3.69, \mathrm{~m}$ & & $4.44, \mathrm{~m}$ & & $3.64, \mathrm{~m}$ \\
\hline \multicolumn{9}{|l|}{7} \\
\hline 8 & 174.0 & & 174.2 & & 165.1 & & 173.0 & \\
\hline \multirow[t]{2}{*}{9} & 36.3 & $2.49, \mathrm{~d}(15.0)$ & 36.3 & $2.51, \mathrm{~d}(15.0)$ & 196.5 & & 39.3 & $2.56, \mathrm{~d}(15.0)$ \\
\hline & & $2.66, \mathrm{~d}(15.0)$ & & $2.70, \mathrm{~d}(15.0)$ & & & & $2.63, \mathrm{~d}(15.0)$ \\
\hline 10 & 98.5 & & 98.7 & & 97.4 & & 98.7 & \\
\hline 11 & 38.4 & $1.56, \mathrm{~m}$ & 38.7 & $1.58, \mathrm{~m}$ & 35.3 & $2.32, \mathrm{~m}$ & 38.7 & $1.59, \mathrm{~m}$ \\
\hline \multirow[t]{2}{*}{12} & 31.1 & $1.60, \mathrm{~m}$ & 32.8 & $1.60, \mathrm{~m}$ & 33.0 & $1.52, \mathrm{~m}$ & 32.9 & $1.56, \mathrm{~m}$ \\
\hline & & $1.94, \mathrm{~m}$ & & $1.94, \mathrm{~m}$ & & $2.16, \mathrm{~m}$ & & $1.99, \mathrm{~m}$ \\
\hline 13 & 74.3 & $3.40, \mathrm{~m}$ & 74.6 & $3.40, \mathrm{~m}$ & 74.0 & $3.39, \mathrm{~m}$ & 74.7 & $3.43, \mathrm{~m}$ \\
\hline 14 & 70.6 & 3.84, dd $(10.0,5.0)$ & 70.9 & $3.86, \mathrm{dd}(10.0,5.0)$ & 73.2 & $3.68, \mathrm{dd}(10.0,5.0)$ & 71.1 & 3.85, dd $(10.0,5.0)$ \\
\hline
\end{tabular}




$\begin{array}{rrl}15 & 77.1 & 3.53, \mathrm{~m} \\ 16 & 36.6 & 1.34, \mathrm{~m} \\ & & 1.47, \mathrm{~m} \\ 17 & 25.6 & 1.50, \mathrm{~m} \\ 18 & 48.5 & 1.65, \mathrm{~m} \\ & & 2.32, \mathrm{~m} \\ 19 & 140.8 & \\ 20 & 122.2 & 5.05, \mathrm{~d}(5.0) \\ 21 & 53.5 & 3.21, \mathrm{~m} \\ 22 & 215.4 & \\ 23 & 41.7 & 2.21, \mathrm{brd}(15.0) \\ & & 2.66, \mathrm{brd}(15.0) \\ 24 & 69.6 & 3.97, \mathrm{~m} \\ 25 & 40.3 & 1.87, \mathrm{~m} \\ 26 & 76.5 & 5.19, \mathrm{brs} \\ 27 & 132.4 & \\ 28 & 128.7 & 4.97, \mathrm{~d}(5.0) \\ 29 & 34.8 & 2.35, \mathrm{~m} \\ 30 & 39.8 & 0.93, \mathrm{~m} \\ & & 2.01, \mathrm{~m} \\ 31 & 84.1 & 3.00, \mathrm{~m} \\ 32 & 73.6 & 3.39, \mathrm{~m} \\ 33 & 30.6 & 1.34, \mathrm{~m} \\ & & 1.98, \mathrm{~m} \\ 34 & 31.2 & 1.06, \mathrm{~m} \\ & & \\ & & \\ & & \end{array}$

$\begin{array}{rl}77.1 & 3.53, \mathrm{~m} \\ 36.5 & 1.34, \mathrm{~m} \\ & 1.47, \mathrm{~m} \\ 26.3 & 1.50, \mathrm{~m} \\ 48.5 & 1.65, \mathrm{~m} \\ & 2.32, \mathrm{~m} \\ 140.4 & \\ 123.5 & 5.17, \mathrm{~d}(5.0) \\ 53.5 & 3.21, \mathrm{~m} \\ 215.4 & \\ 41.7 & 2.21, \mathrm{brd}(15.0) \\ & 2.66, \mathrm{brd}(15.0) \\ 70.0 & 4.01, \mathrm{~m} \\ 40.7 & 1.90, \mathrm{~m} \\ 76.6 & 5.22, \mathrm{brs} \\ 132.7 & \\ 128.9 & 4.98, \mathrm{~d}(5.0) \\ 35.1 & 2.35, \mathrm{~m} \\ 35.1 & 0.93, \mathrm{~m} \\ & 2.01, \mathrm{~m} \\ 84.4 & 3.00, \mathrm{~m} \\ 73.8 & 3.39, \mathrm{~m} \\ 32.9 & 1.34, \mathrm{~m} \\ & 1.98, \mathrm{~m} \\ 31.4 & 1.06, \mathrm{~m} \\ & \end{array}$

$\begin{array}{rl}75.2 & 3.39, \mathrm{~m} \\ 35.8 & 1.35, \mathrm{~m} \\ & 1.56, \mathrm{~m} \\ 26.7 & 1.66, \mathrm{~m} \\ 49.0 & 1.80, \mathrm{~m} \\ & 2.17, \mathrm{~m} \\ 138.8 & \\ 123.6 & 5.03, \mathrm{~d}(5.0) \\ 53.3 & 3.28, \mathrm{~m} \\ 213.8 & \\ 43.6 & 2.10, \mathrm{brd}(15.0) \\ & 2.77, \mathrm{brd}(15.0) \\ 70.4 & 3.92, \mathrm{~m} \\ 40.0 & 1.89, \mathrm{~m} \\ 77.8 & 5.33, \mathrm{brs} \\ 132.6 & \\ 130.0 & 5.09, \mathrm{~d}(5.0) \\ 34.9 & 2.18, \mathrm{~m} \\ 39.4 & 1.14, \mathrm{~m} \\ & 1.91, \mathrm{~m} \\ 75.8 & 3.59, \mathrm{~m} \\ 75.6 & 3.36, \mathrm{~m} \\ 32.4 & 1.35, \mathrm{~m} \\ & 1.98, \mathrm{~m} \\ 31.2 & 1.06, \mathrm{~m} \\ & \end{array}$


$1.61, \mathrm{~m}$

35

$$
33.81 .42, \mathrm{~m}
$$

$1.65, \mathrm{~m}$

$36 \quad 20.4 \quad 1.21, \mathrm{~m}$

$37 \quad 13.9 \quad 0.88, \mathrm{t}(7.5)$

$38 \quad 16.9 \quad 0.93, \mathrm{~d}(6.5)$

$39 \quad 18.8 \quad 0.76, \mathrm{~d}(6.5)$

$40 \quad 15.5 \quad 1.63, \mathrm{~s}$

$41 \quad 10.1 \quad 0.90, \mathrm{~d}(6.5)$

$42 \quad 13.9 \quad 1.66, \mathrm{~s}$

$43 \quad 56.1 \quad 3.35, \mathrm{~s}$ (on C13)

$44 \quad 57.6 \quad 3.36, \mathrm{~s}$ (on C15)

$45 \quad 56.6 \quad 3.39, \mathrm{~s}($ on $\mathrm{C} 31)$
1.61, m

$17.1 \quad 1.18, \mathrm{t}(7.5)$

$17.10 .96, d(6.5)$

$18.90 .78, \mathrm{~d}(6.5)$

$16.1 \quad 1.63, \mathrm{~s}$

$10.1 \quad 0.90, \mathrm{~d}(6.5)$

$14.81 .66, \mathrm{~s}$

56.4 3.37, s (on C13)

57.93 .37 , s (on C15)

56.8 3.41, s (on C31)
$1.61, \mathrm{~m}$

$33.31 .42, \mathrm{~m}$

1.66, m

$20.76 \quad 1.27, \mathrm{~m}$

$14.4 \quad 0.90, \mathrm{t}(7.5)$

$16.51 .00, \mathrm{~d}(6.5)$

$20.80 .93, \mathrm{~d}(6.5)$

$16.21 .59, \mathrm{~s}$

$9.8 \quad 0.87, \mathrm{~d}(6.5)$

$14.41 .62, \mathrm{~s}$

56.6 3.40, s (on C13)

57.3 3.30, s (on C15)
1.61, m

$35.8 \quad 2.25, \mathrm{~m}$

2.45, m

$135.8 \quad 5.72, \mathrm{~m}$

116.85 .00 , dd $(15.0,10.0)$ 5.03 , dd $(15.0,10.0)$

$17.20 .96, \mathrm{~d}(6.5)$

$19.1 \quad 0.77, \mathrm{~d}(6.5)$

$15.91 .67, \mathrm{~s}$

$10.10 .90, \mathrm{~d}(6.5)$

$14.4 \quad 1.65, \mathrm{~s}$

56.53 .38 , s (on C13)

$58.0 \quad 3.37$, s (on C15) 


\begin{tabular}{|c|c|c|c|c|c|c|}
\hline & 9-deo & $\begin{array}{l}\text { xo-31-O-demethyl-36,37- } \\
\text { dihydroFK506 (12) }\end{array}$ & 9-de & $\begin{array}{c}\text { xo-31-O-demethylFK520 } \\
\text { (13) }\end{array}$ & 9-dec & $\begin{array}{c}\text { xo-31- } O \text {-demethylFK523 } \\
\text { (14) }\end{array}$ \\
\hline & $\delta_{\mathrm{C}}$ & $\delta_{\mathrm{H}},(J$ in $\mathrm{Hz})$ & $\delta_{\mathrm{C}}$ & $\delta_{\mathrm{H}},(J$ in $\mathrm{Hz})$ & $\delta_{\mathrm{C}}$ & $\delta_{\mathrm{H}},(J$ in $\mathrm{Hz})$ \\
\hline 1 & 169.7 & & 169.7 & & 169.6 & \\
\hline 2 & 52.6 & 4.85, brd $(5.0)$ & 52.9 & 4.87, brd $(5.0)$ & 52.8 & 4.90, brd $(5.0)$ \\
\hline 3 & 26.9 & $1.70, \mathrm{~m}$ & 26.9 & $1.70, \mathrm{~m}$ & 26.9 & $1.70, \mathrm{~m}$ \\
\hline & & $2.23, \mathrm{~m}$ & & $2.23, \mathrm{~m}$ & & $2.24, \mathrm{~m}$ \\
\hline 4 & 21.0 & $1.32, \mathrm{~m}$ & 21.0 & $1.32, \mathrm{~m}$ & 20.7 & $1.31, \mathrm{~m}$ \\
\hline & & $1.72, \mathrm{~m}$ & & $1.72, \mathrm{~m}$ & & $1.72, \mathrm{~m}$ \\
\hline 5 & 24.8 & $1.52, \mathrm{~m}$ & 24.7 & $1.52, \mathrm{~m}$ & 24.7 & $1.51, \mathrm{~m}$ \\
\hline & & $1.68, \mathrm{~m}$ & & $1.68, \mathrm{~m}$ & & $1.68, \mathrm{~m}$ \\
\hline 6 & 43.0 & $3.19, \mathrm{~m}$ & 43.0 & $3.19, \mathrm{~m}$ & 42.9 & $3.21, \mathrm{~m}$ \\
\hline & & $3.70, \mathrm{~m}$ & & $3.70, \mathrm{~m}$ & & $3.72, \mathrm{~m}$ \\
\hline 7 & & & & & & \\
\hline 8 & 174.4 & & 174.3 & & 174.3 & \\
\hline 9 & 37.5 & $2.49, \mathrm{~d}(15.0)$ & 37.5 & $2.49, \mathrm{~d}(15.0)$ & 36.3 & $2.51, \mathrm{~d}(15.0)$ \\
\hline & & $2.67, \mathrm{~d}(15.0)$ & & $2.67, \mathrm{~d}(15.0)$ & & $2.70, \mathrm{~d}(15.0)$ \\
\hline 10 & 98.9 & & 98.8 & & 98.7 & \\
\hline 11 & 38.8 & $1.56, \mathrm{~m}$ & 38.8 & $1.56, \mathrm{~m}$ & 38.7 & $1.58, \mathrm{~m}$ \\
\hline
\end{tabular}




\begin{tabular}{|c|c|c|}
\hline 12 & 32.9 & $1.60, \mathrm{~m}$ \\
\hline & & $1.94, \mathrm{~m}$ \\
\hline 13 & 74.7 & $3.40, \mathrm{~m}$ \\
\hline 14 & 71.0 & $3.84, \mathrm{dd}(10.0,5.0)$ \\
\hline 15 & 77.2 & $3.53, \mathrm{~m}$ \\
\hline 16 & 36.6 & $1.34, \mathrm{~m}$ \\
\hline & & $1.47, \mathrm{~m}$ \\
\hline 17 & 26.9 & $1.63, \mathrm{~m}$ \\
\hline 18 & 48.5 & $1.64, \mathrm{~m}$ \\
\hline & & $2.33, \mathrm{~m}$ \\
\hline 19 & 141.2 & \\
\hline 20 & 122.5 & $5.05, \mathrm{~d}(5.0)$ \\
\hline 21 & 53.8 & $3.20, \mathrm{~m}$ \\
\hline 22 & 215.4 & \\
\hline 23 & 42.20 & 2.20, brd $(15.0)$ \\
\hline & & 2.64, brd $(15.0)$ \\
\hline 24 & 70.0 & $3.97, \mathrm{~m}$ \\
\hline 25 & 40.1 & $1.85, \mathrm{~m}$ \\
\hline 26 & 76.9 & 5.20, brs \\
\hline
\end{tabular}

\begin{tabular}{|c|c|}
\hline \multirow[t]{2}{*}{32.9} & $1.60, \mathrm{~m}$ \\
\hline & $1.94, \mathrm{~m}$ \\
\hline 74.6 & $3.41, \mathrm{~m}$ \\
\hline 70.9 & 3.86 , dd $(10.0,5.0)$ \\
\hline 77.2 & $3.53, \mathrm{~m}$ \\
\hline \multirow[t]{2}{*}{36.6} & $1.34, \mathrm{~m}$ \\
\hline & $1.47, \mathrm{~m}$ \\
\hline 25.9 & $1.63, \mathrm{~m}$ \\
\hline \multirow[t]{2}{*}{48.5} & $1.64, \mathrm{~m}$ \\
\hline & $2.33, \mathrm{~m}$ \\
\hline \multicolumn{2}{|l|}{141.3} \\
\hline 122.3 & $5.05, \mathrm{~d}(5.0)$ \\
\hline 55.7 & $3.20, \mathrm{~m}$ \\
\hline \multicolumn{2}{|l|}{215.4} \\
\hline \multirow[t]{2}{*}{42.2} & 2.20, brd $(15.0)$ \\
\hline & 2.64, brd $(15.0)$ \\
\hline 69.8 & $3.98, \mathrm{~m}$ \\
\hline 40.2 & $1.85, \mathrm{~m}$ \\
\hline 76.9 & 5.20 , brs \\
\hline
\end{tabular}

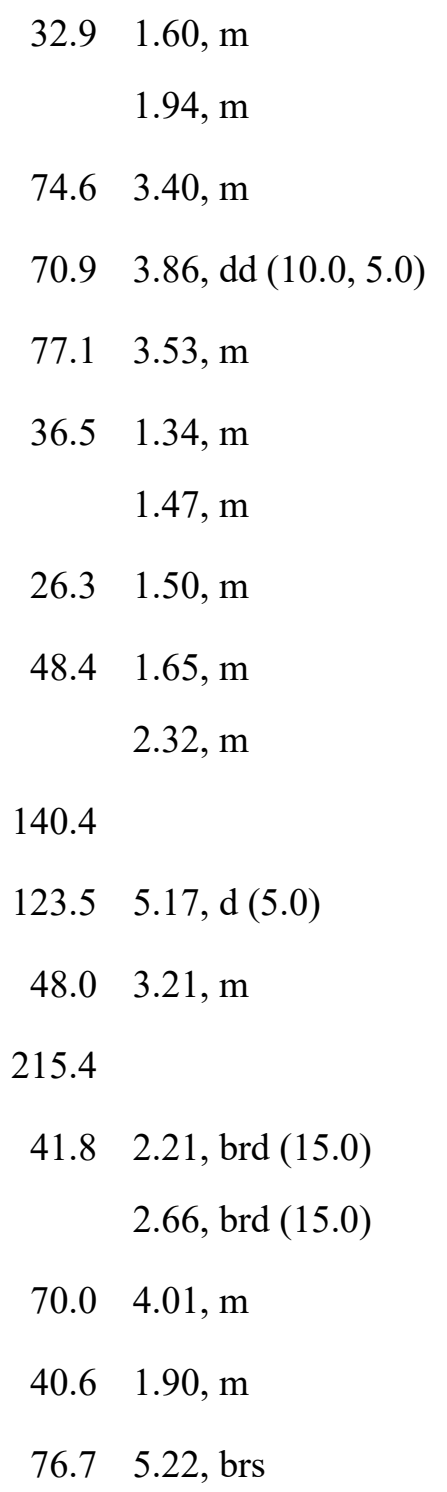




$\begin{array}{rrl}27 & 132.8 & \\ 28 & 129.0 & 4.97, \mathrm{~d}(5.0) \\ 29 & 35.3 & 2.32, \mathrm{~m} \\ 30 & 39.5 & 1.12, \mathrm{~m} \\ & & 1.88, \mathrm{~m} \\ 31 & 75.2 & 3.53, \mathrm{~m} \\ 32 & 75.2 & 3.40, \mathrm{~m} \\ 33 & 32.3 & 1.33, \mathrm{~m} \\ & & 1.95, \mathrm{~m} \\ 34 & 31.2 & 1.04, \mathrm{~m} \\ & & 1.59, \mathrm{~m} \\ 35 & 34.1 & 1.46, \mathrm{~m} \\ & & 1.62, \mathrm{~m} \\ 36 & 20.73 & 1.22, \mathrm{~m} \\ 37 & 14.3 & 0.88, \mathrm{t}(7.5) \\ 38 & 17.2 & 0.94, \mathrm{~d}(6.5) \\ 39 & 19.2 & 0.76, \mathrm{~d}(6.5) \\ 40 & 15.8 & 1.63, \mathrm{~s} \\ 41 & 10.1 & 0.85, \mathrm{~d}(6.5)\end{array}$

$\begin{array}{ll}132.8 & \\ 128.9 & 4.97, \mathrm{~d}(5.0) \\ 35.3 & 2.32, \mathrm{~m} \\ 39.5 & 1.12, \mathrm{~m} \\ & 1.88, \mathrm{~m} \\ 75.2 & 3.53, \mathrm{~m} \\ 75.2 & 3.40, \mathrm{~m} \\ 32.3 & 1.33, \mathrm{~m} \\ & 1.95, \mathrm{~m} \\ 31.2 & 1.04, \mathrm{~m} \\ & 1.59, \mathrm{~m} \\ 25.1 & 1.52, \mathrm{~m} \\ & 1.68, \mathrm{~m} \\ 12.0 & 0.88, \mathrm{t}(7.5) \\ 17.1 & 0.95, \mathrm{~d}(6.5) \\ 19.1 & 0.77, \mathrm{~d}(6.5) \\ 15.8 & 1.65, \mathrm{~s} \\ 10.0 & 0.86, \mathrm{~d}(6.5) \\ 14.7 & 1.67, \mathrm{~s}\end{array}$

\section{8}

$128.8 \quad 4.98, \mathrm{~d}(5.0)$

$35.2 \quad 2.35, \mathrm{~m}$

$39.41 .17, \mathrm{~m}$

1.91, m

$75.7 \quad 3.43, \mathrm{~m}$

$75.23 .36, \mathrm{~m}$

$32.21 .34, \mathrm{~m}$

$1.98, \mathrm{~m}$

$31.21 .06, \mathrm{~m}$

$1.61, \mathrm{~m}$

$17.1 \quad 1.18, \mathrm{~d}(7.5)$

$17.1 \quad 0.96, \mathrm{~d}(6.5)$

$18.9 \quad 0.78, \mathrm{~d}(6.5)$

$16.11 .66, \mathrm{~s}$

$10.1 \quad 0.88, \mathrm{~d}(6.5)$

14.7 1.67, s

56.4 3.37, s (on C13) 
(a)

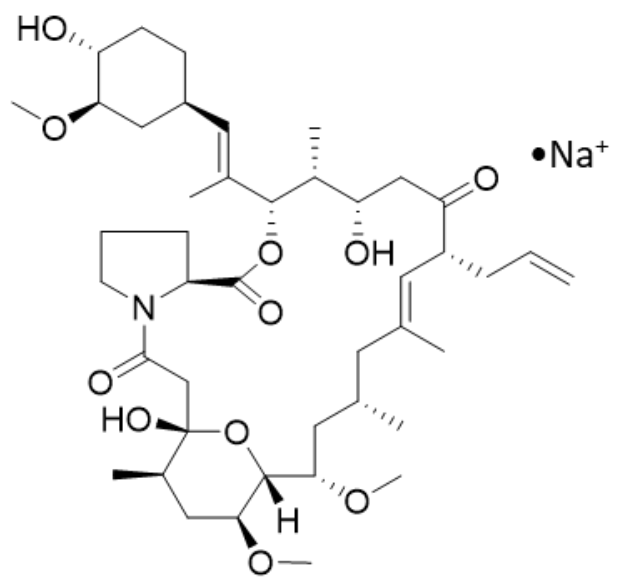

9-deoxo-prolylFK506 (2)

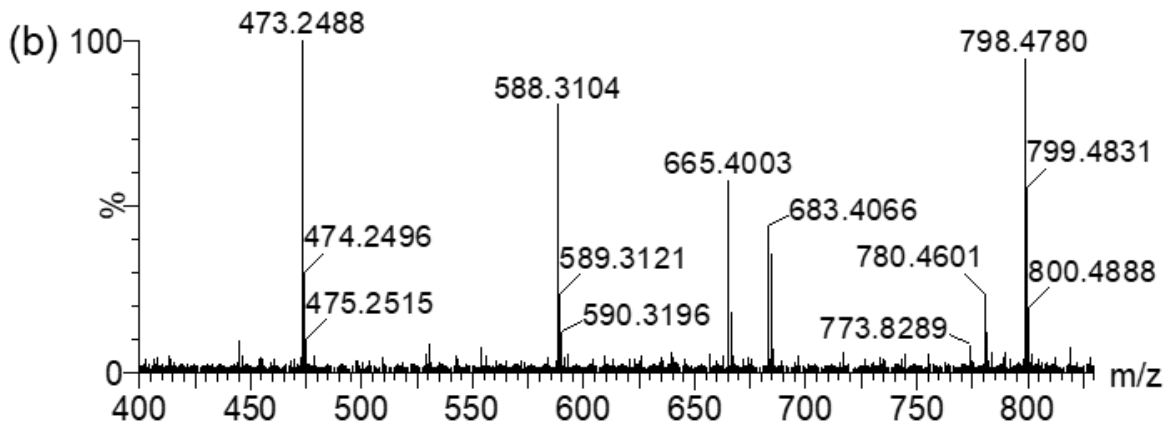

Figure S1. ESI-qTOF-HR-MS analysis of 9-deoxo-prolylFK506 (2) obtained from $\Delta \mathrm{fkbD}$ strain. (a) Chemical structure of $\mathbf{2}$, (b) MS/MS spectrum of 2. 
(a)

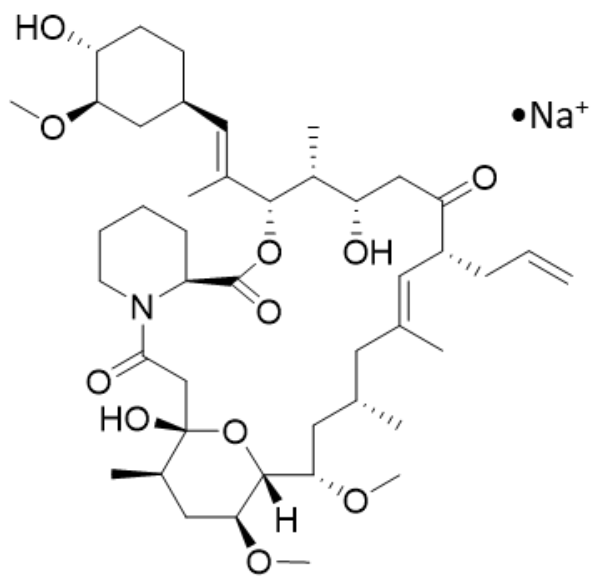

9-deoxoFK506 (3)

(b) 100

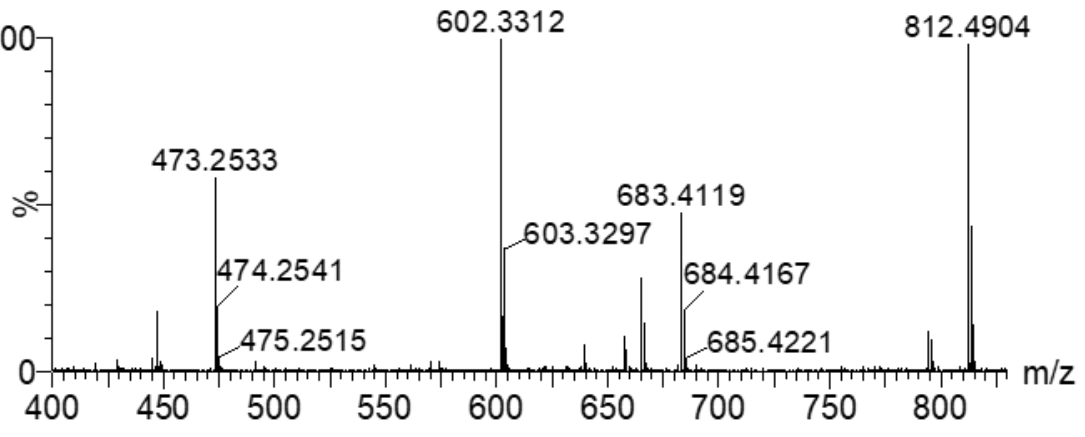

Figure S2. ESI-qTOF-HR-MS analysis of 9-deoxoFK506 (3) obtained from $\Delta \mathrm{fkbD}$ strain. (a) Chemical structure of $\mathbf{3}$, (b) MS/MS spectrum of $\mathbf{3}$. 
(a)

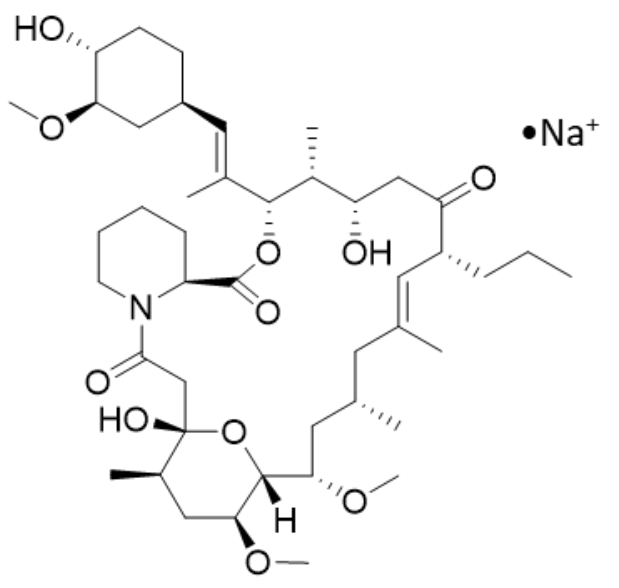

9-deoxo-36,37-dihydroFK506 (6)

(b) 100

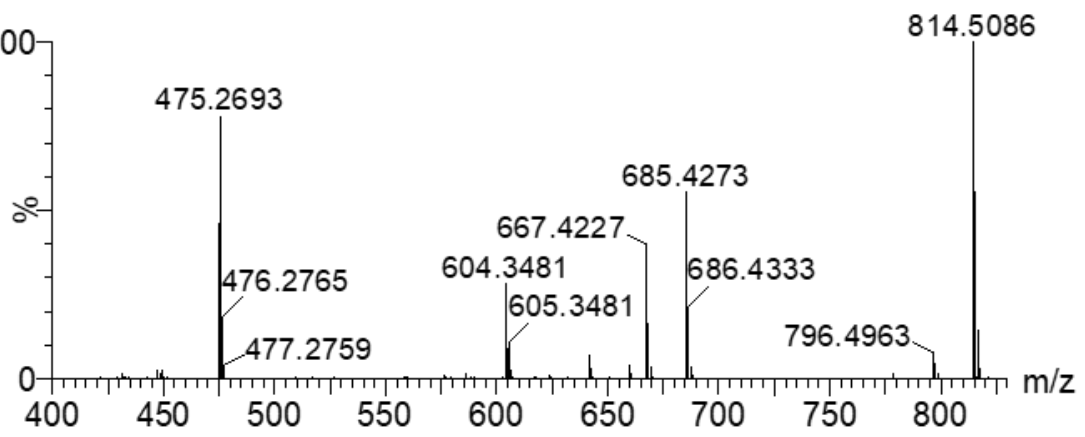

Figure S3. ESI-qTOF-HR-MS analysis of 9-deoxo-36,37-dihydroFK506 (6) obtained from $\Delta \mathrm{tcsD}-\Delta \mathrm{fkbD}$ strain. (a) Chemical structure of $\mathbf{6}$, (b) MS/MS data of $\mathbf{6}$. 
(a)

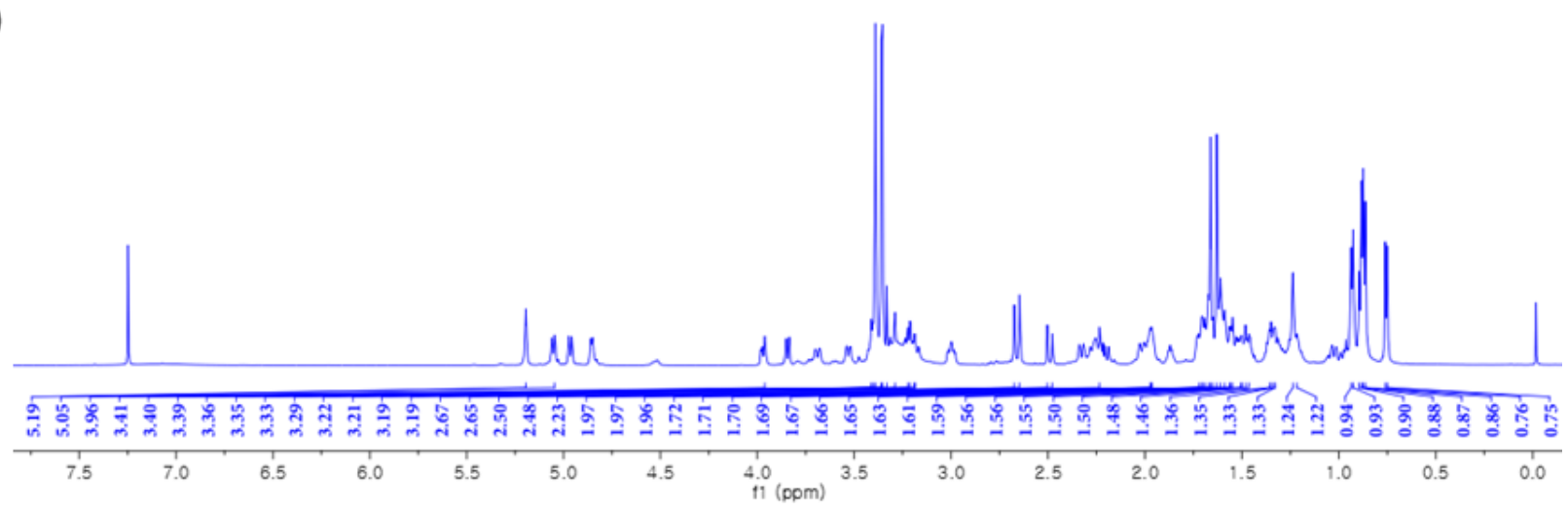

(b)

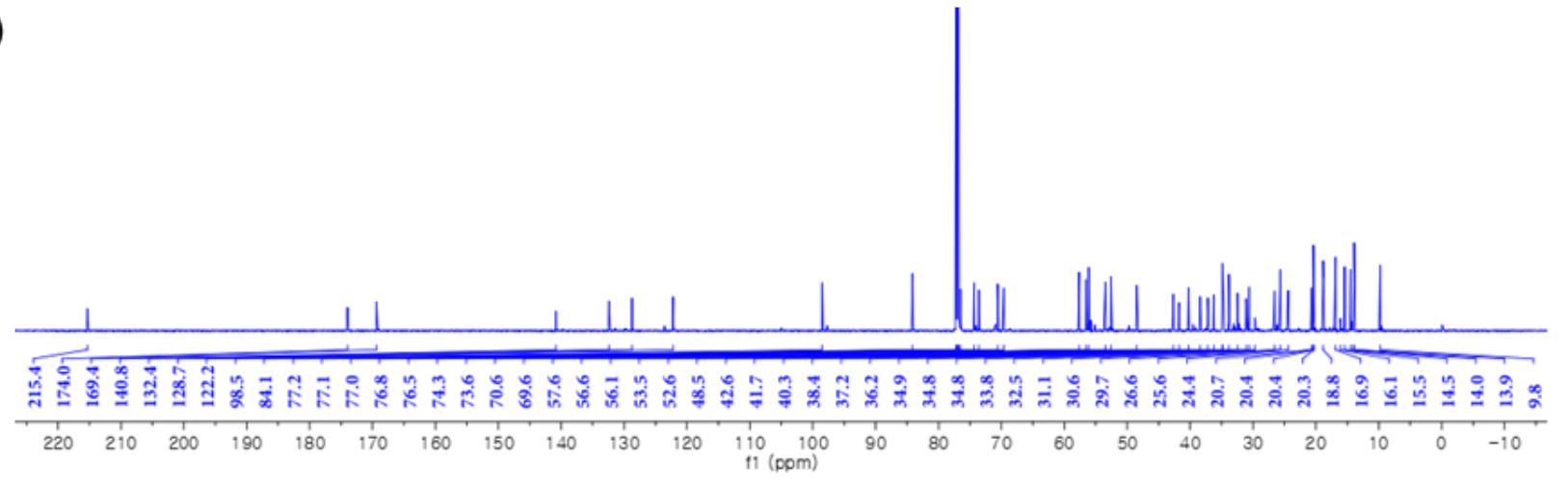

(c)

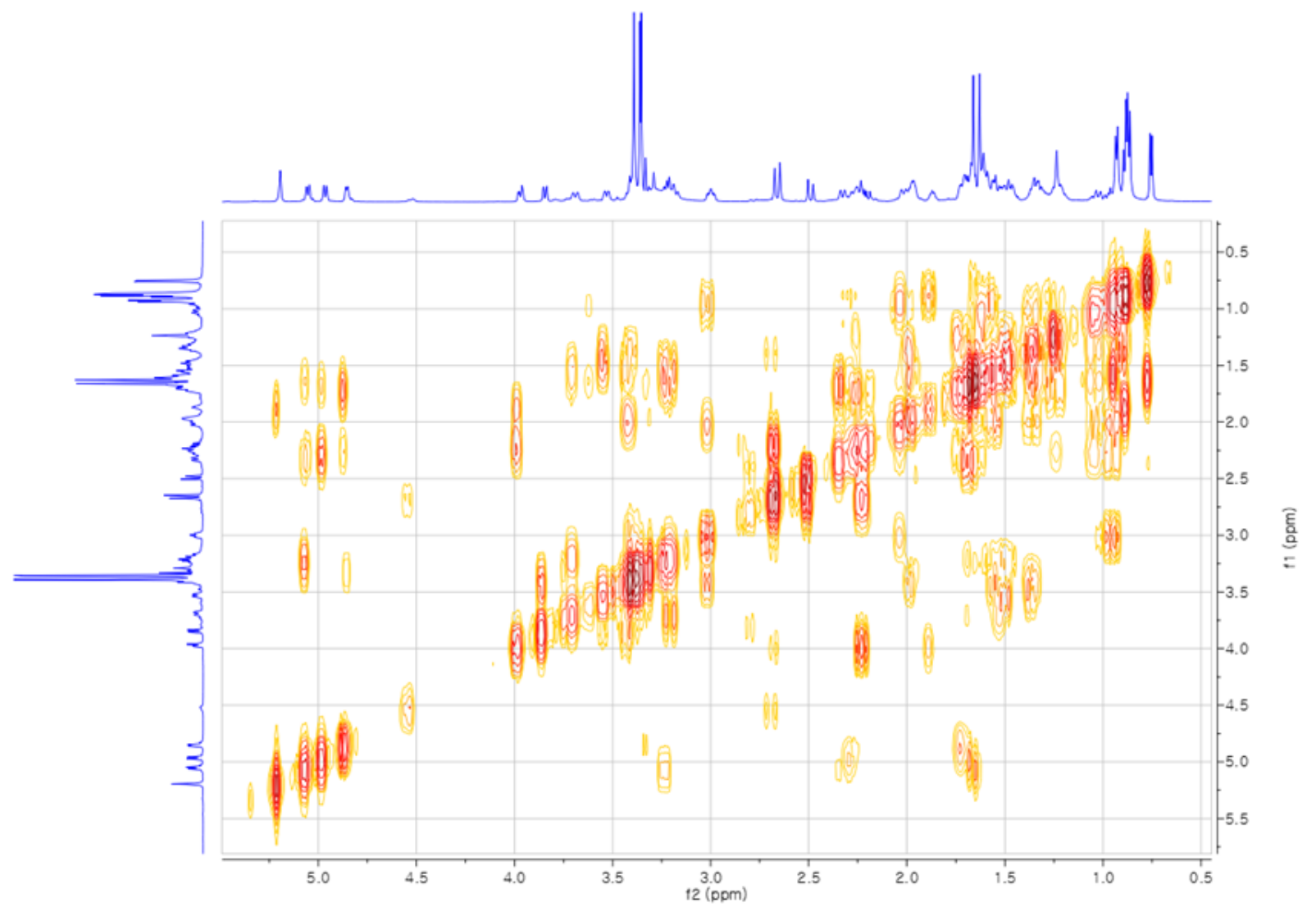


(d)

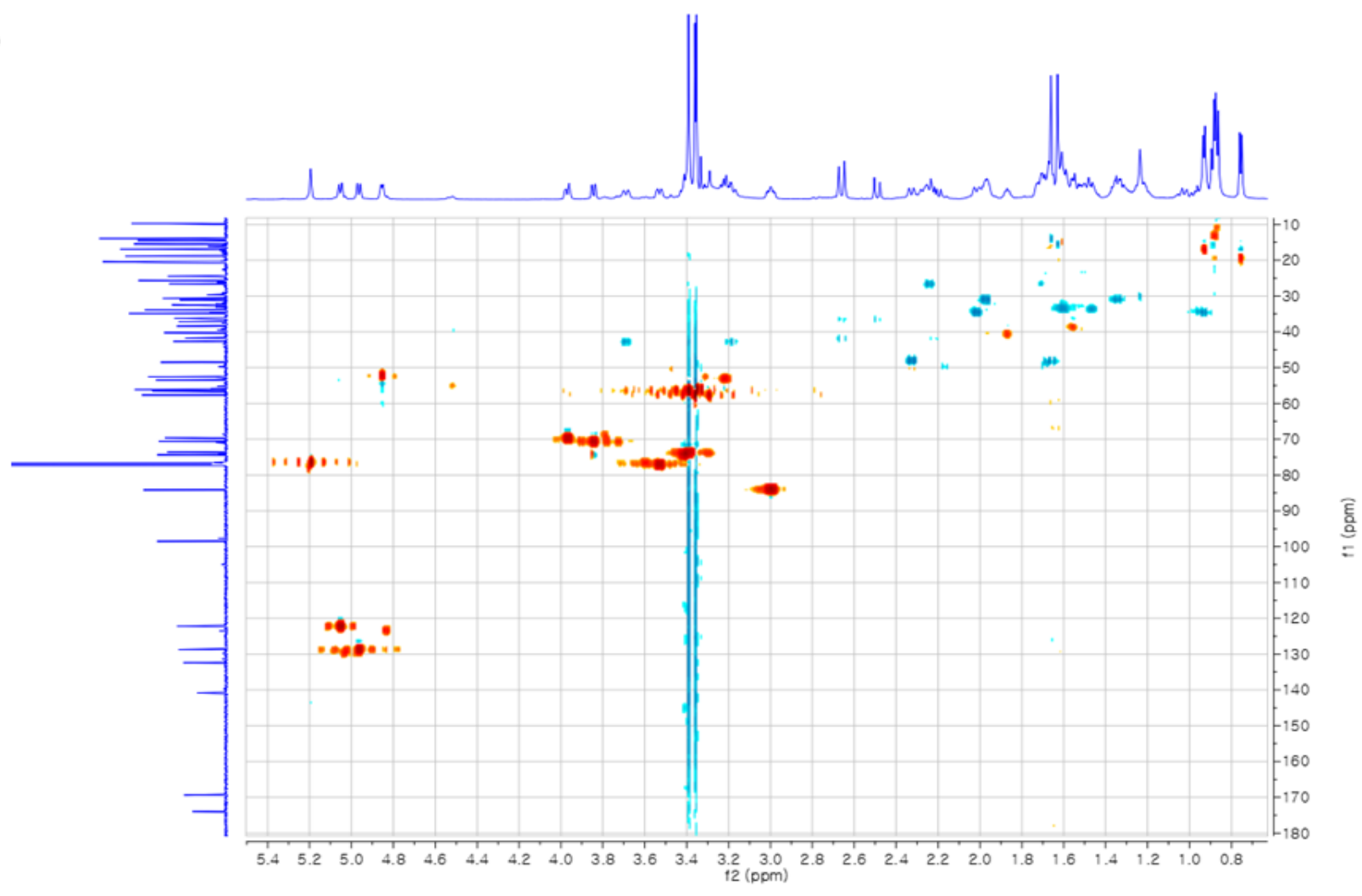

(e)

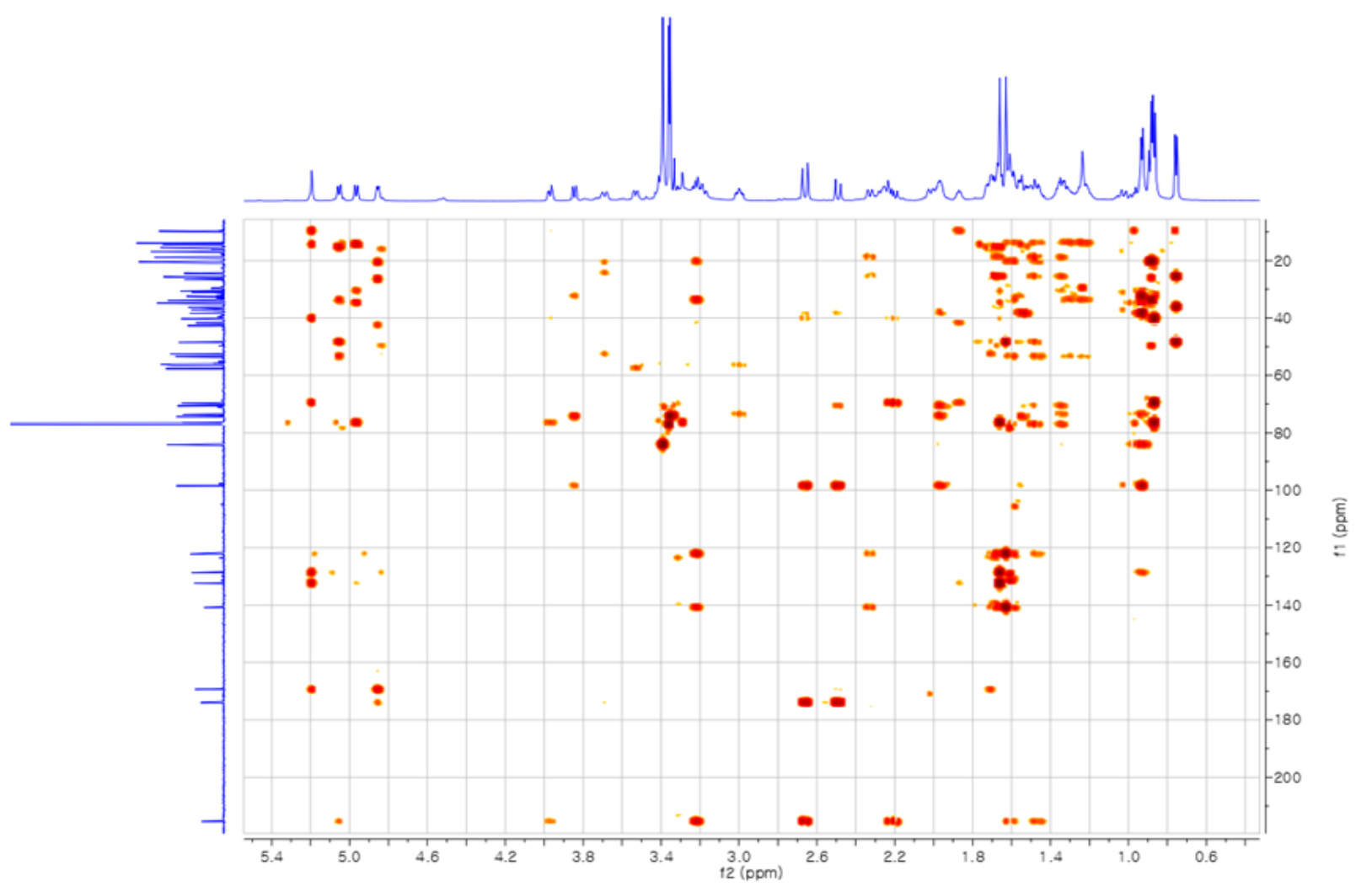

Figure S4. The structural determination of 9-deoxo-36,37-dihydroFK506 (6). (a) ${ }^{1} \mathrm{H}(500 \mathrm{MHz})$, (b) ${ }^{13} \mathrm{C}(125 \mathrm{MHz})$, (c) ${ }^{1} \mathrm{H}-{ }^{1} \mathrm{H}$ gCOSY, (d) ${ }^{1} \mathrm{H}_{-}{ }^{13} \mathrm{C}$ gHSQC, and (e) ${ }^{1} \mathrm{H}_{-}{ }^{13} \mathrm{C}$ gHMBC NMR data of 6 in $\mathrm{CDCl}_{3}$ obtained from $\Delta \mathrm{tcsD}-\Delta \mathrm{fkbD}$ strain. 
(a)
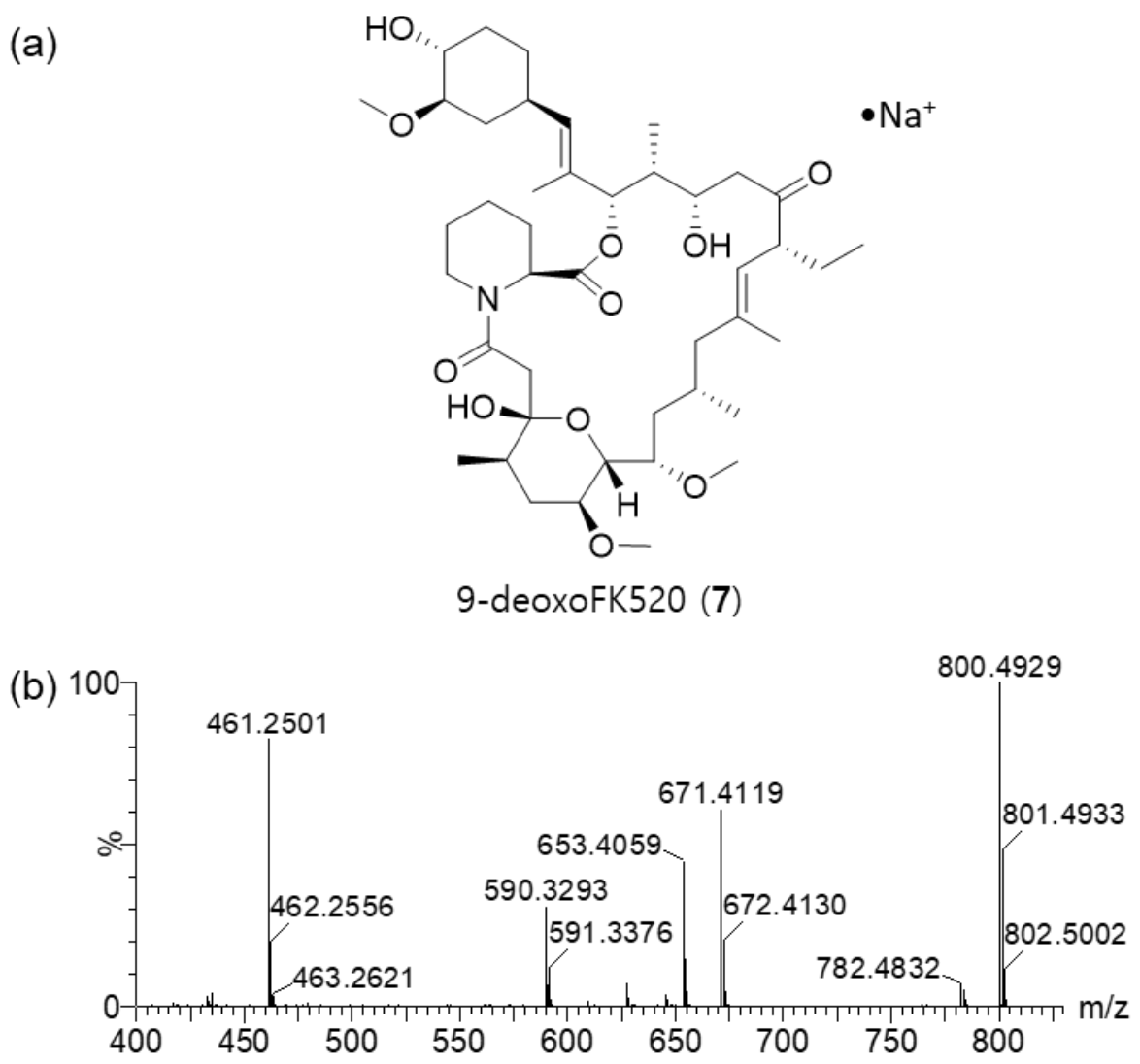

Figure S5. ESI-qTOF-HR-MS analysis of 9-deoxoFK520 (7) obtained from $\Delta$ tcsB- $\Delta$ fkbD strain. (a) Chemical structure of 7, (b) MS/MS spectrum of 7. 
(a)

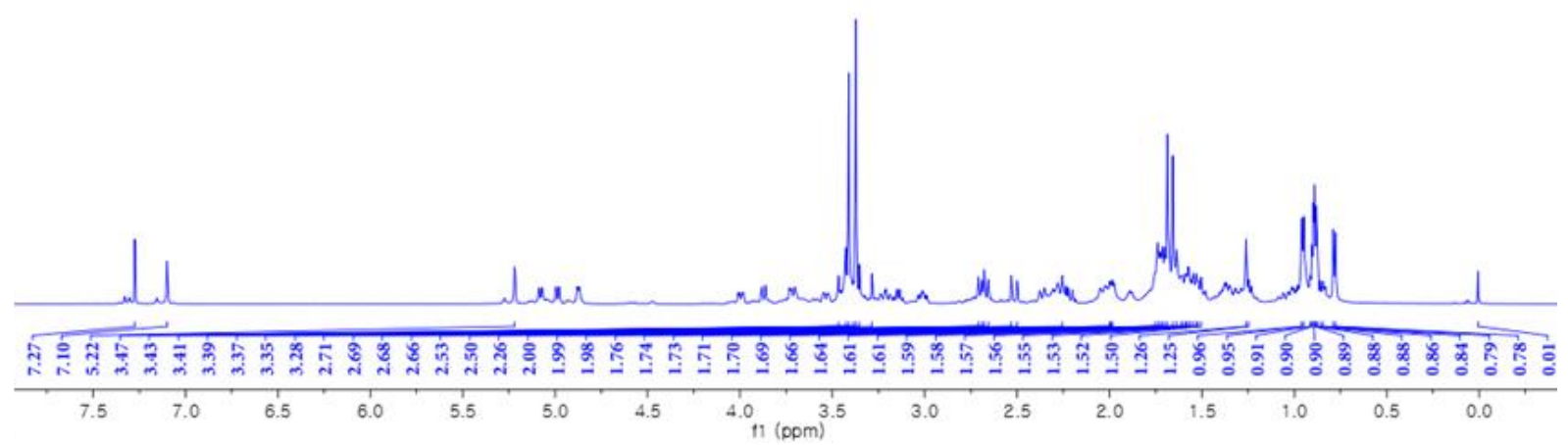

(b)

\begin{tabular}{|c|c|c|c|c|c|c|c|c|c|c|c|c|c|c|c|c|c|c|c|c|}
\hline & & & & 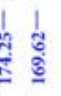 & & & 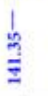 & के & & $\begin{array}{l}1 \\
\underset{2}{n} \\
2\end{array}$ & - & 角 & $\begin{array}{l}8 \% 8 \\
58\end{array}$ & & $\overline{\bar{x}}$ & $\begin{array}{l}1 \\
0 \\
0 \\
0\end{array}$ & 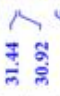 & 5. & $\begin{array}{l}70 \\
0\end{array}$ & 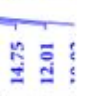 \\
\hline 210 & 200 & 190 & 180 & 170 & 160 & 150 & 140 & 130 & 120 & $\begin{array}{c}110 \quad 100 \\
11(\mathrm{ppm})\end{array}$ & 90 & 80 & $\frac{1}{70}$ & 60 & 50 & 10 & $\frac{1}{30}$ & $\frac{1}{20}$ & 10 & $\frac{1}{0}$ \\
\hline
\end{tabular}

(c)

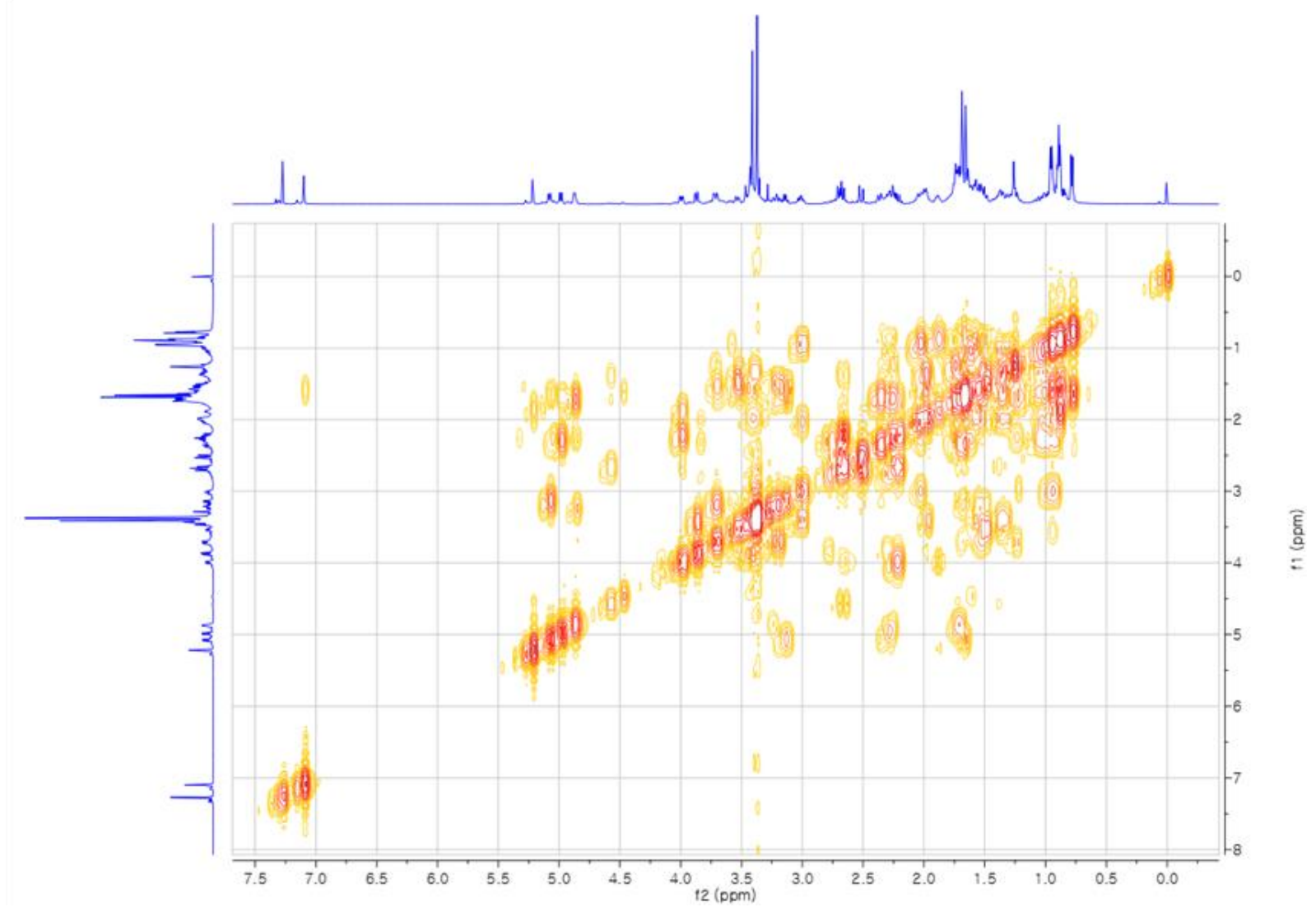


(d)

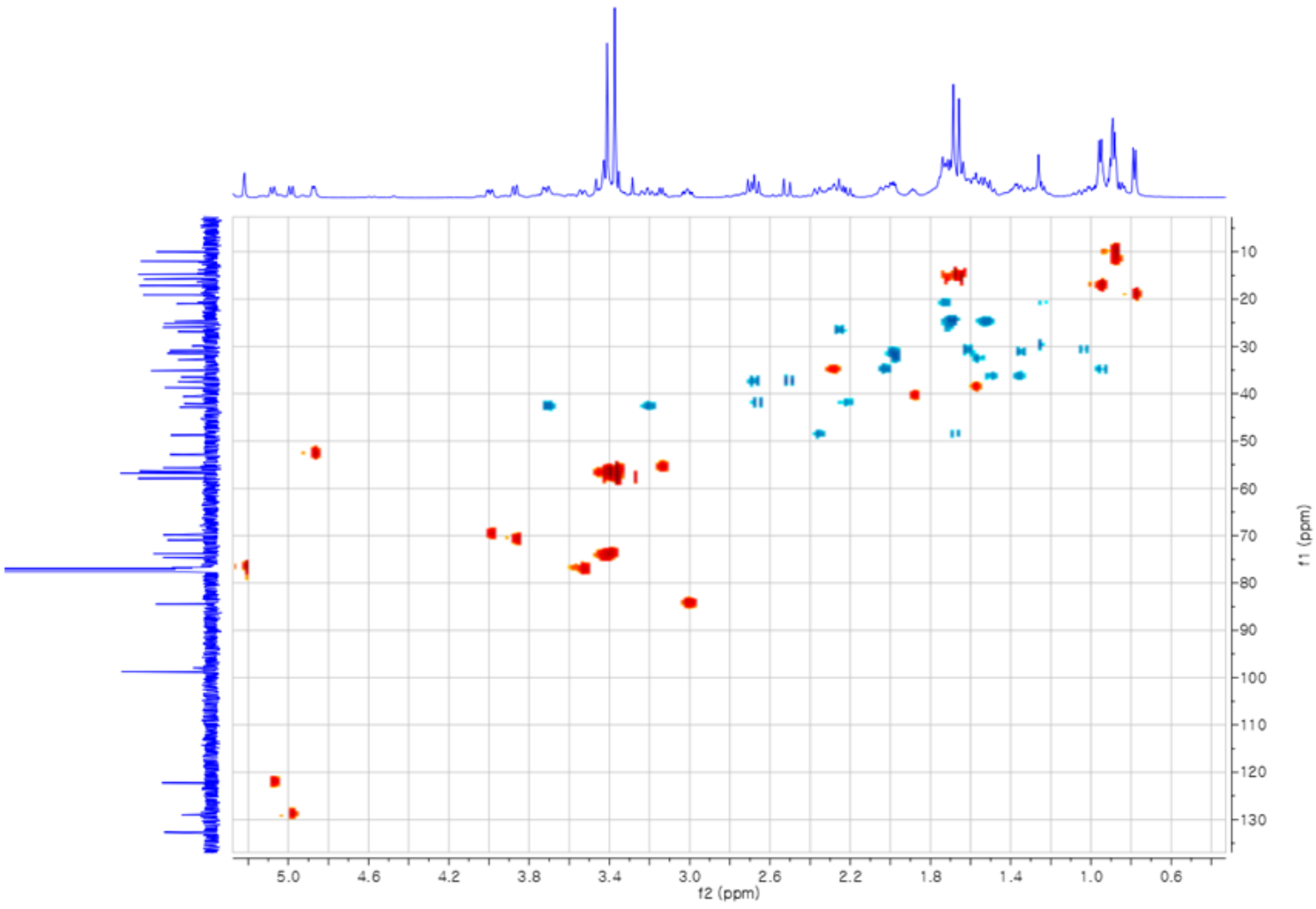

(e)

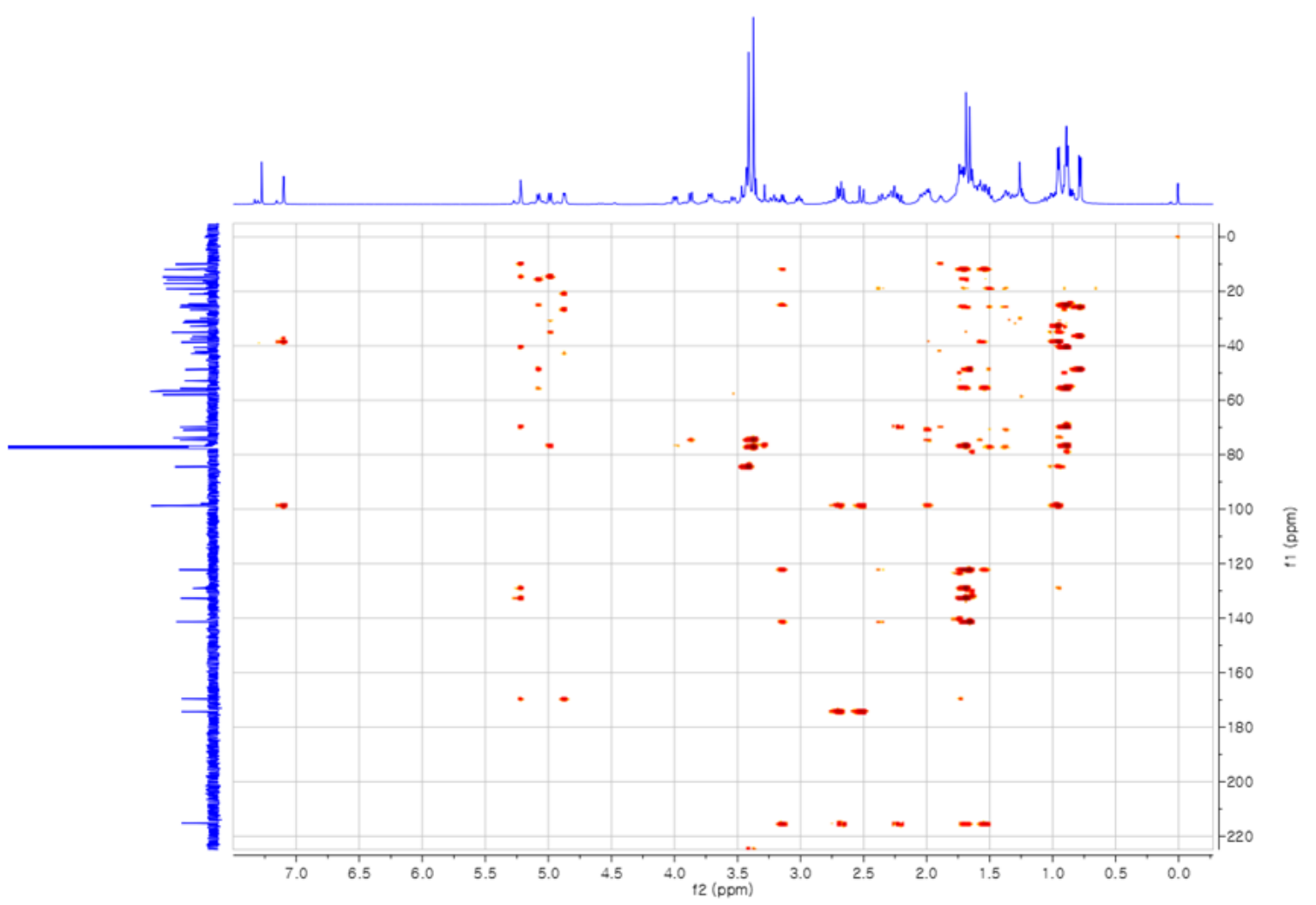

Figure S6. The structural determination of 9-deoxoFK520 (7). (a) ${ }^{1} \mathrm{H}(500 \mathrm{MHz}),\left(\right.$ b) ${ }^{13} \mathrm{C}(125 \mathrm{MHz})$, (c) ${ }^{1} \mathrm{H}-{ }^{1} \mathrm{H}$ gCOSY, (d) ${ }^{1} \mathrm{H}-{ }^{13} \mathrm{C}$ gHSQC, and (e) ${ }^{1} \mathrm{H}_{-}{ }^{13} \mathrm{C}$ gHMBC NMR data of 7 in $\mathrm{CDCl}_{3}$ obtained from $\Delta \mathrm{tcsB}-\Delta \mathrm{fkbD}$ strain. 
(a)

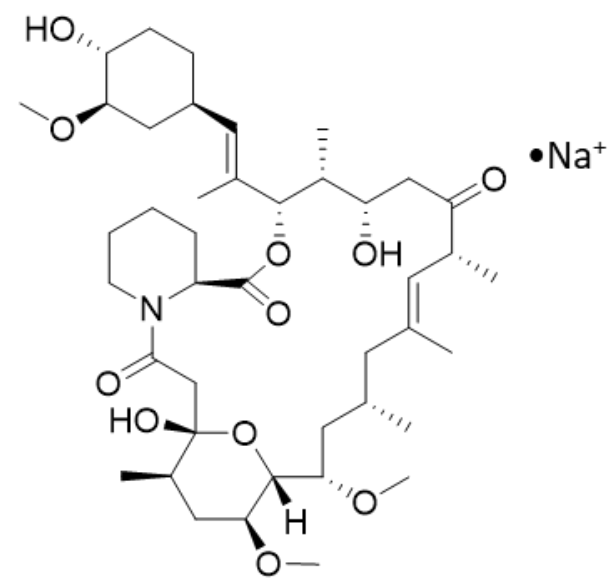

9-deoxoFK523 (8)

(b) 100

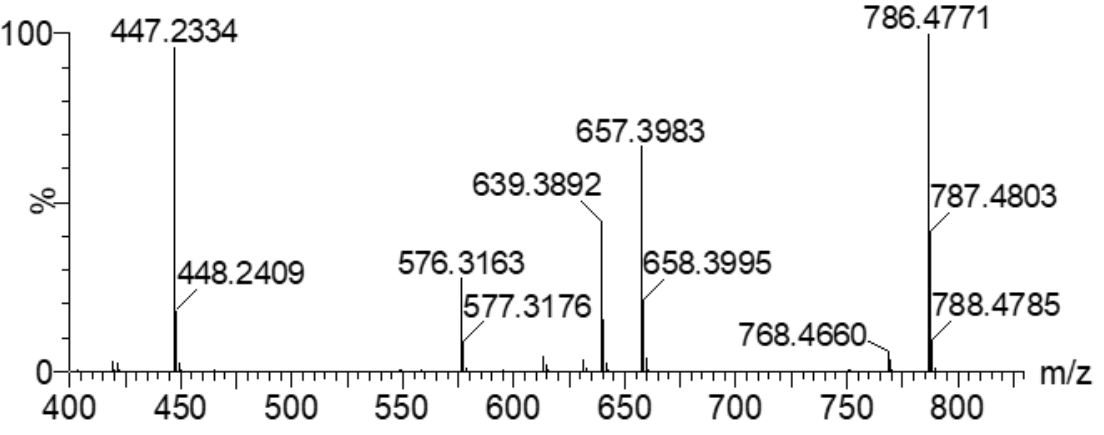

Figure S7. ESI-qTOF-HR-MS analysis of 9-deoxoFK523 (8) obtained from $\Delta$ tcsB- $\Delta$ fkbD strain. (a) Chemical structure of $\mathbf{8}$, (b) MS/MS spectrum of $\mathbf{8}$. 
(a)

lum

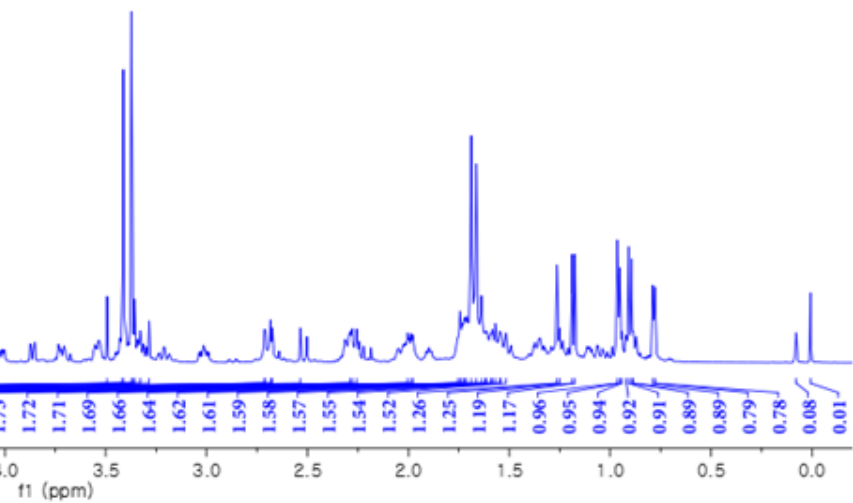

(b)

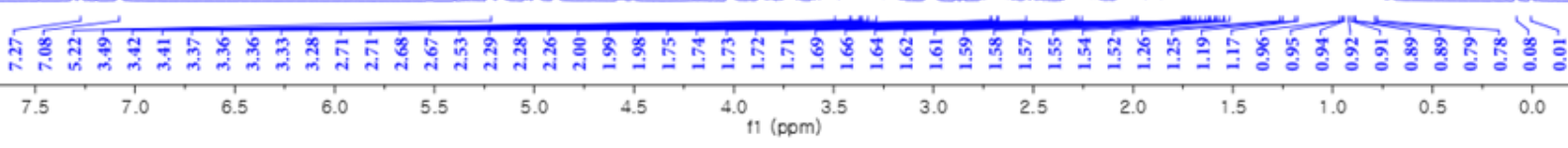

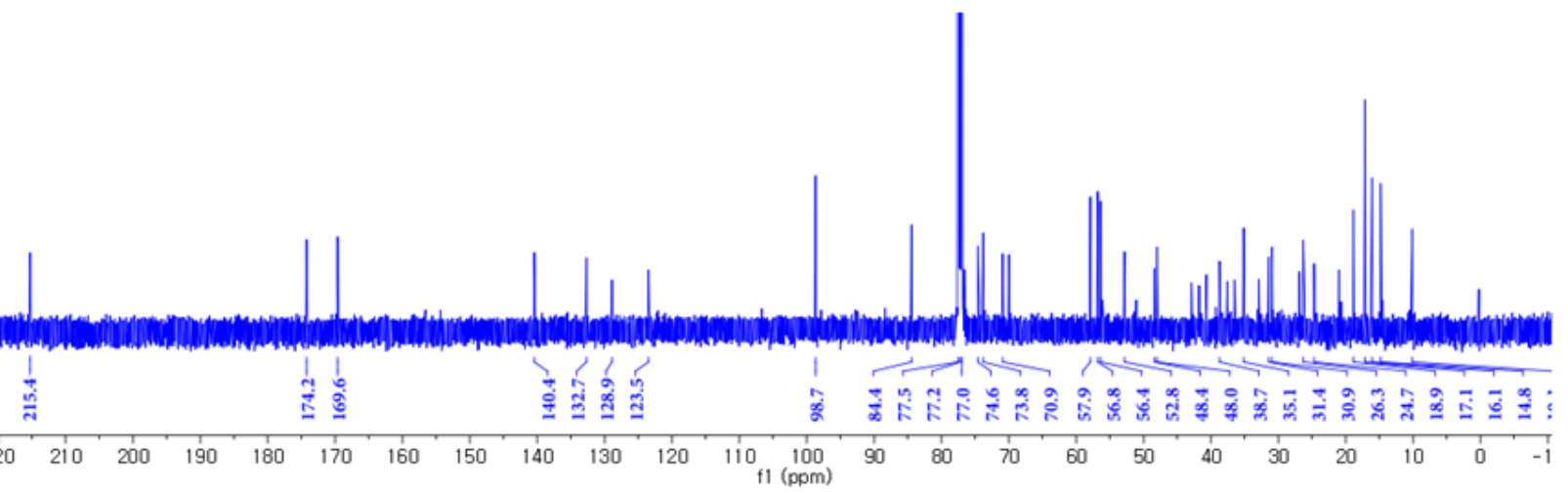

(c)

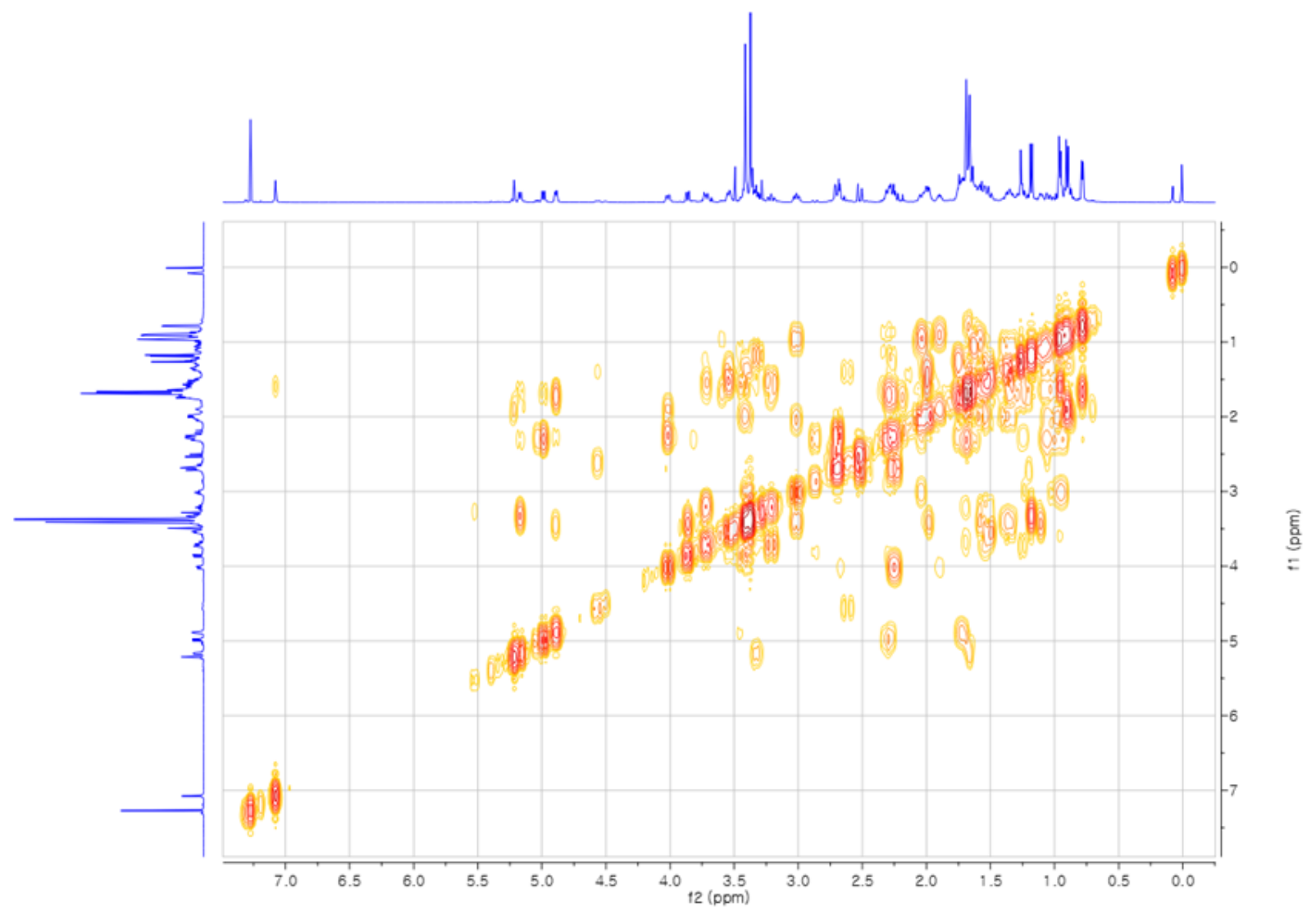


(d)

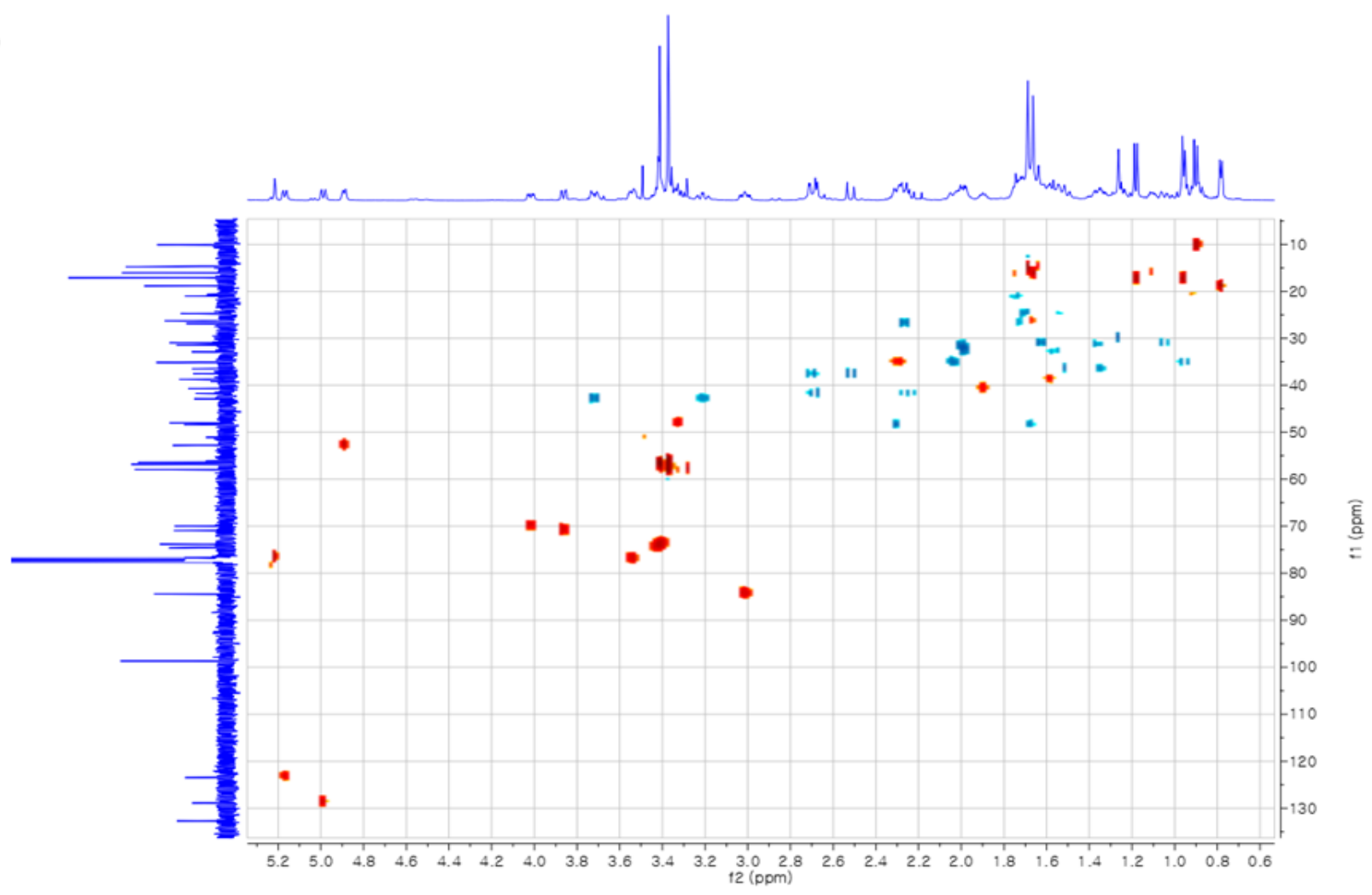

(e)

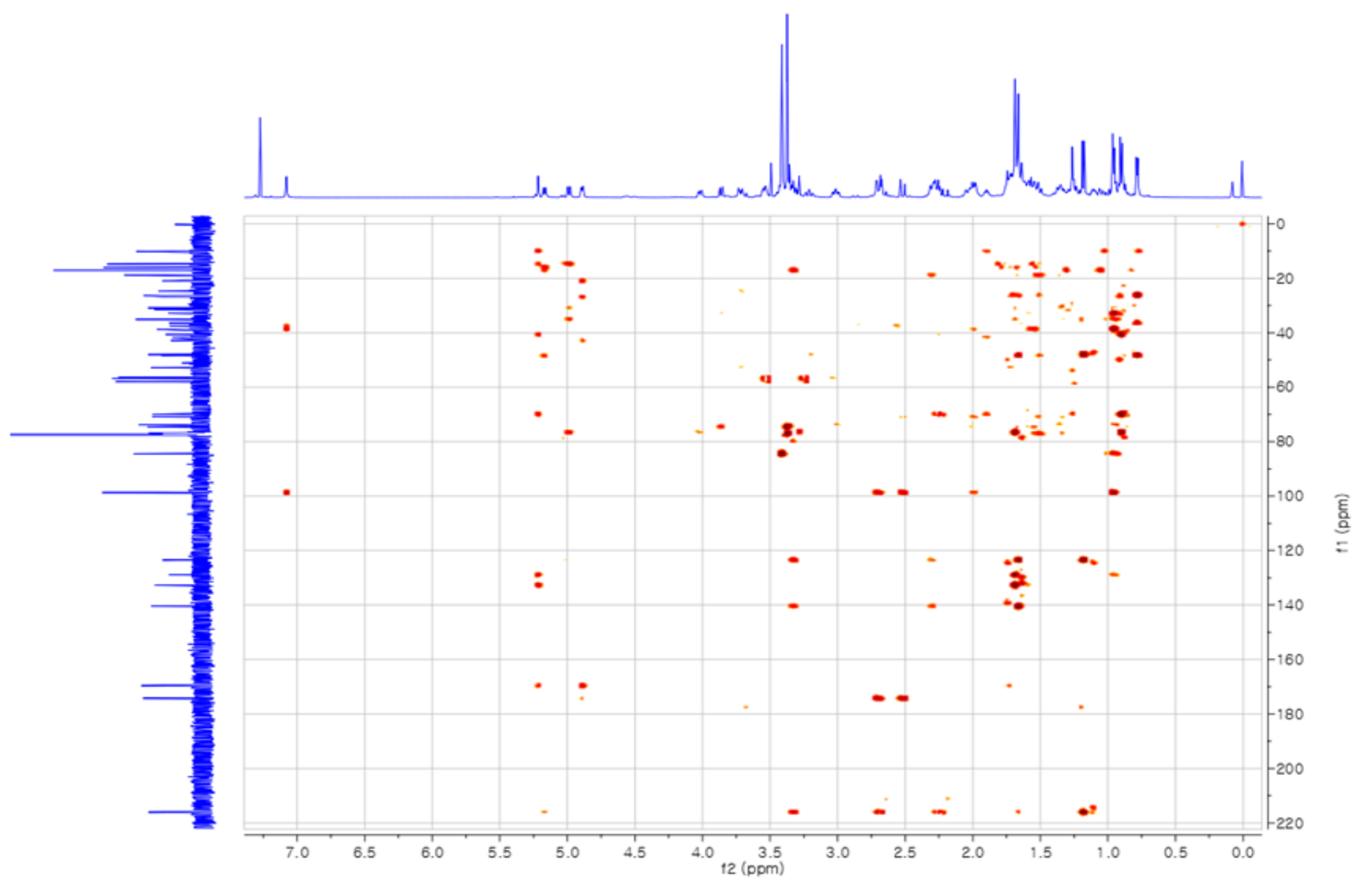

Figure S8. The structural determination of 9-deoxoFK523 (8). (a) ${ }^{1} \mathrm{H}(500 \mathrm{MHz})$, (b) ${ }^{13} \mathrm{C}(125 \mathrm{MHz})$, (c) ${ }^{1} \mathrm{H}-{ }^{1} \mathrm{H}$ gCOSY, (d) ${ }^{1} \mathrm{H}_{-}{ }^{13} \mathrm{C}$ gHSQC, and (e) ${ }^{1} \mathrm{H}_{-}{ }^{13} \mathrm{C}$ gHMBC NMR data of 8 in $\mathrm{CDCl}_{3}$ obtained from $\Delta \mathrm{tcsB}-\Delta \mathrm{fkbD}$ strain. 
(a)

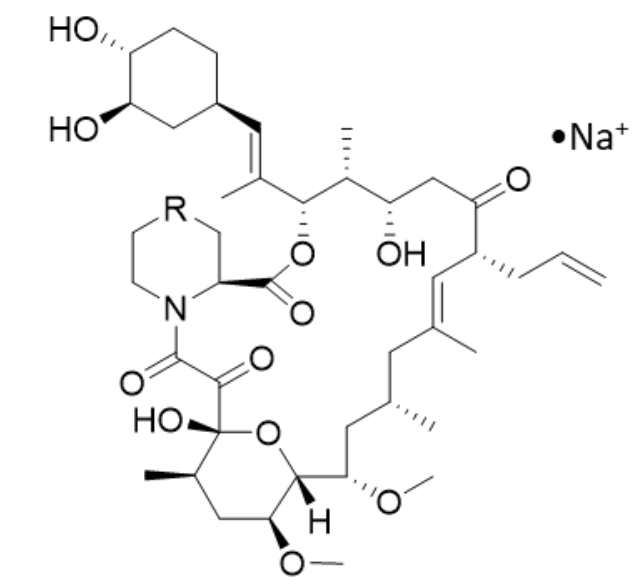

$\begin{array}{ll}\text { 31-O-demethylFK506 (4) } & \mathrm{R}=\mathrm{CH}_{2} \\ \text { 31-O-demethyl-prolyIFK506 } & \mathrm{R}=\text { - }\end{array}$

(b) 100

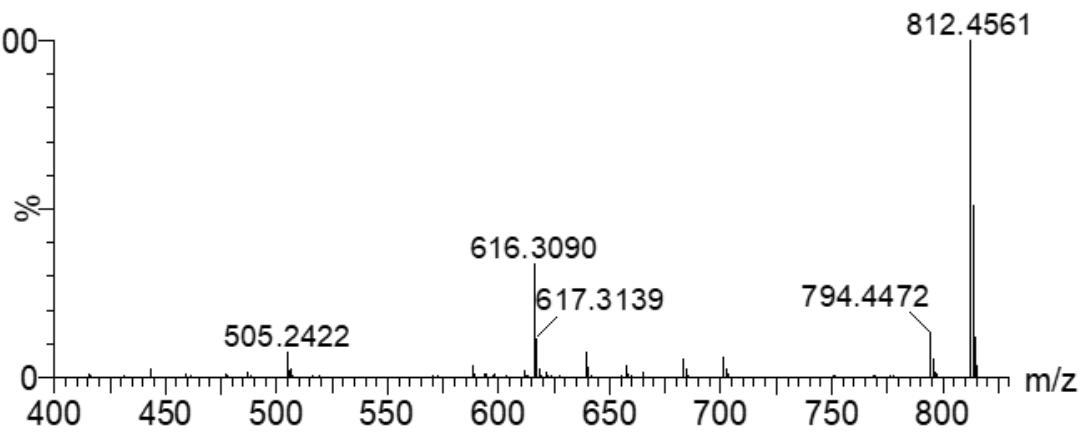

(c)

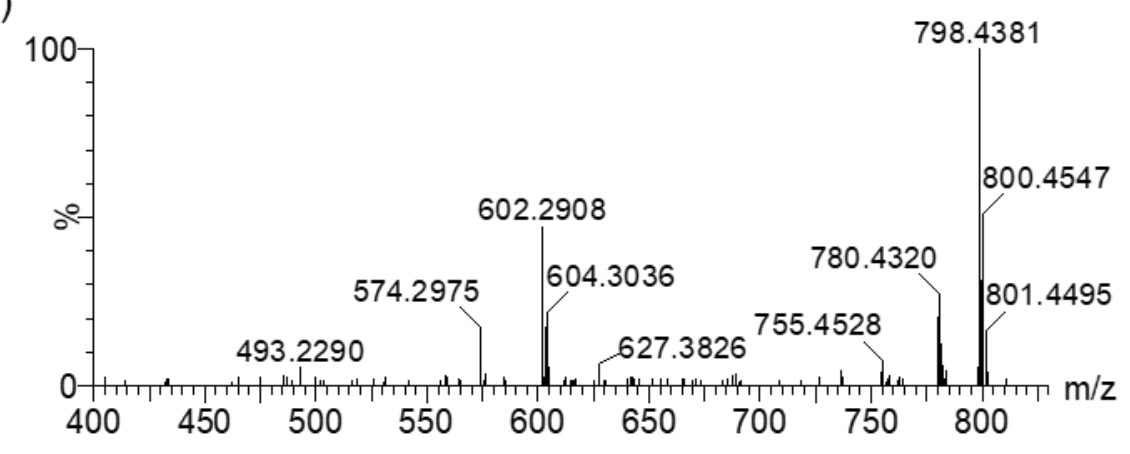

Figure S9. ESI-qTOF-HR-MS analysis of 31-O-demethylFK506 (4) from $\Delta \mathrm{fkbM}$ strain. (a) Chemical structure of 4, (b) MS/MS spectrum of 4 and (c) 31-O-demethyl-prolylFK506, respectively. 
(a)

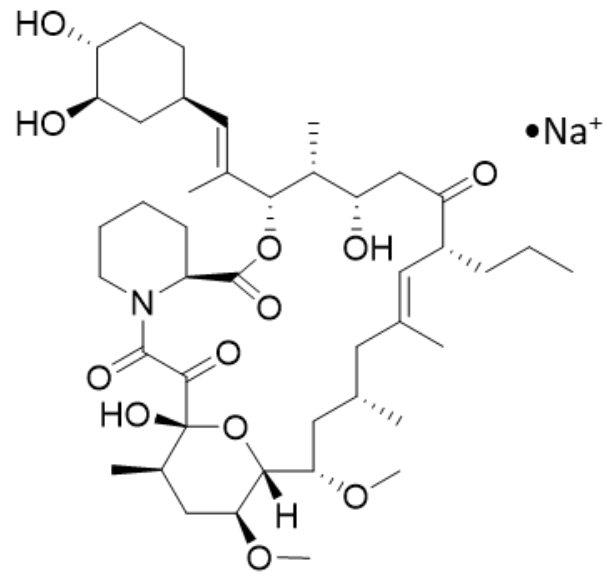

31-O-demethyl-36,37-dihydroFK506 (9)

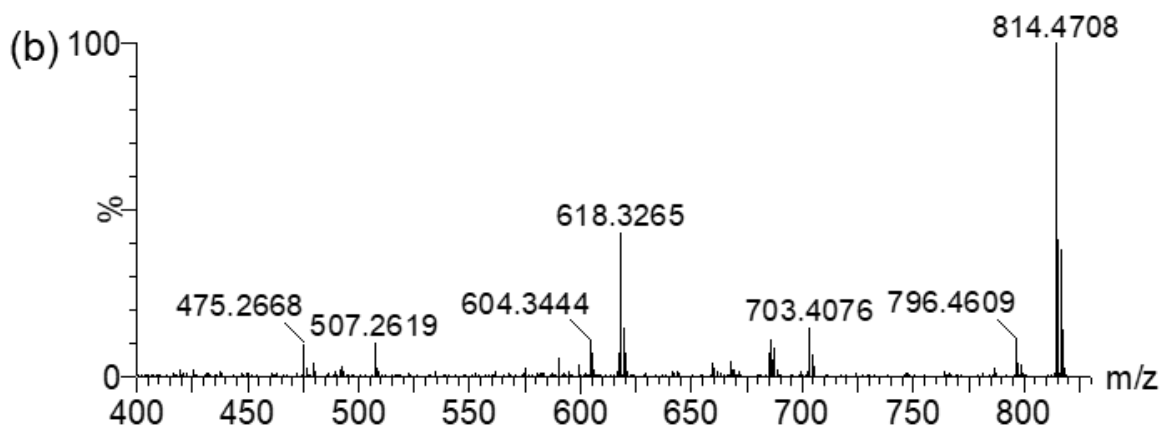

Figure S10. ESI-qTOF-HR-MS analysis of 31-O-demethyl-36,37-dihydroFK506 (9) obtained from $\Delta \mathrm{tcsD}-\Delta \mathrm{fkbM}$ strain. (a) Chemical structure of $\mathbf{9}$, (b) MS/MS spectrum of $\mathbf{9}$. 
(a)

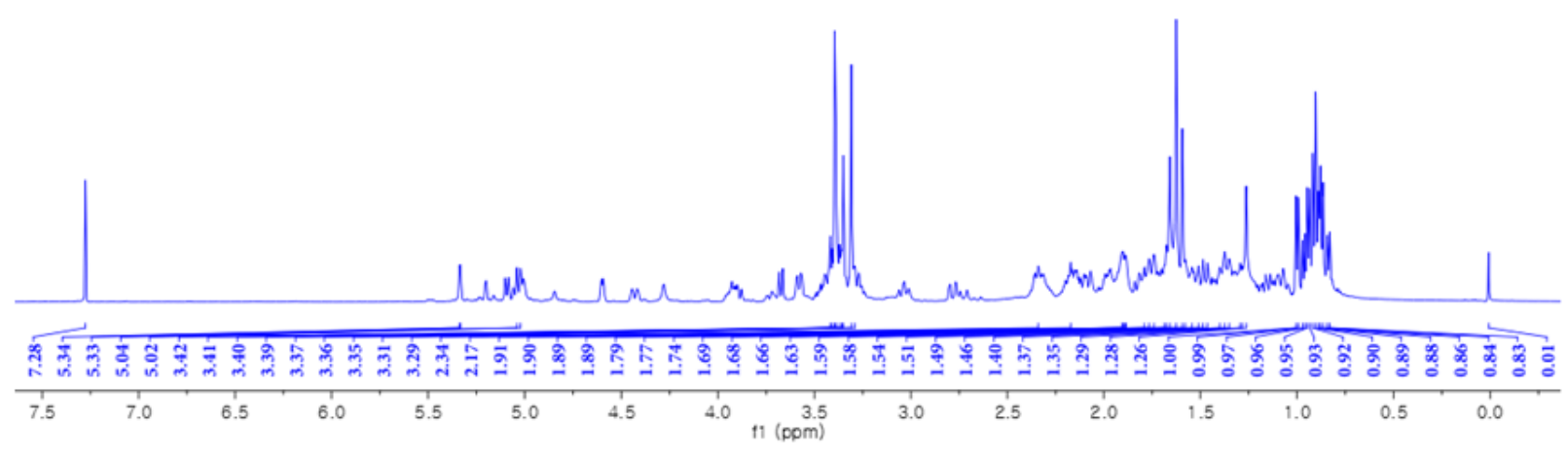

(b)

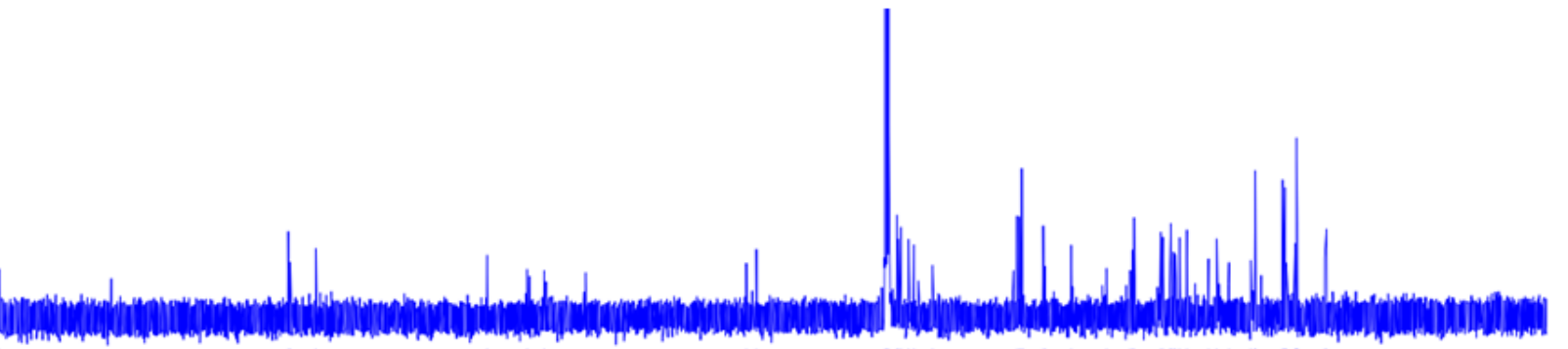

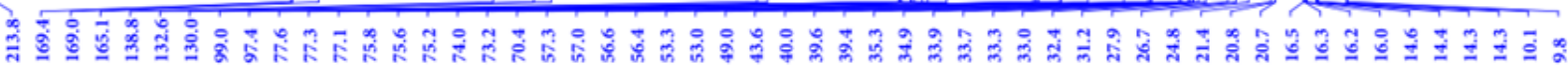

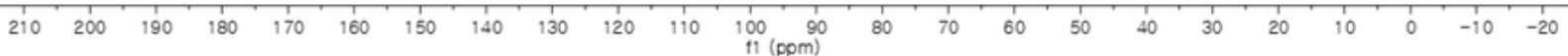

(c)

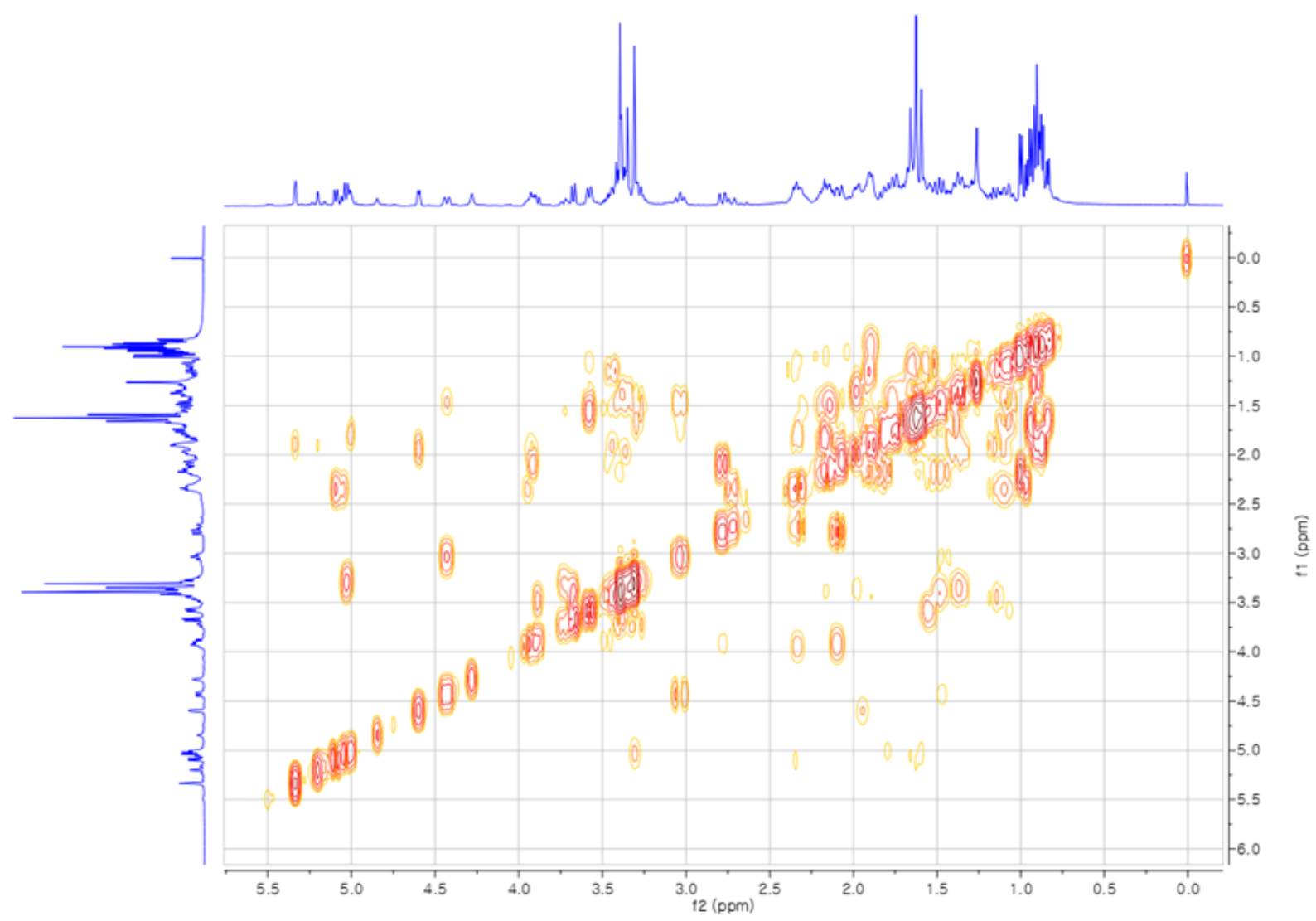


(d)

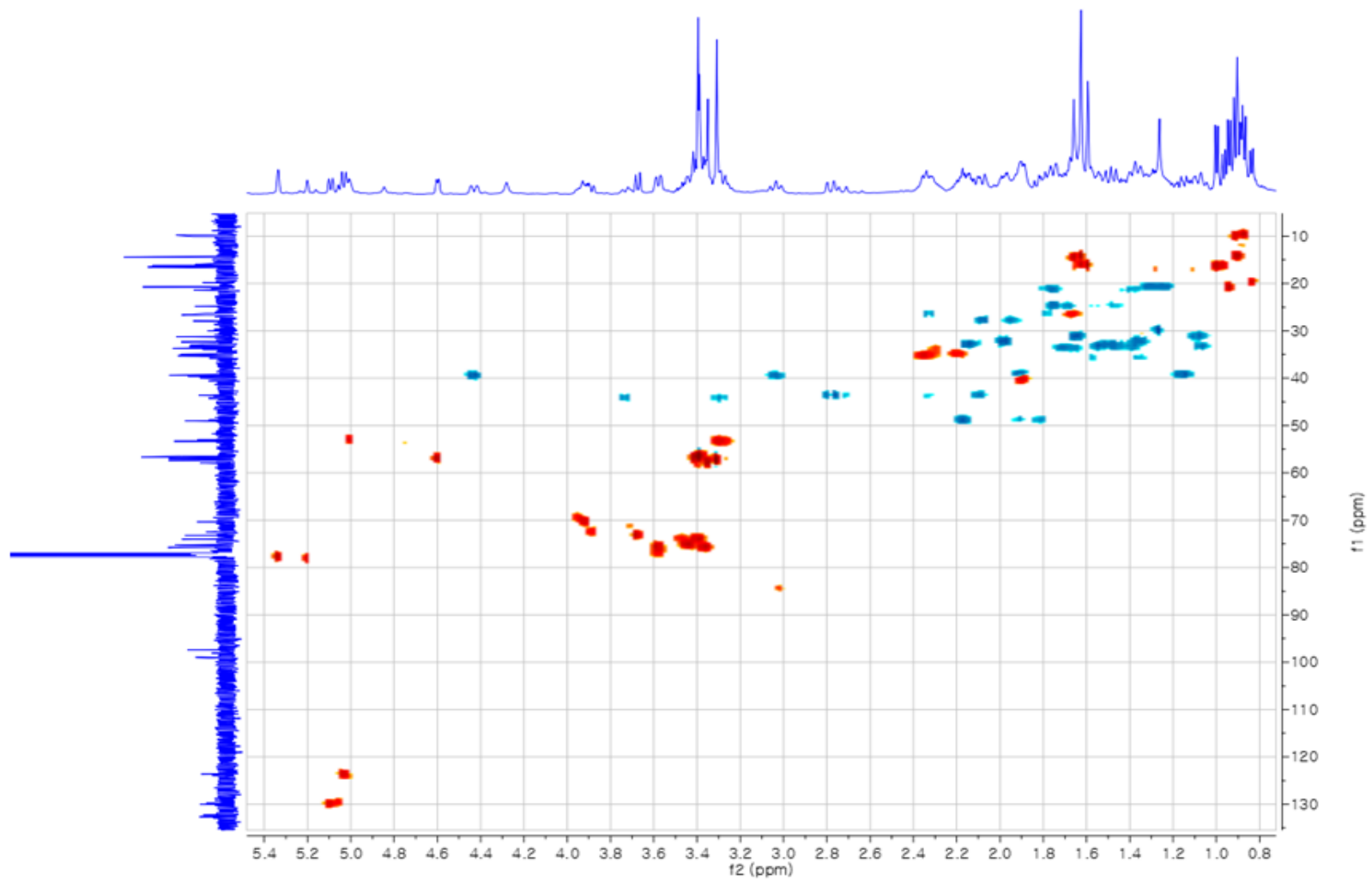

(e)

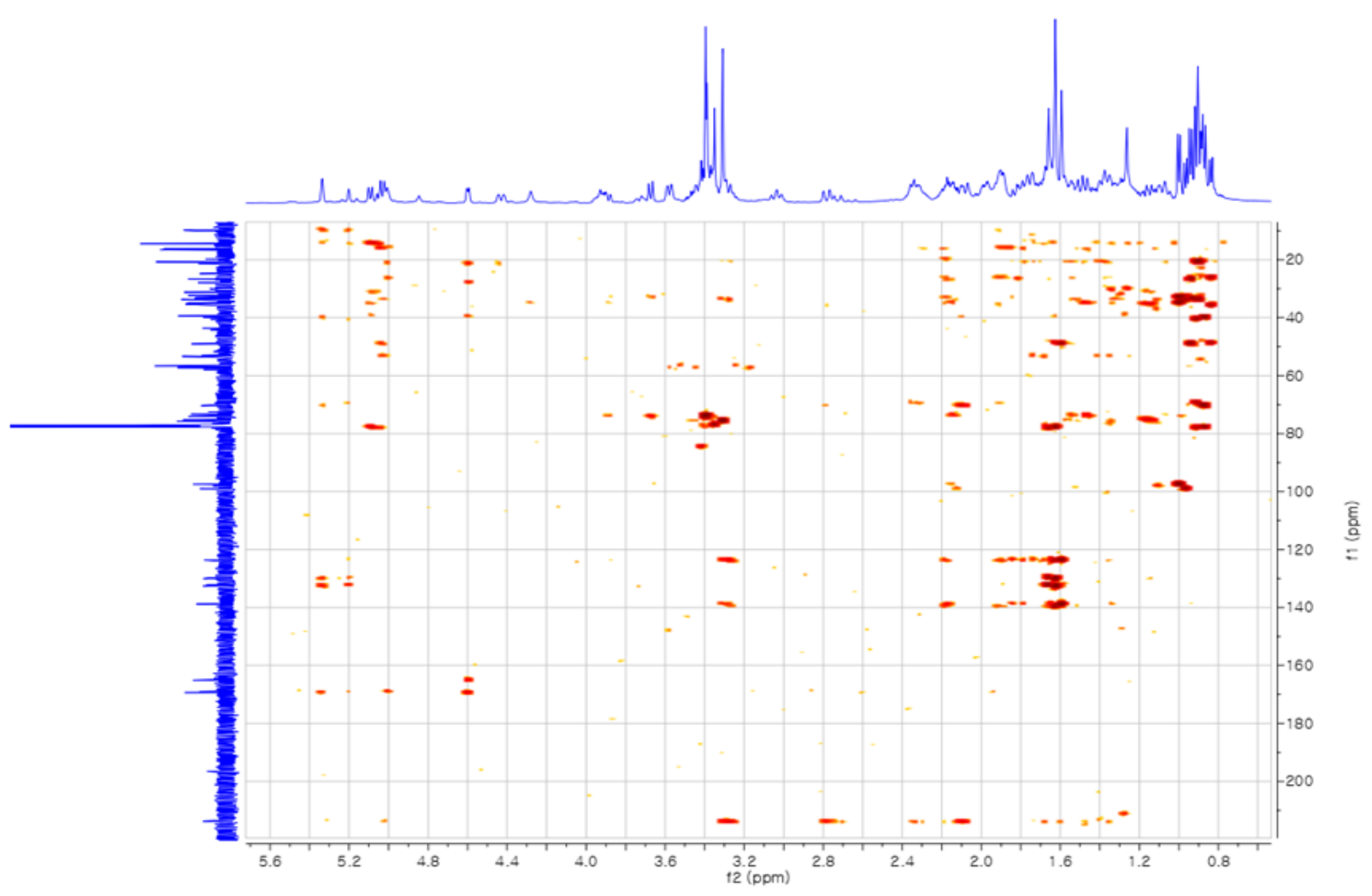

Figure S11. The structural determination of 31-O-demethyl-36,37-dihydroFK506 (9). (a) ${ }^{1} \mathrm{H}(500$ $\mathrm{MHz}$ ), (b) ${ }^{13} \mathrm{C}(125 \mathrm{MHz})$, (c) ${ }^{1} \mathrm{H}-{ }^{1} \mathrm{H}$ gCOSY, (d) ${ }^{1} \mathrm{H}-{ }^{13} \mathrm{C}$ gHSQC, and (e) ${ }^{1} \mathrm{H}-{ }^{13} \mathrm{C}$ gHMBC NMR data of 9 in $\mathrm{CDCl}_{3}$ obtained from $\Delta \mathrm{tcsD}-\Delta \mathrm{fkbM}$ strain. 
(a)

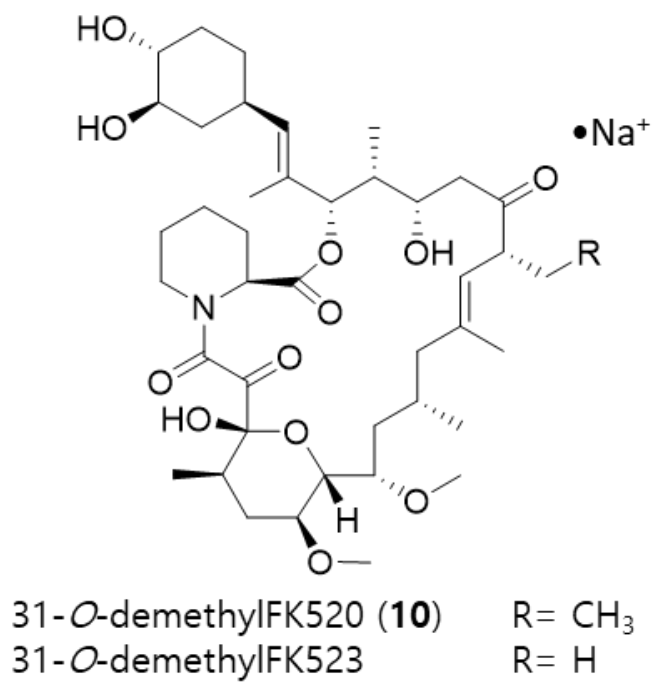

(b)

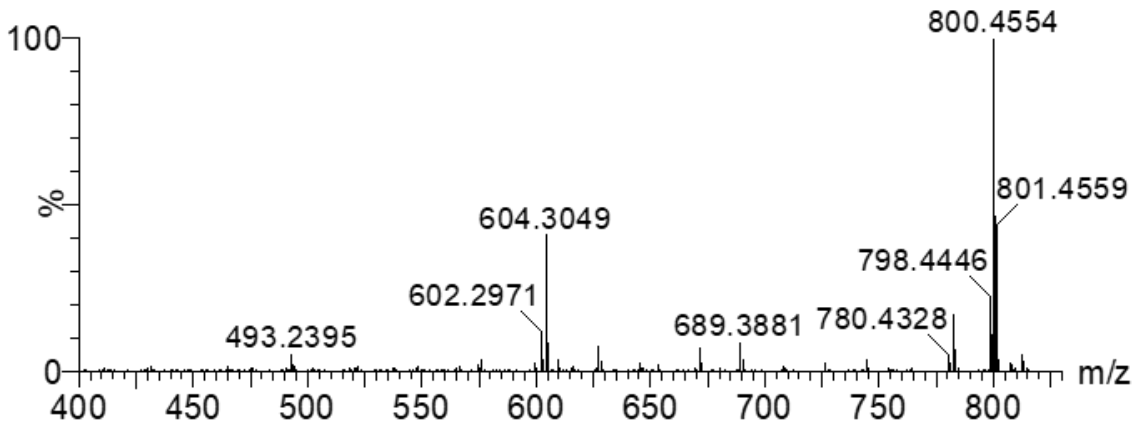

(c)

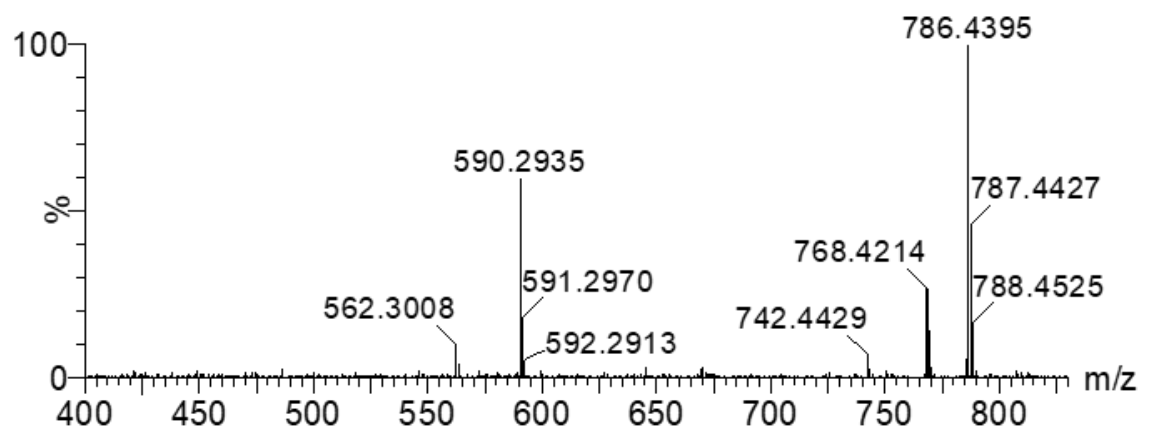

Figure S12. ESI-qTOF-HR-MS analysis of 31-O-demethylFK520 (10) obtained from $\Delta \mathrm{tcsB}-\Delta \mathrm{fkbM}$ strain. (a) Chemical structure of 10 along with 31-O-demethylFK523, (b) MS/MS spectrum of 10 and (c) 31-O-demethylFK523, respectively. 
(a)

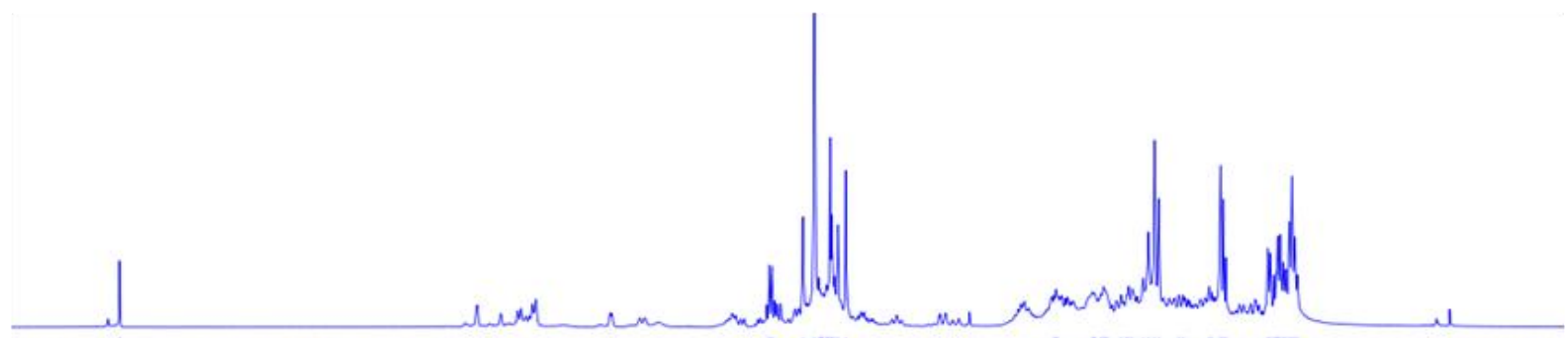

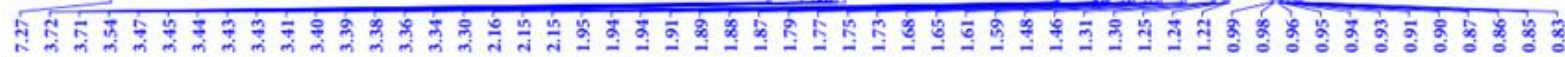

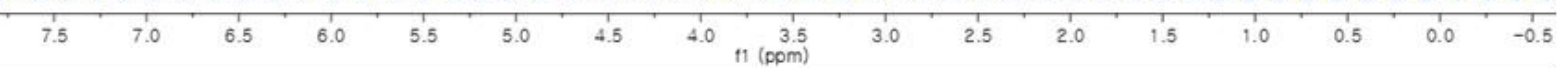

(b)

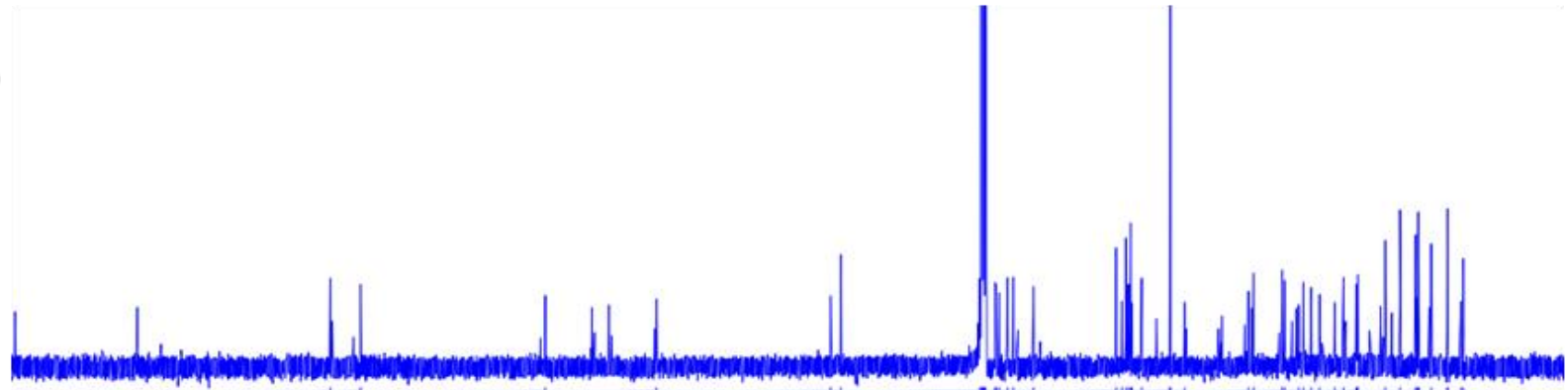

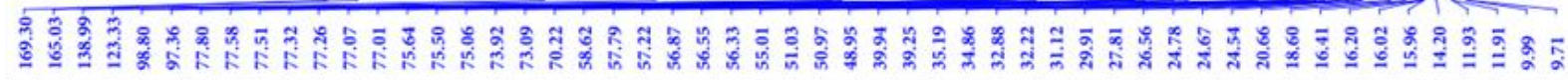

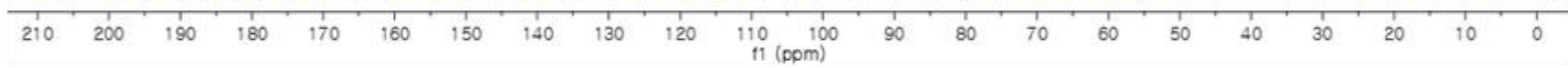

(c)

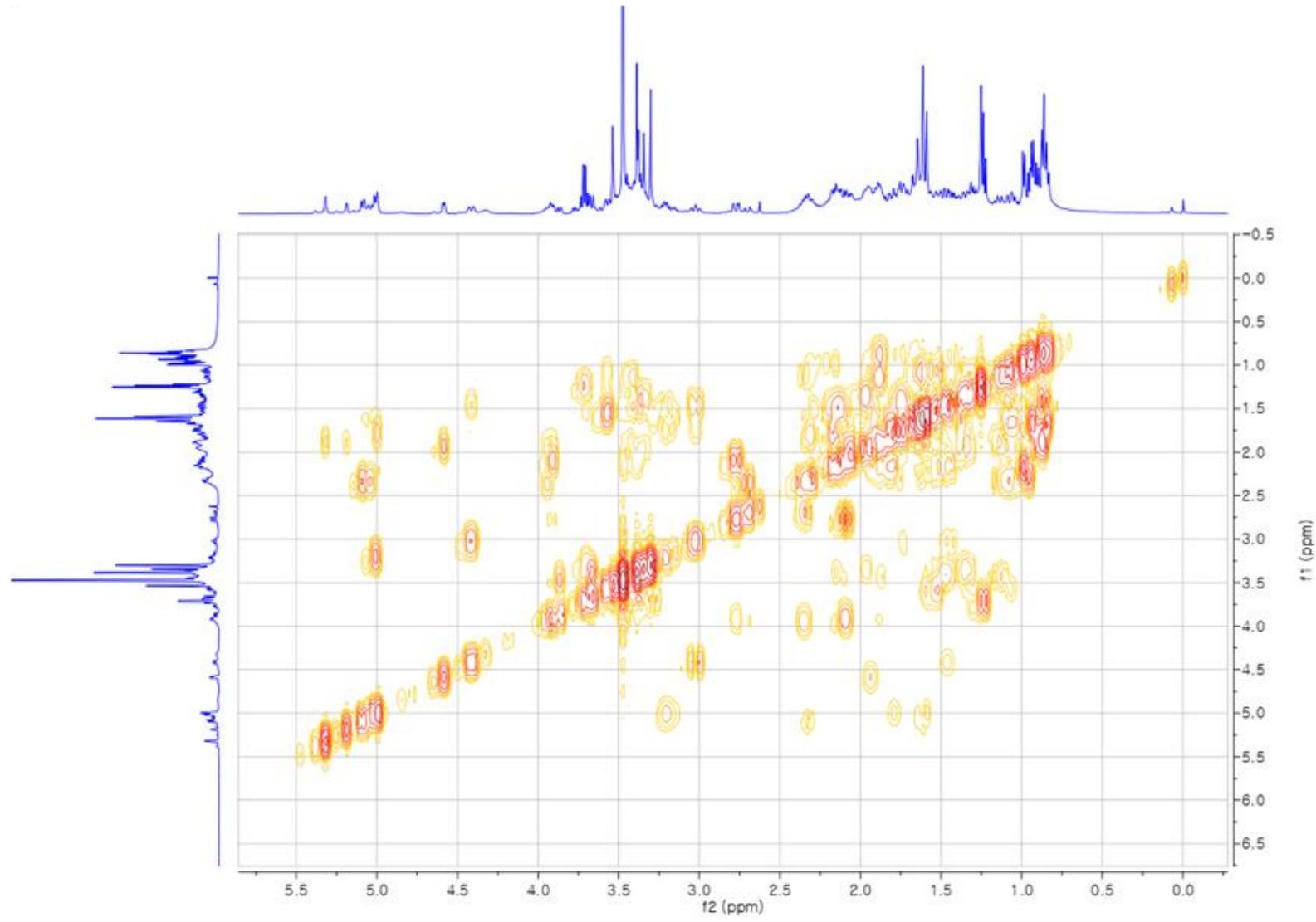


(d)

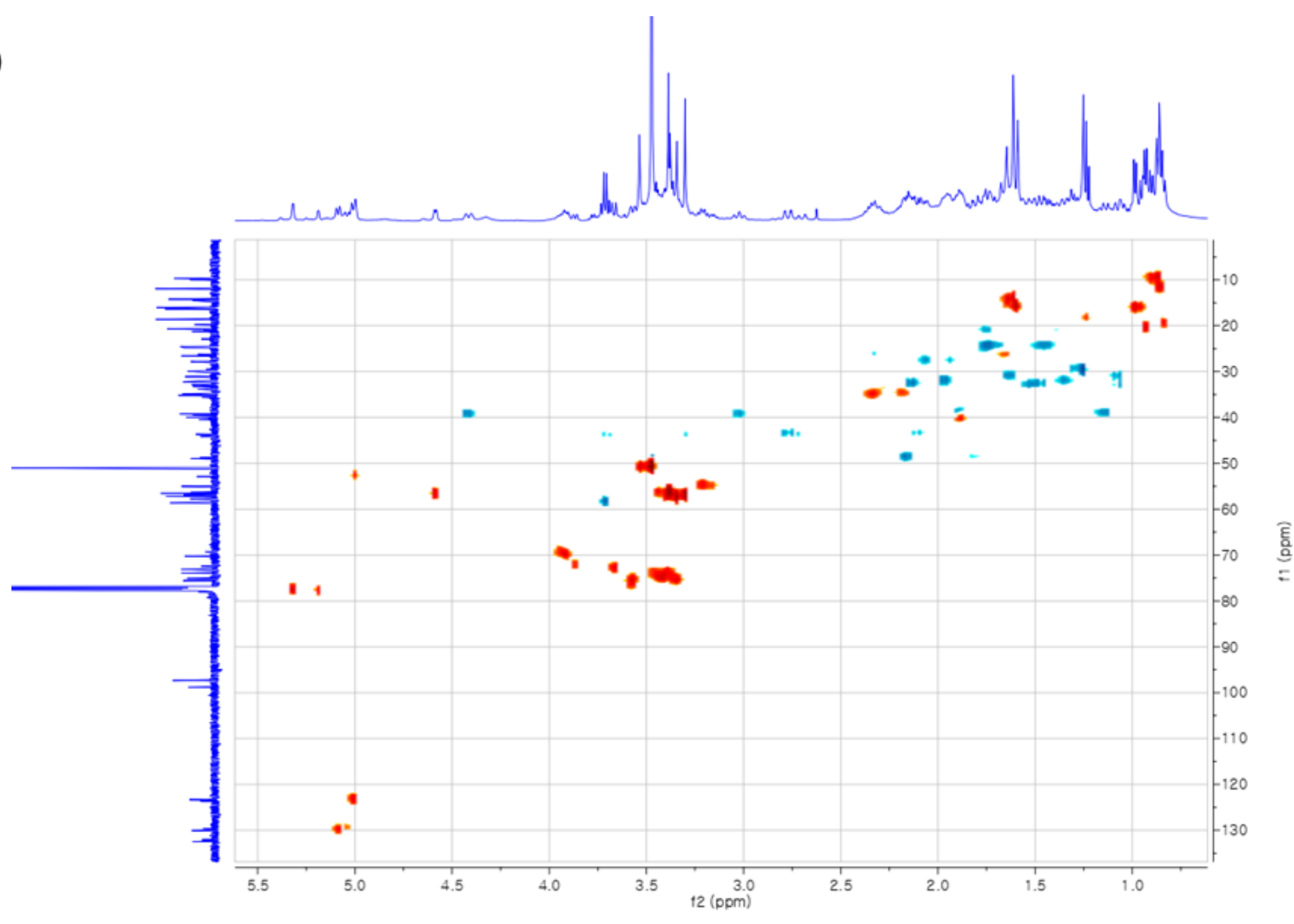

(e)

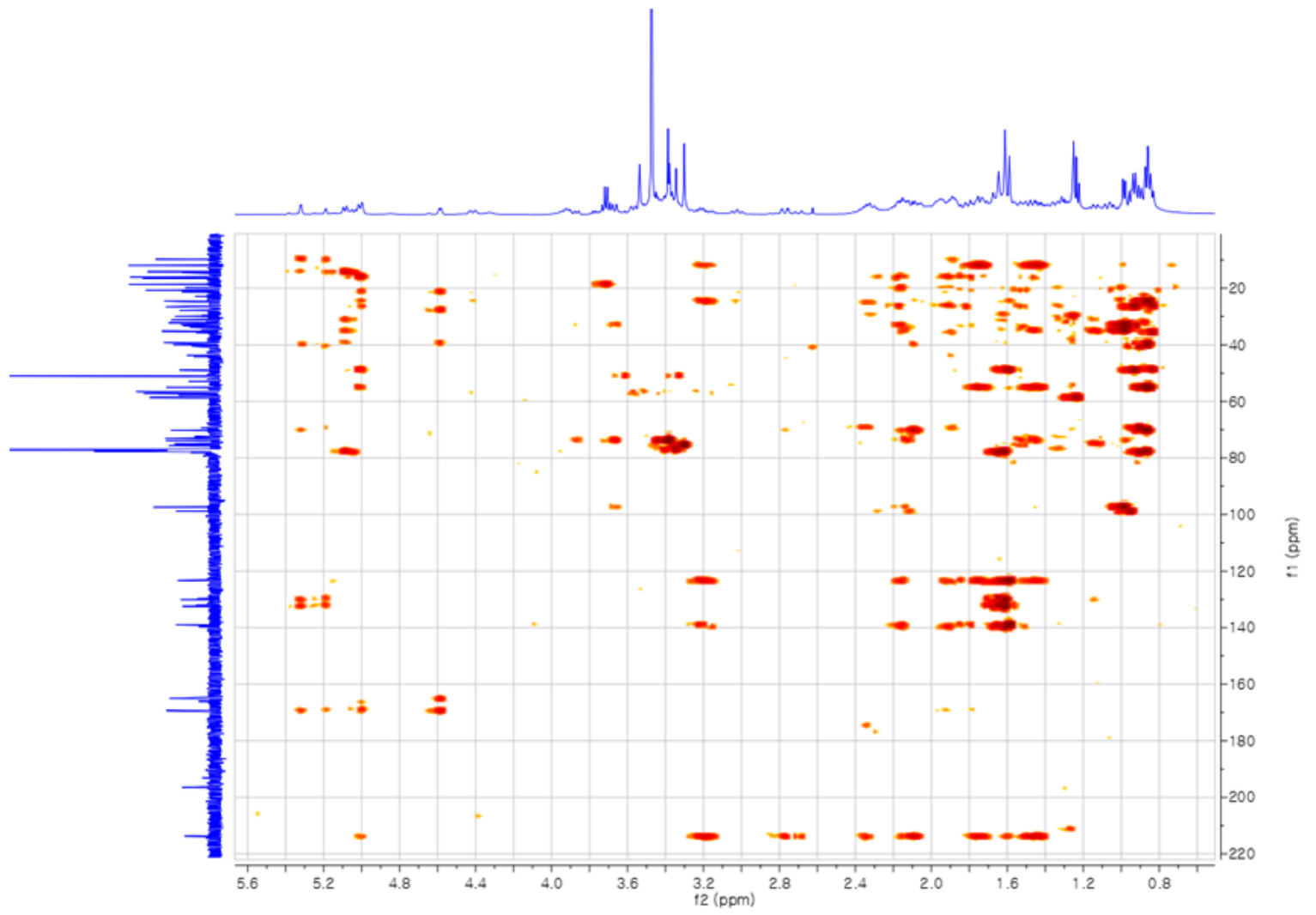

Figure S13. The structural determination of 31-O-demethylFK520 (10). (a) ${ }^{1} \mathrm{H}(500 \mathrm{MHz})$, (b) ${ }^{13} \mathrm{C}$ (125 MHz), (c) ${ }^{1} \mathrm{H}-{ }^{1} \mathrm{H} \mathrm{gCOSY}$, (d) ${ }^{1} \mathrm{H}_{-}{ }^{13} \mathrm{C}$ gHSQC, and (e) ${ }^{1} \mathrm{H}_{-}{ }^{13} \mathrm{C}$ gHMBC NMR data of 10 in $\mathrm{CDCl}_{3}$ obtained from $\Delta \mathrm{tcsB}-\Delta \mathrm{fkbM}$ strain. 
(a)

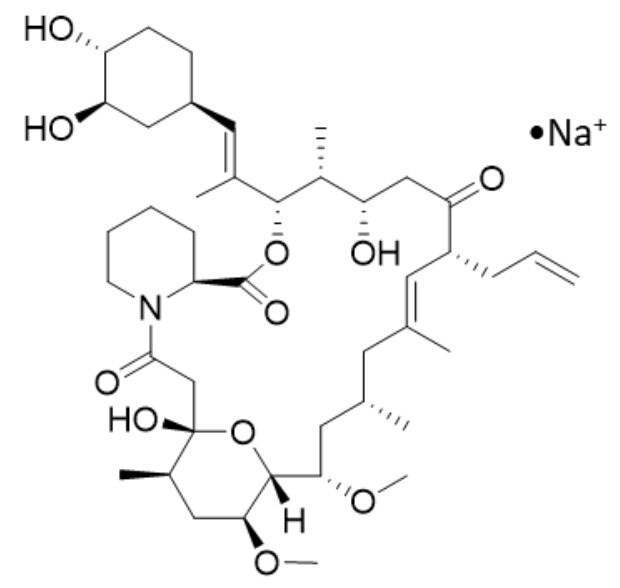

9-deoxo-31-O-demethylFK506 (5)

(b)

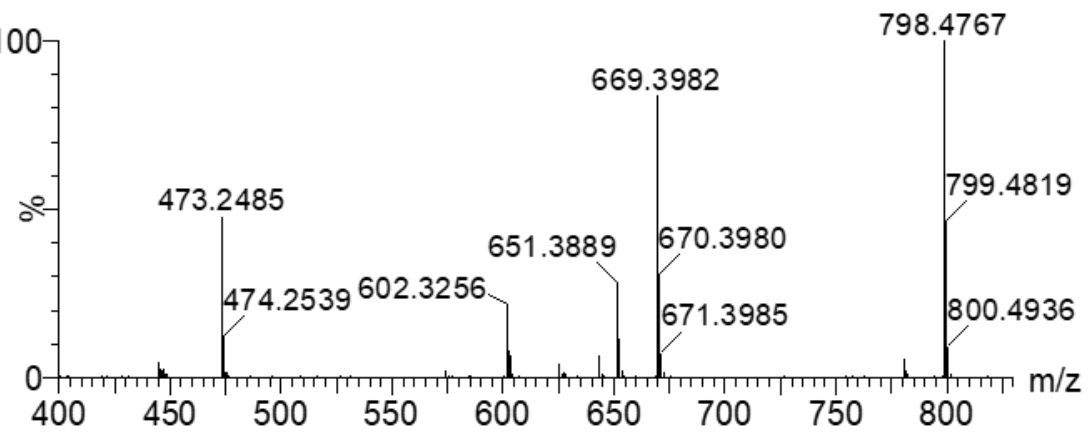

Figure S14. ESI-qTOF-HR-MS analysis of 9-deoxo-31-O-demethylFK506 (5) obtained from $\Delta \mathrm{fkbDM}$ strain. (a) Chemical structure of 5, (b) MS/MS spectrum of $\mathbf{5}$. 
(a)

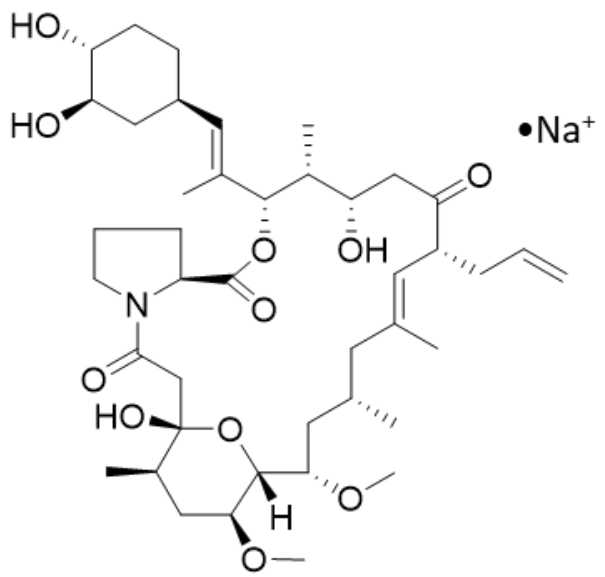

9-deoxo-31-O-demethyl-prolylFK506 (11)

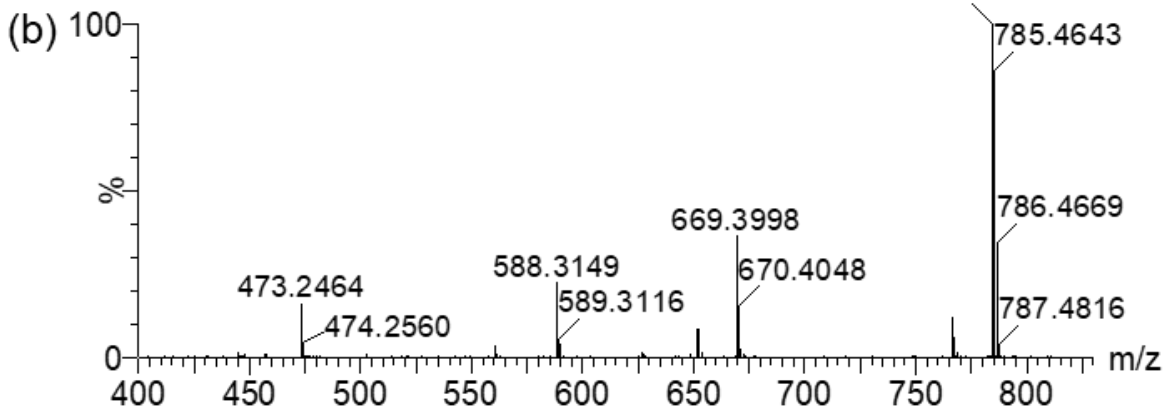

Figure S15. ESI-qTOF-HR-MS analysis of 9-deoxo-31-O-demethyl-prolylFK506 (11) obtained from $\Delta \mathrm{fkbDM}$ strain. (a) Chemical structure of 11, (b) MS/MS spectrum of $\mathbf{1 1}$. 
(a)

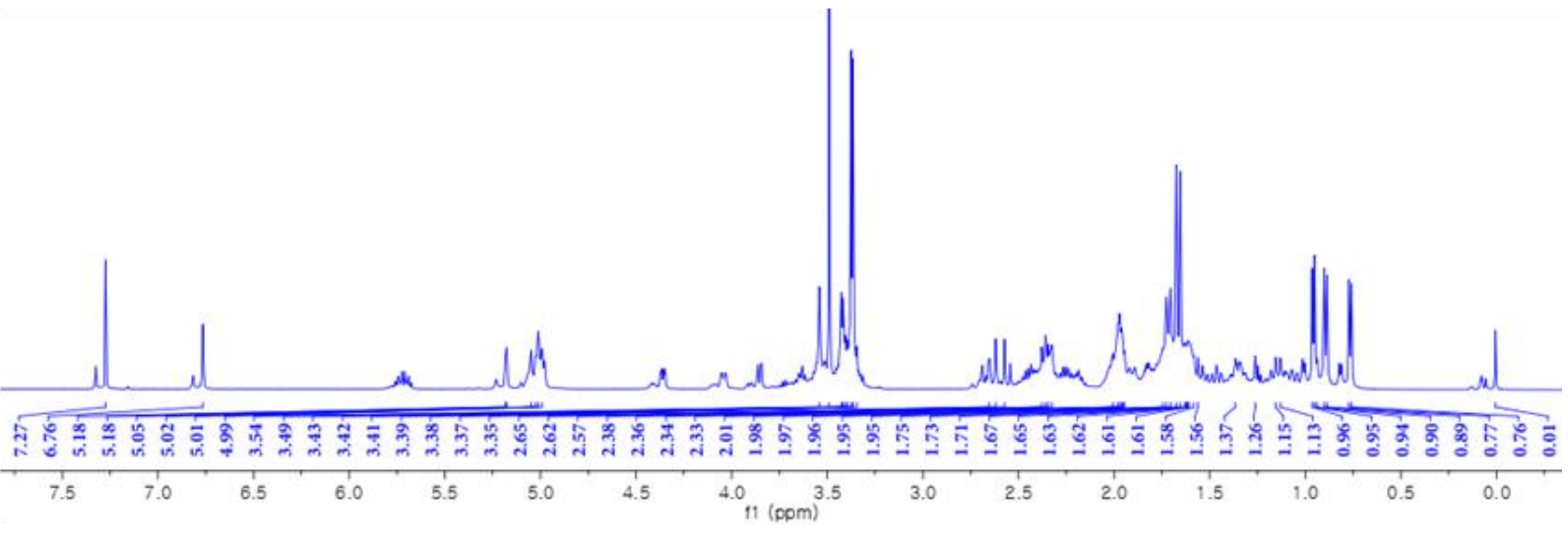

(b)

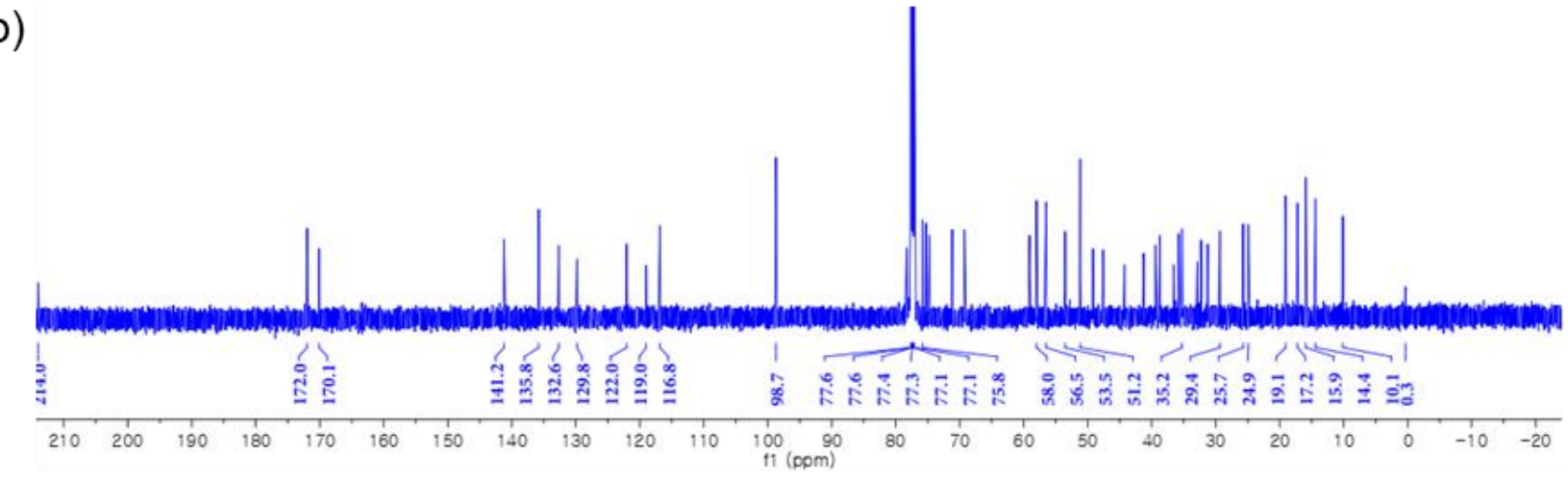

(c)

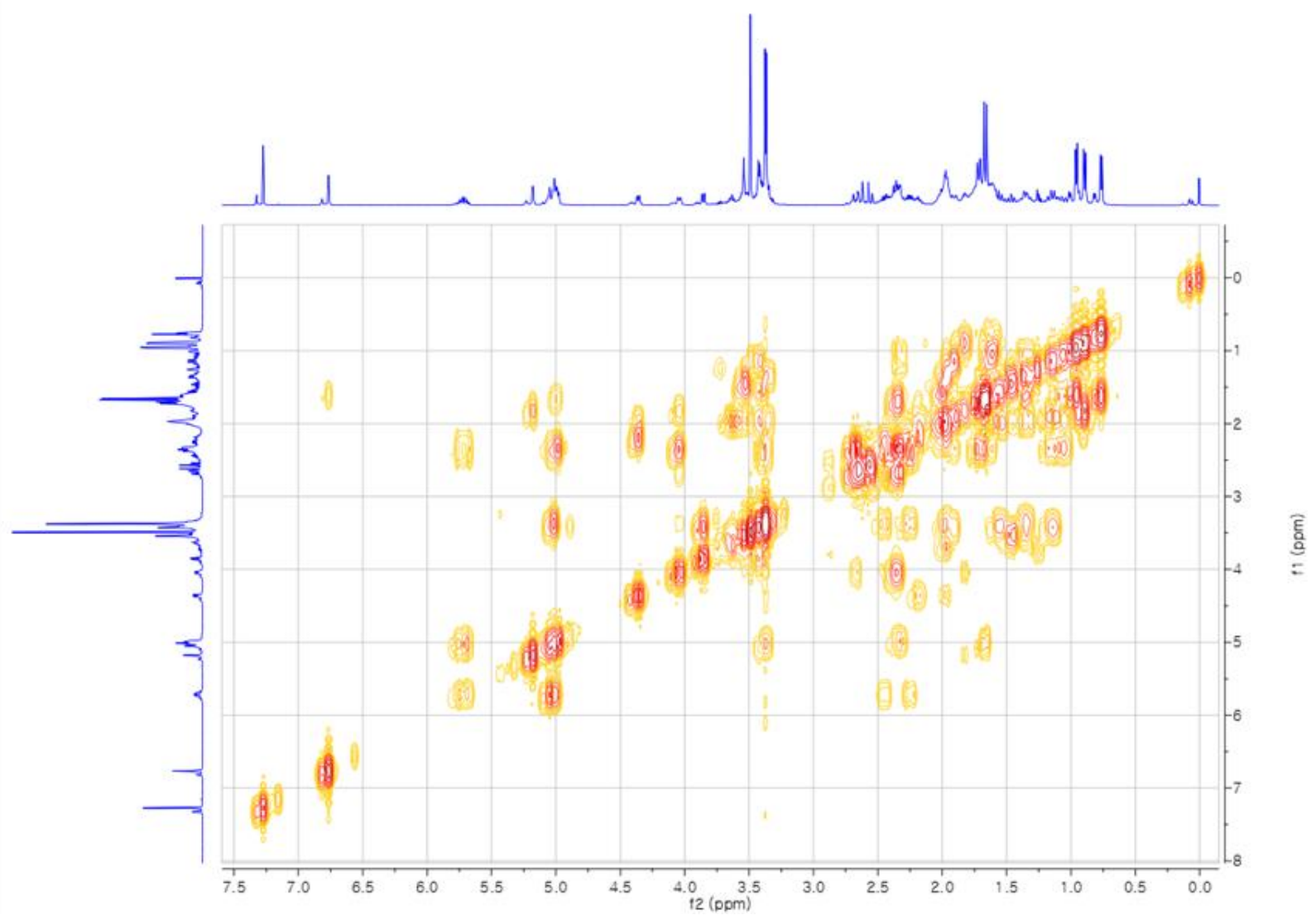


(d)

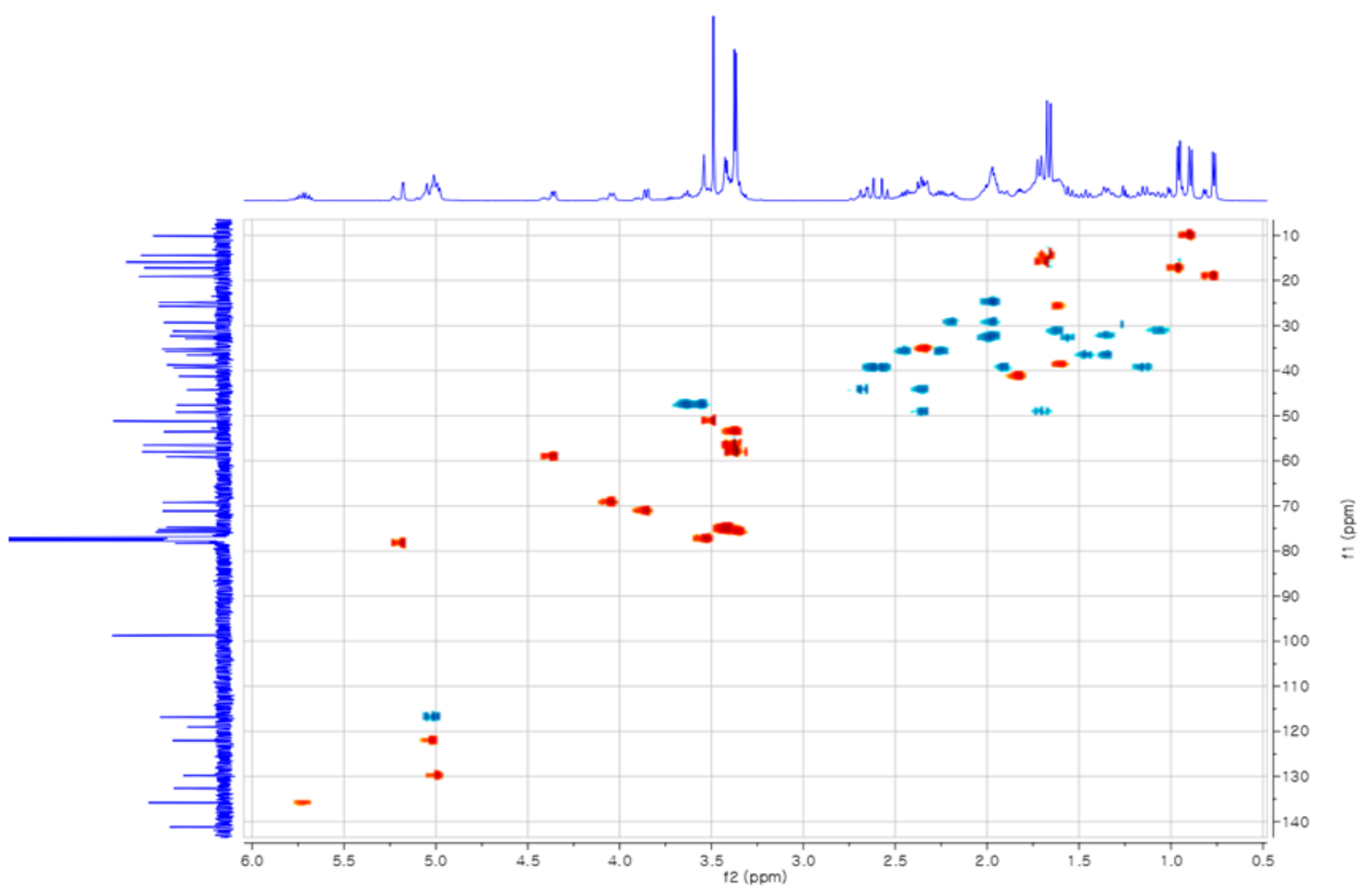

(e)

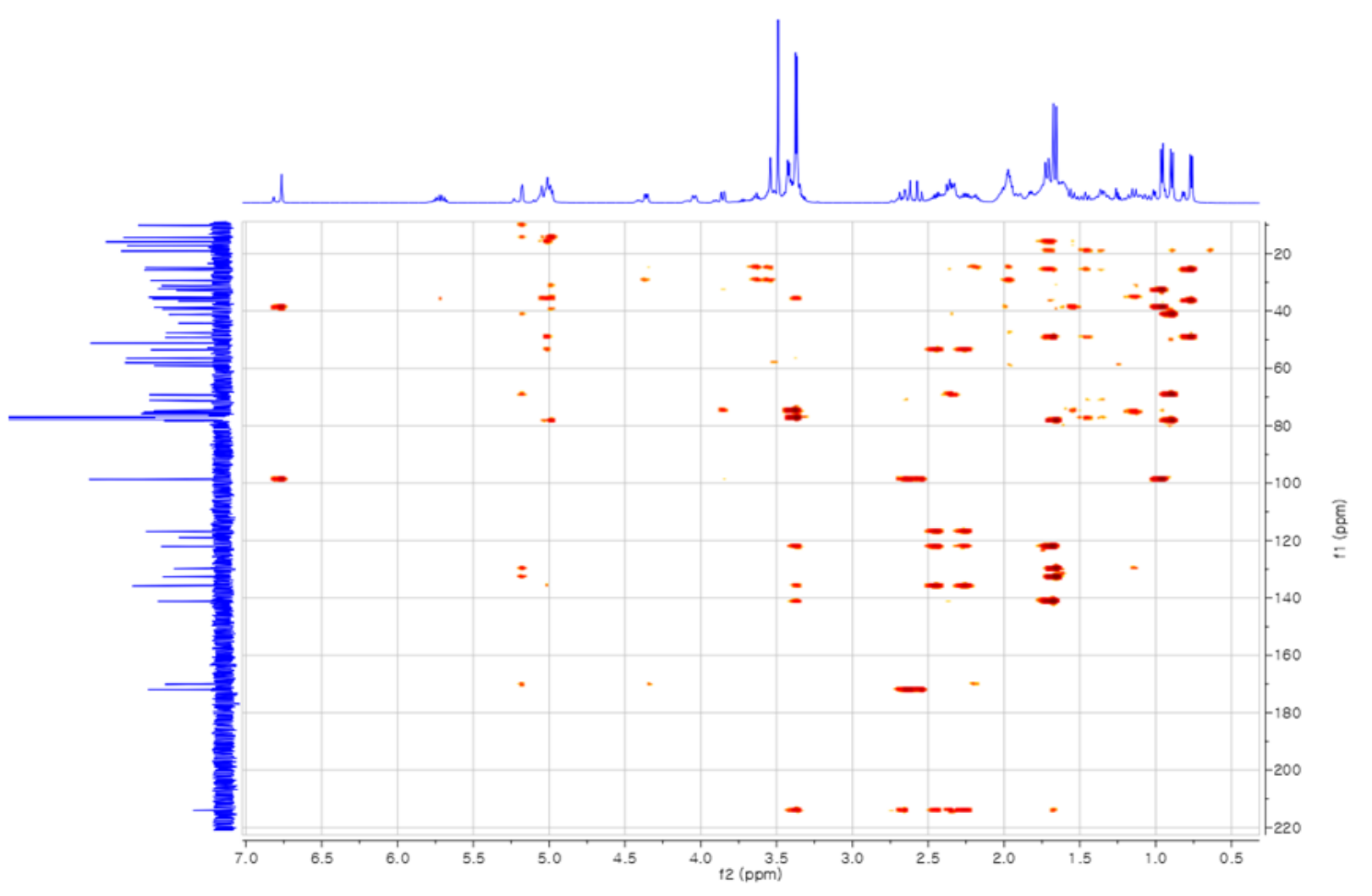

Figure S16. The structural determination of 9-deoxo-31-O-demethyl-prolylFK506 (11). (a) ${ }^{1} \mathrm{H}(500$ $\mathrm{MHz}$, (b) ${ }^{13} \mathrm{C}(125 \mathrm{MHz})$, (c) ${ }^{1} \mathrm{H}-{ }^{1} \mathrm{H}$ gCOSY, (d) ${ }^{1} \mathrm{H}-{ }^{13} \mathrm{C}$ gHSQC, and (e) ${ }^{1} \mathrm{H}_{-}{ }^{13} \mathrm{C}$ gHMBC NMR data of $\mathbf{1 1}$ in $\mathrm{CDCl}_{3}$ obtained from $\triangle \mathrm{fkbDM}$ strain. 
(a)

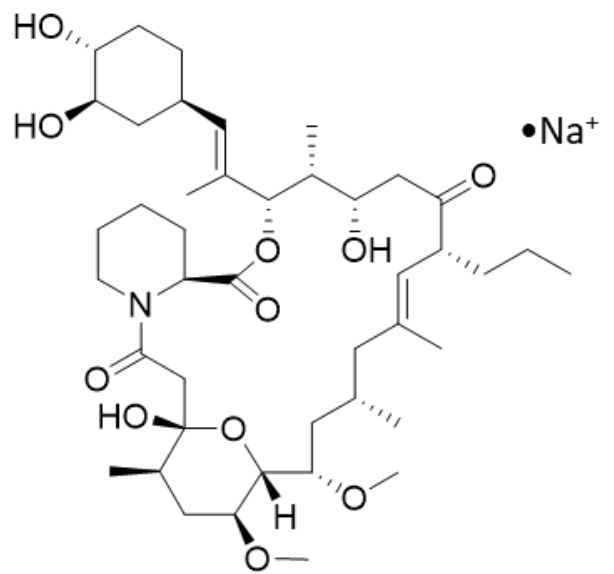

9-deoxo-31-O-demethyl-36,37-dihydroFK506 (12)

(b)

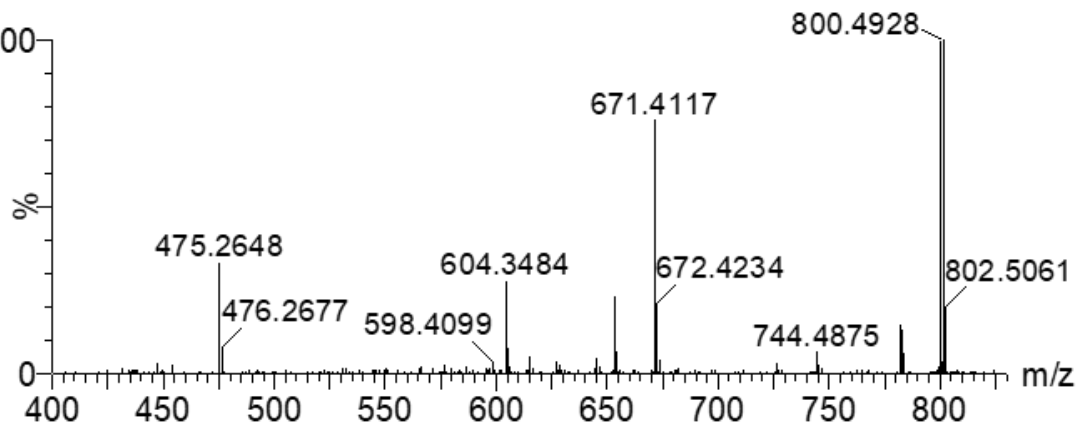

Figure S17. ESI-qTOF-HR-MS analysis of 9-deoxo-31-O-demethyl-36,37-dihydroFK506 (12) obtained from $\Delta \mathrm{tcsD}-\Delta \mathrm{fkbDM}$ strain. (a) Chemical structure of 12, (b) MS/MS spectrum of 12. 
(a)

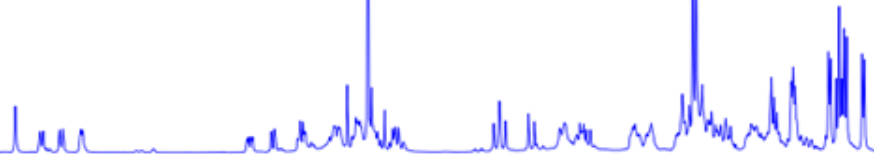

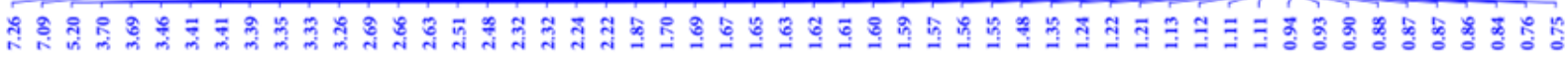

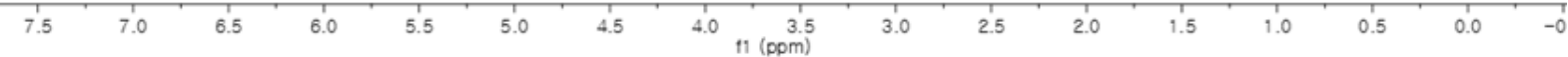

(b)

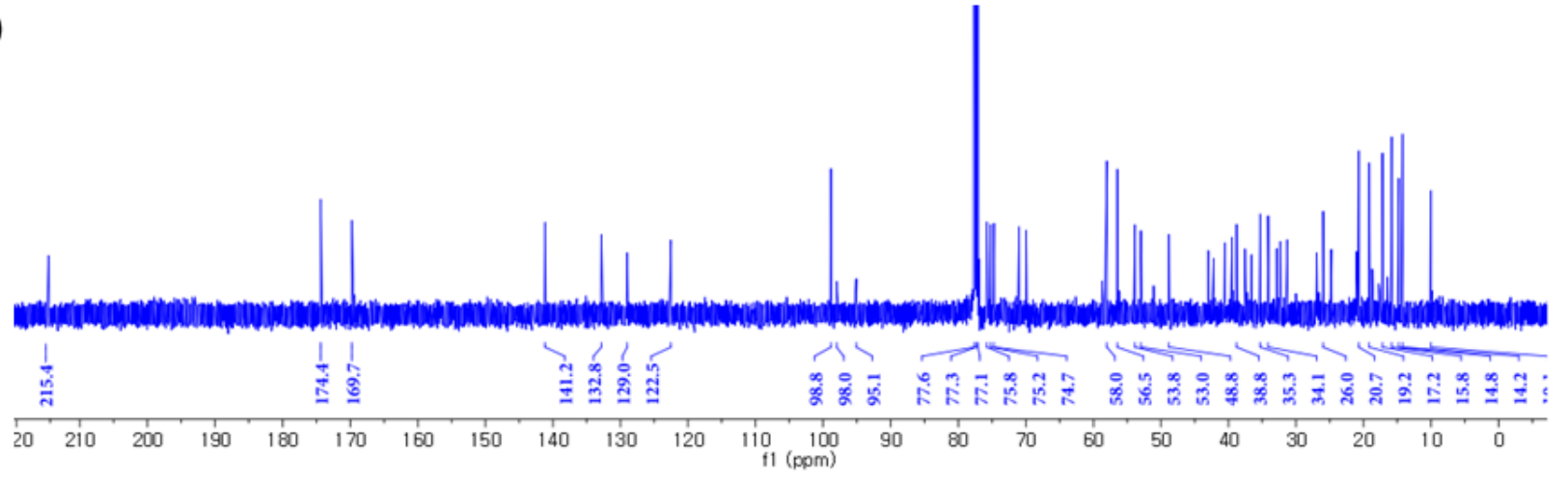

(c)

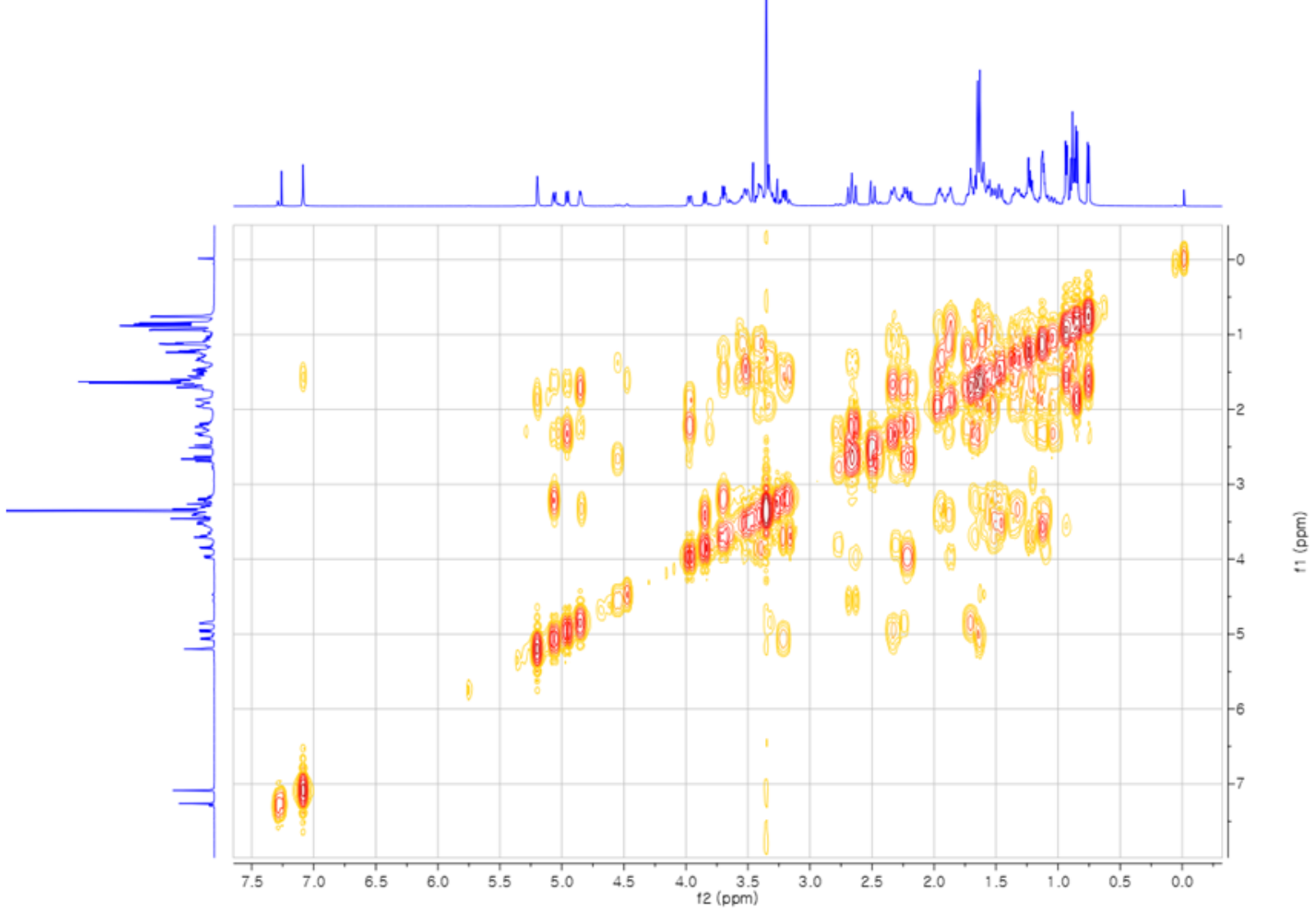


(d)

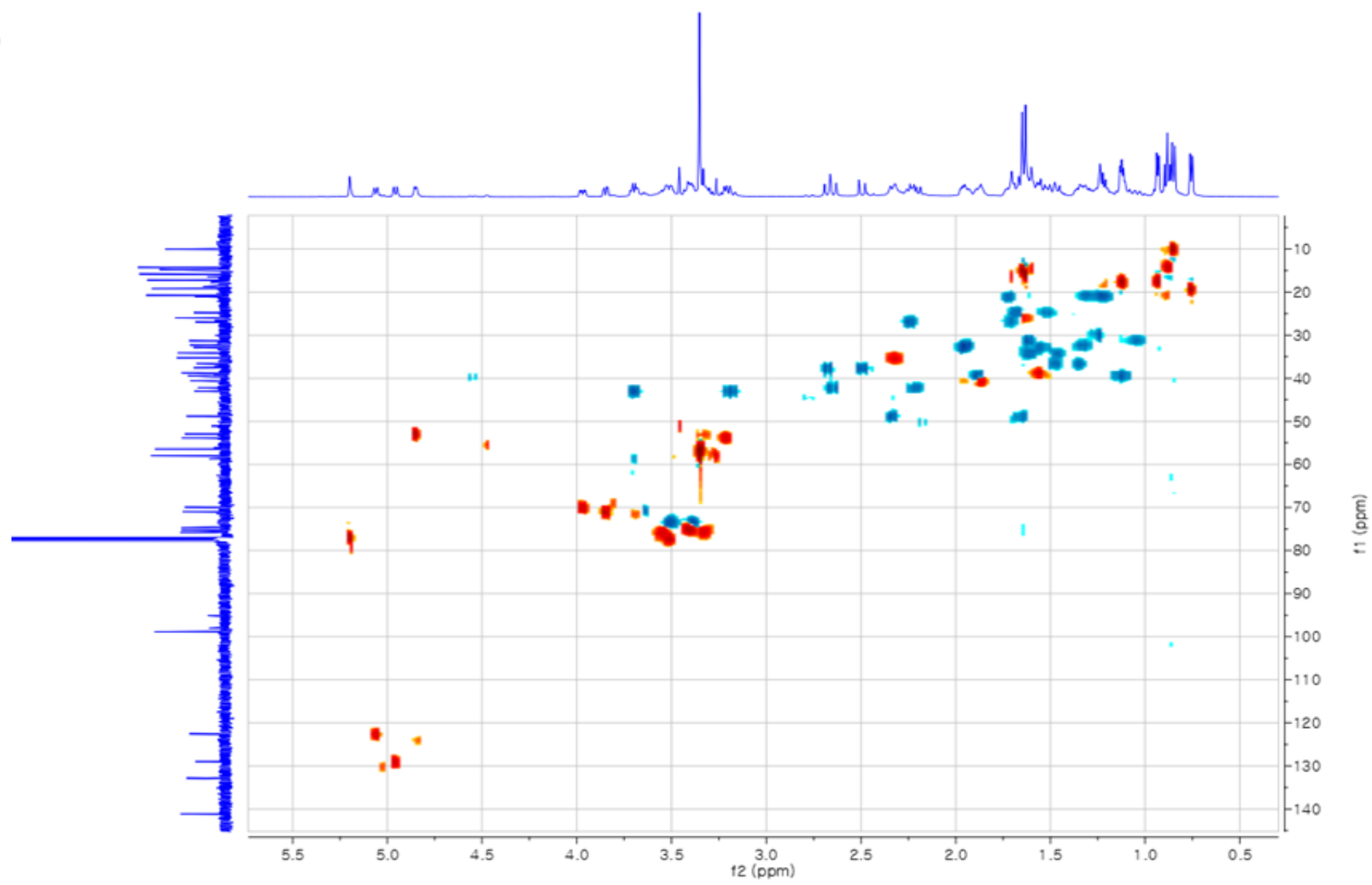

(e)

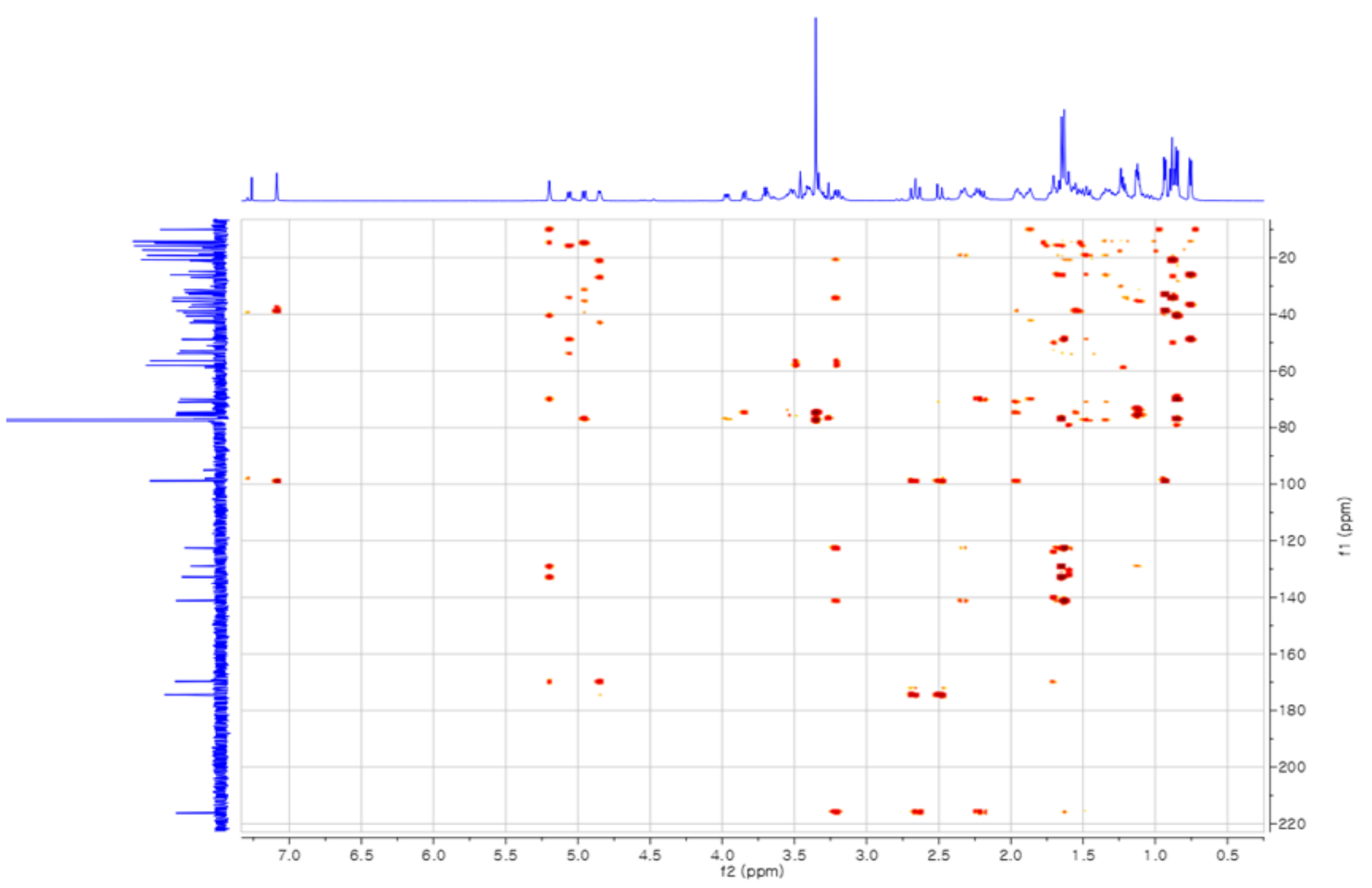

Figure S18. The structural determination of 9-deoxo-31-O-demethyl-36,37-dihydroFK506 (12). (a) ${ }^{1} \mathrm{H}(500 \mathrm{MHz})$, (b) ${ }^{13} \mathrm{C}(125 \mathrm{MHz})$, (c) ${ }^{1} \mathrm{H}-{ }^{1} \mathrm{H}$ gCOSY, (d) ${ }^{1} \mathrm{H}-{ }^{13} \mathrm{C}$ gHSQC, and (e) ${ }^{1} \mathrm{H}_{-}{ }^{13} \mathrm{C}$ gHMBC NMR data of 12 in $\mathrm{CDCl}_{3}$ obtained from $\Delta \mathrm{tcsD}-\Delta \mathrm{fkbDM}$ strain. 
(a)

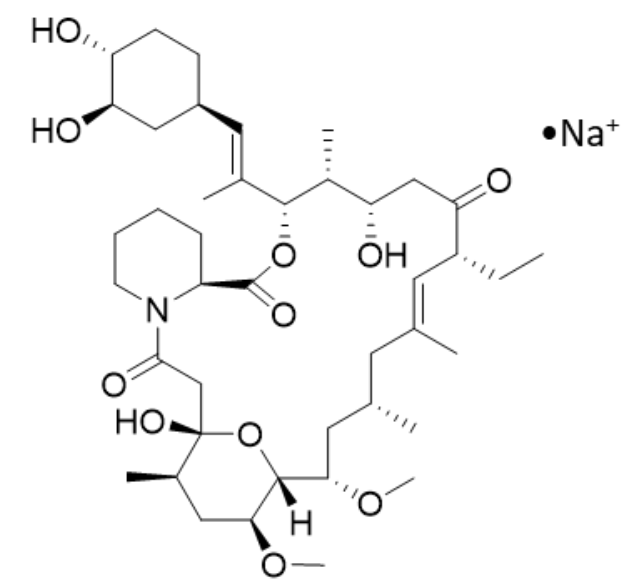

9-deoxo-31-O-demethylFK520 (13)

(b)

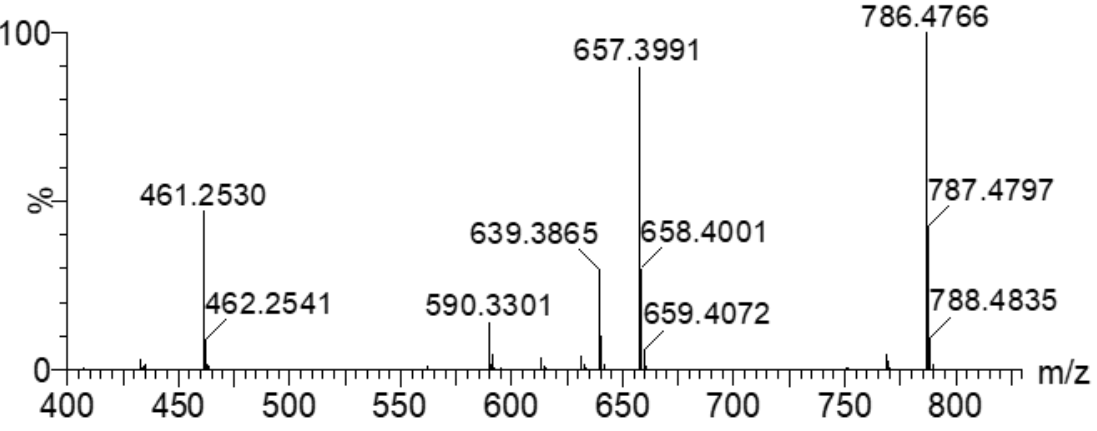

Figure S19. ESI-qTOF-HR-MS analysis of 9-deoxo-31-O-demethylFK520 (13) obtained from $\Delta$ tcsB- $\Delta$ fkbDM strain. (a) Chemical structure of 13, (b) MS/MS spectrum of 13 . 
(a)

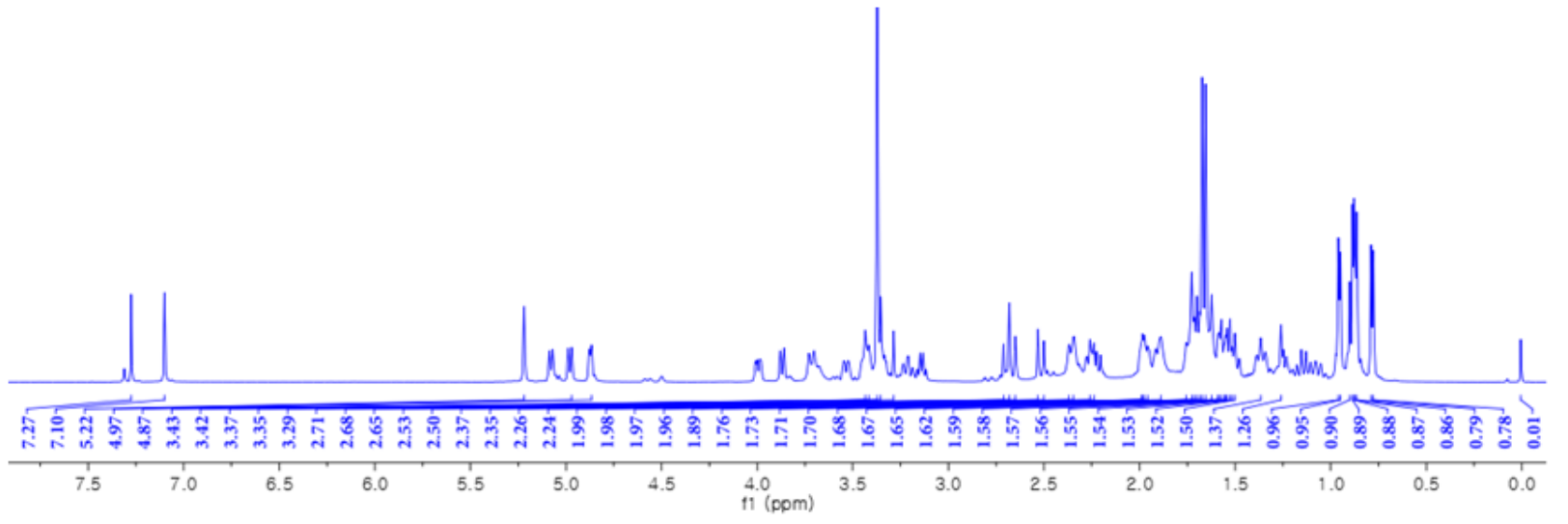

(b)

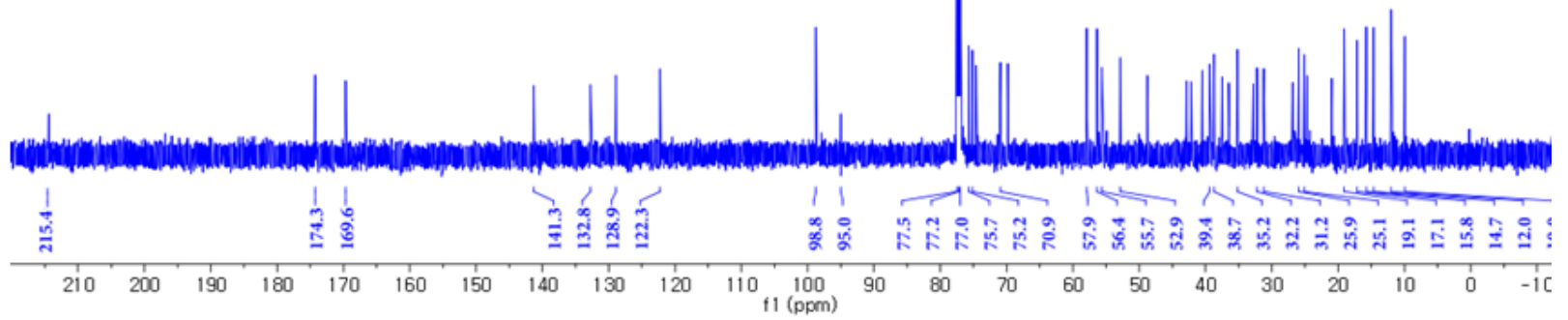

(c)

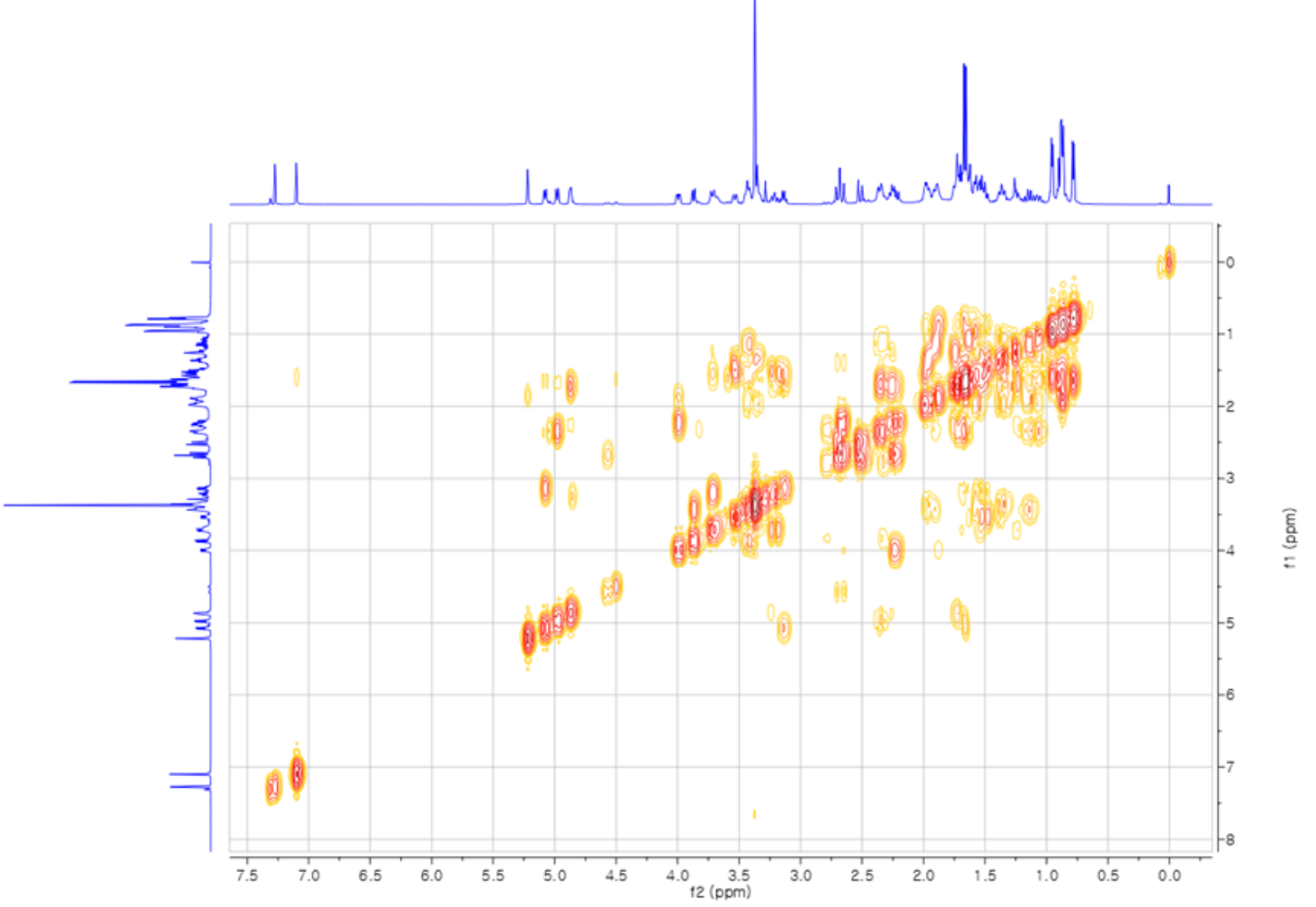


(d)

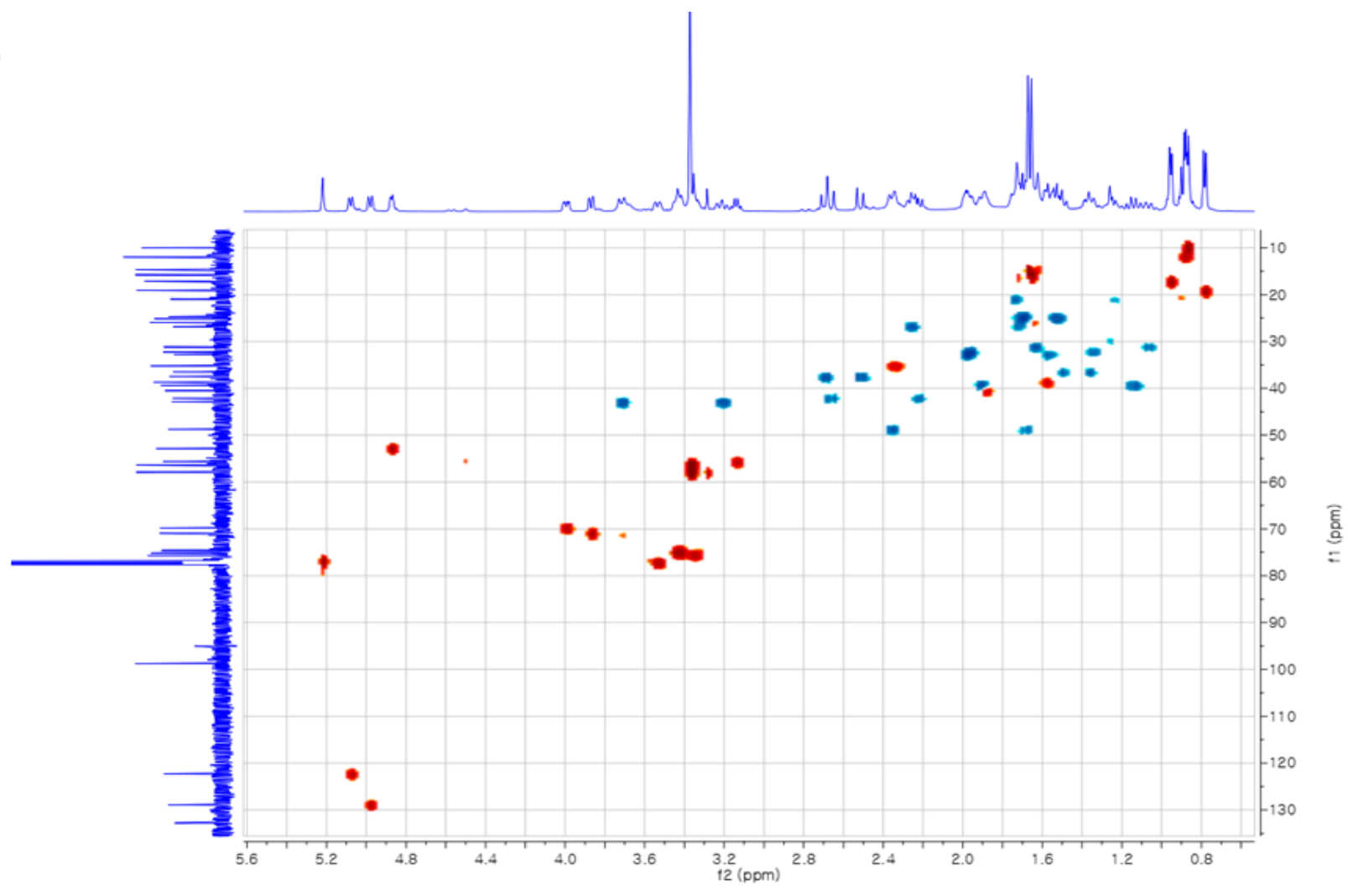

(e)

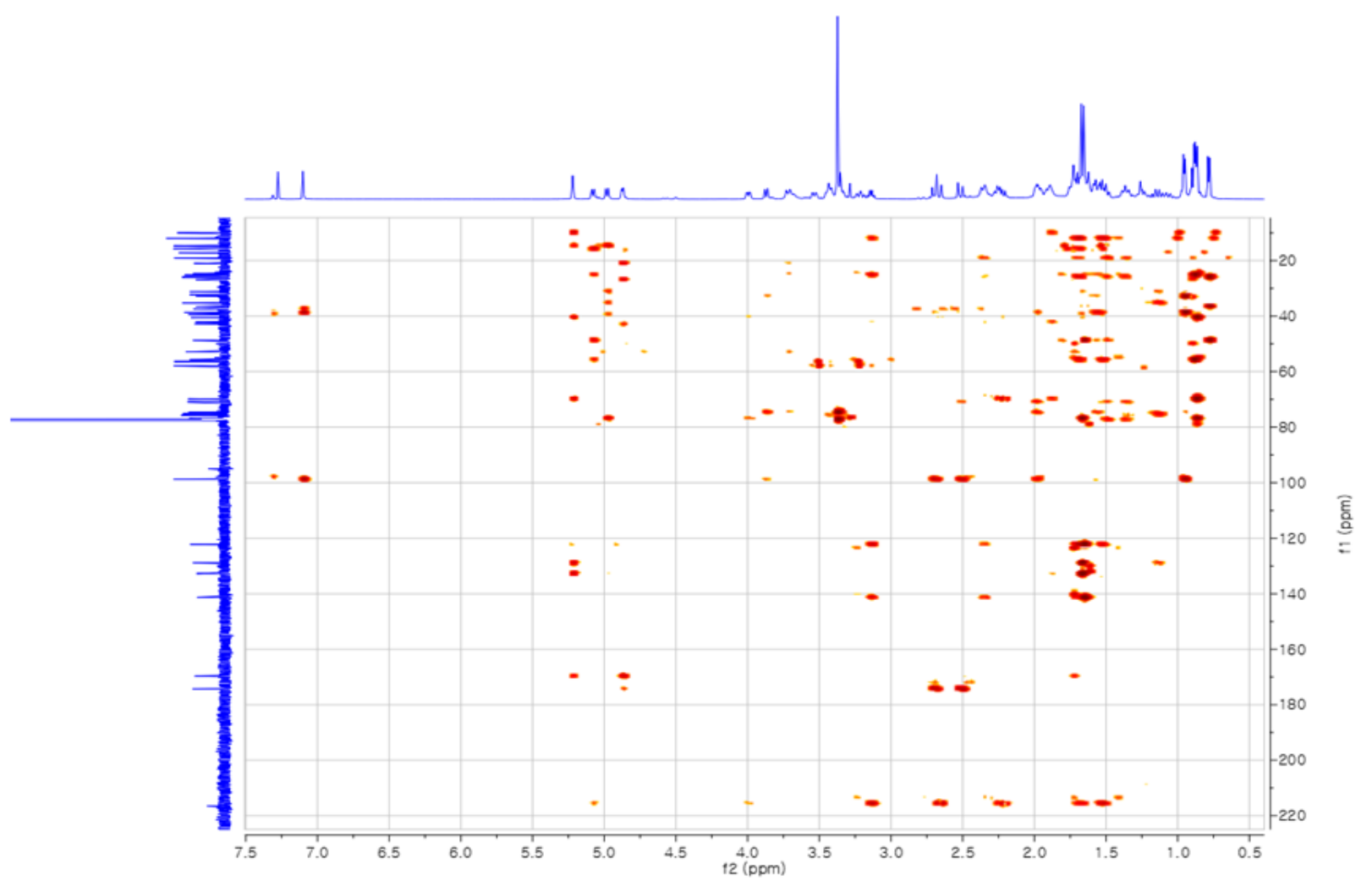

Figure S20. The structural determination of 9-deoxo-31-O-demethylFK520 (13). (a) ${ }^{1} \mathrm{H}(500 \mathrm{MHz})$, (b) ${ }^{13} \mathrm{C}$ (125 MHz), (c) ${ }^{1} \mathrm{H}_{-}{ }^{1} \mathrm{H}$ gCOSY, (d) ${ }^{1} \mathrm{H}_{-}{ }^{13} \mathrm{C}$ gHSQC, and (e) ${ }^{1} \mathrm{H}_{-}{ }^{13} \mathrm{C}$ gHMBC NMR data of 13 in $\mathrm{CDCl}_{3}$ obtained from $\Delta \mathrm{tcsB}-\Delta \mathrm{fkbDM}$ strain. 
(a)

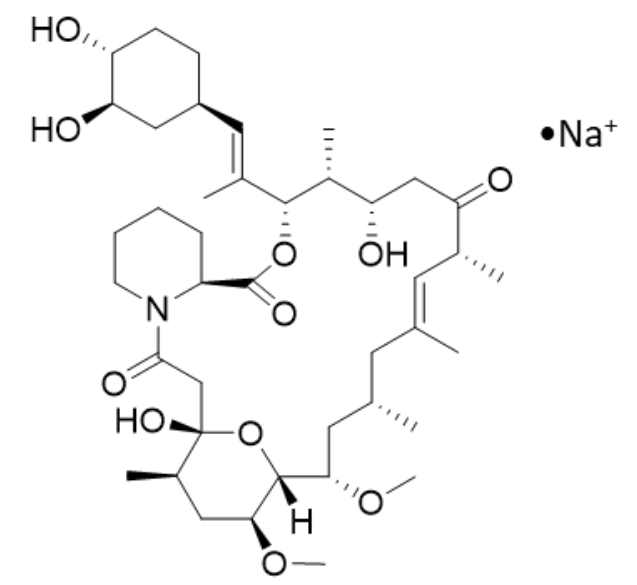

9-deoxo-31-O-demethylFK523 (14)

(b)

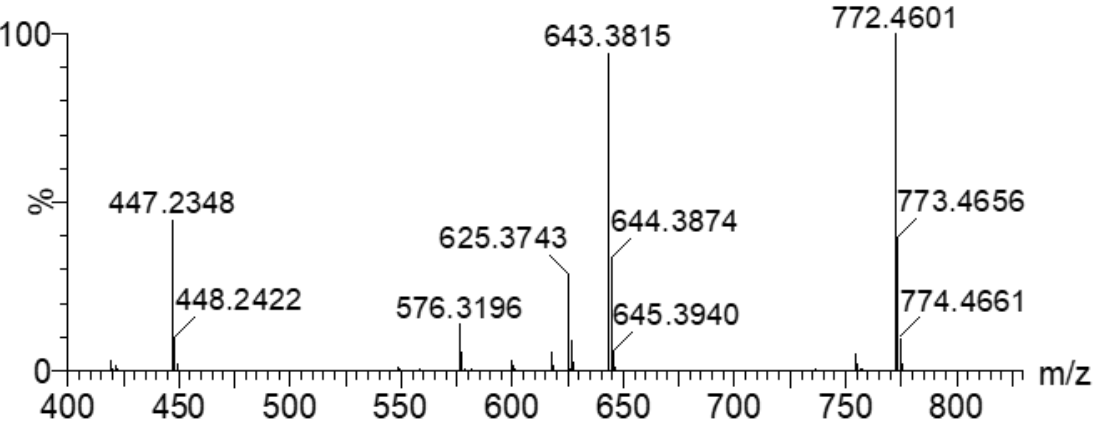

Figure S21. ESI-qTOF-HR-MS analysis of 9-deoxo-31-O-demethylFK523 (14) obtained from $\Delta$ tcsB- $\Delta$ fkbDM strain. (a) Chemical structure of $\mathbf{1 4}$, (b) MS/MS spectrum of $\mathbf{1 4}$. 
(a)

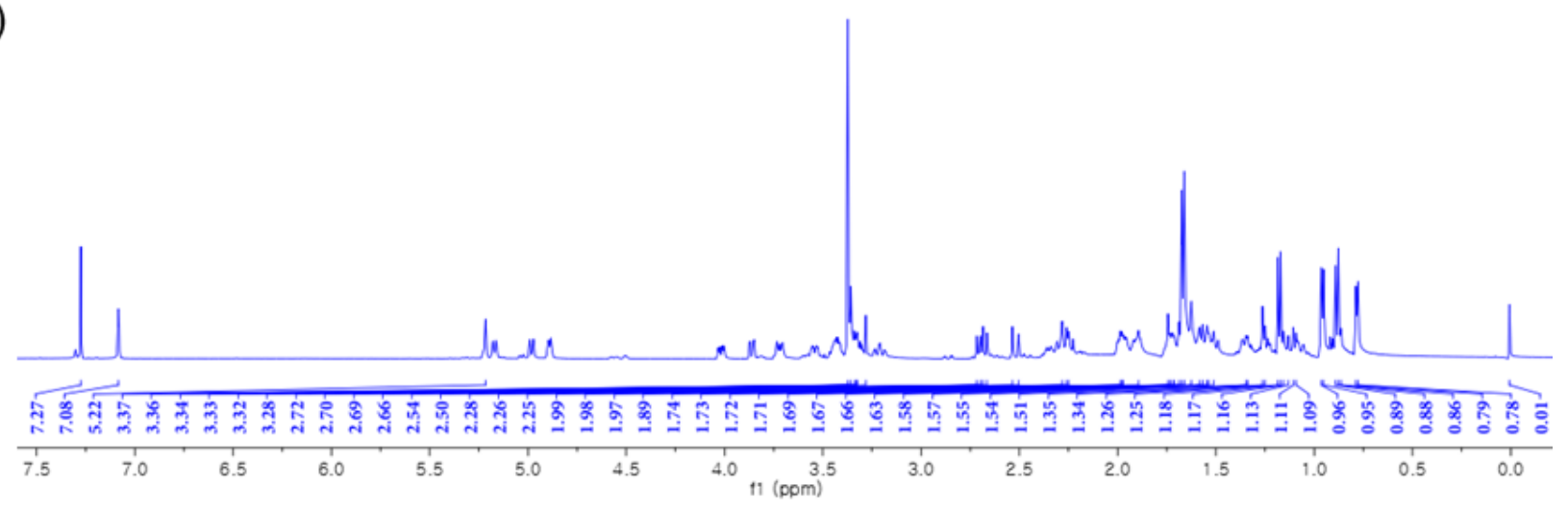

(b)

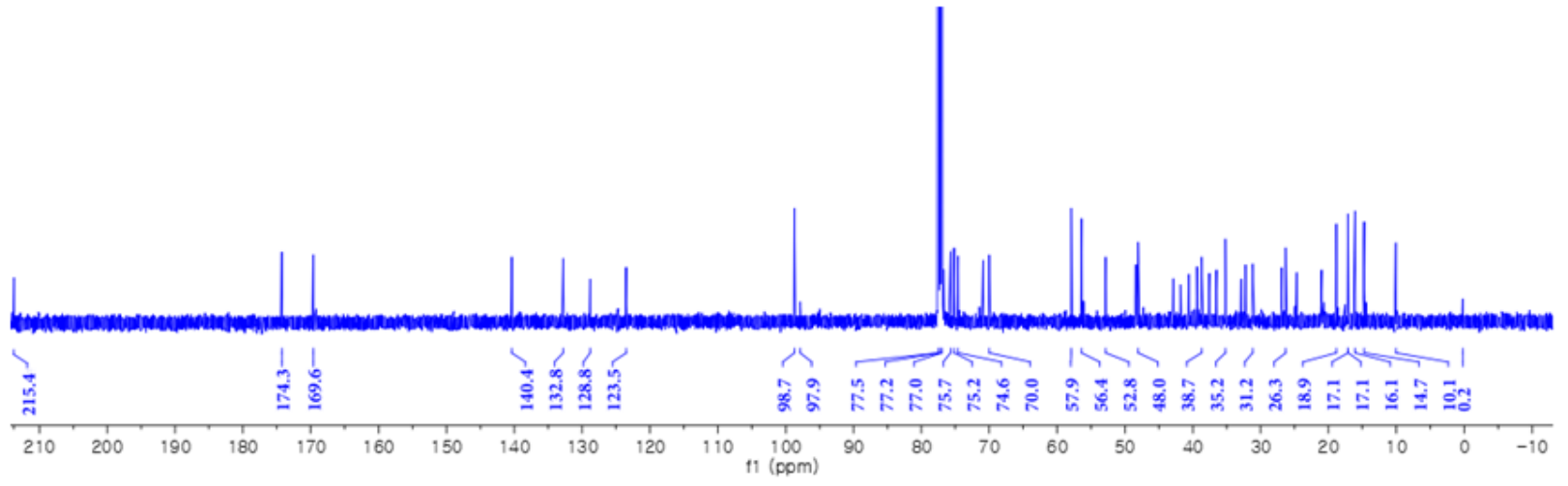

(c)

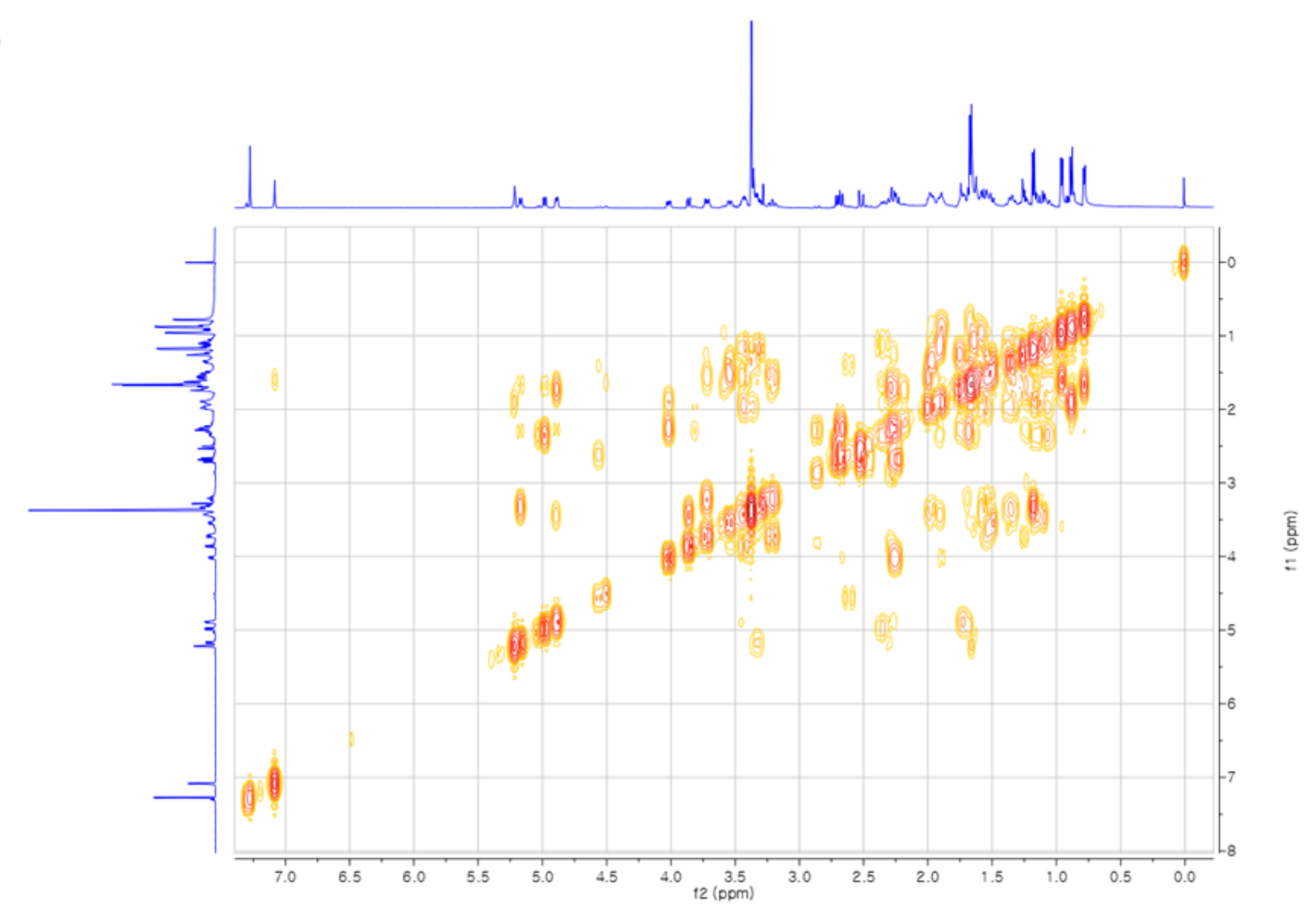


(d)

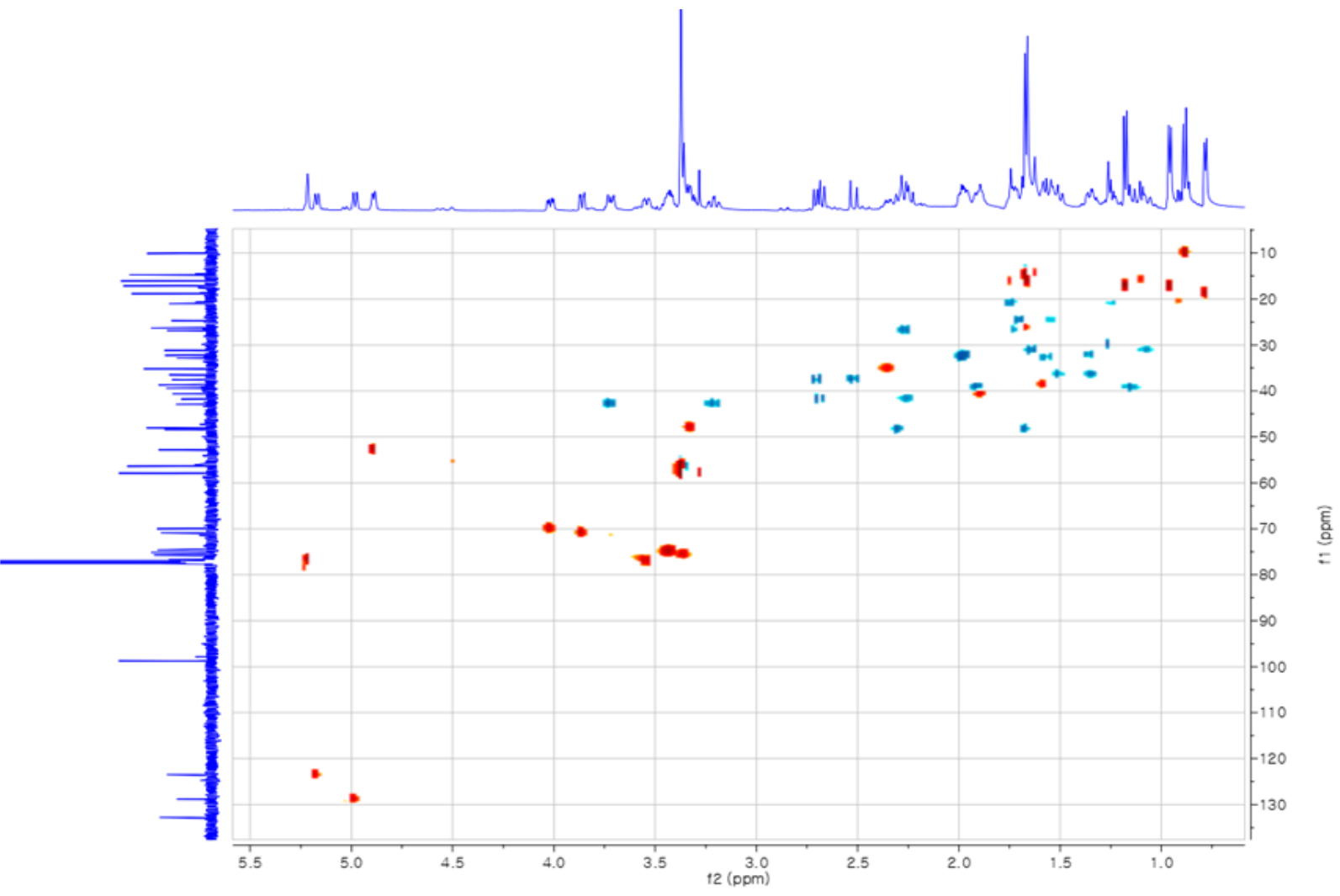

(e)

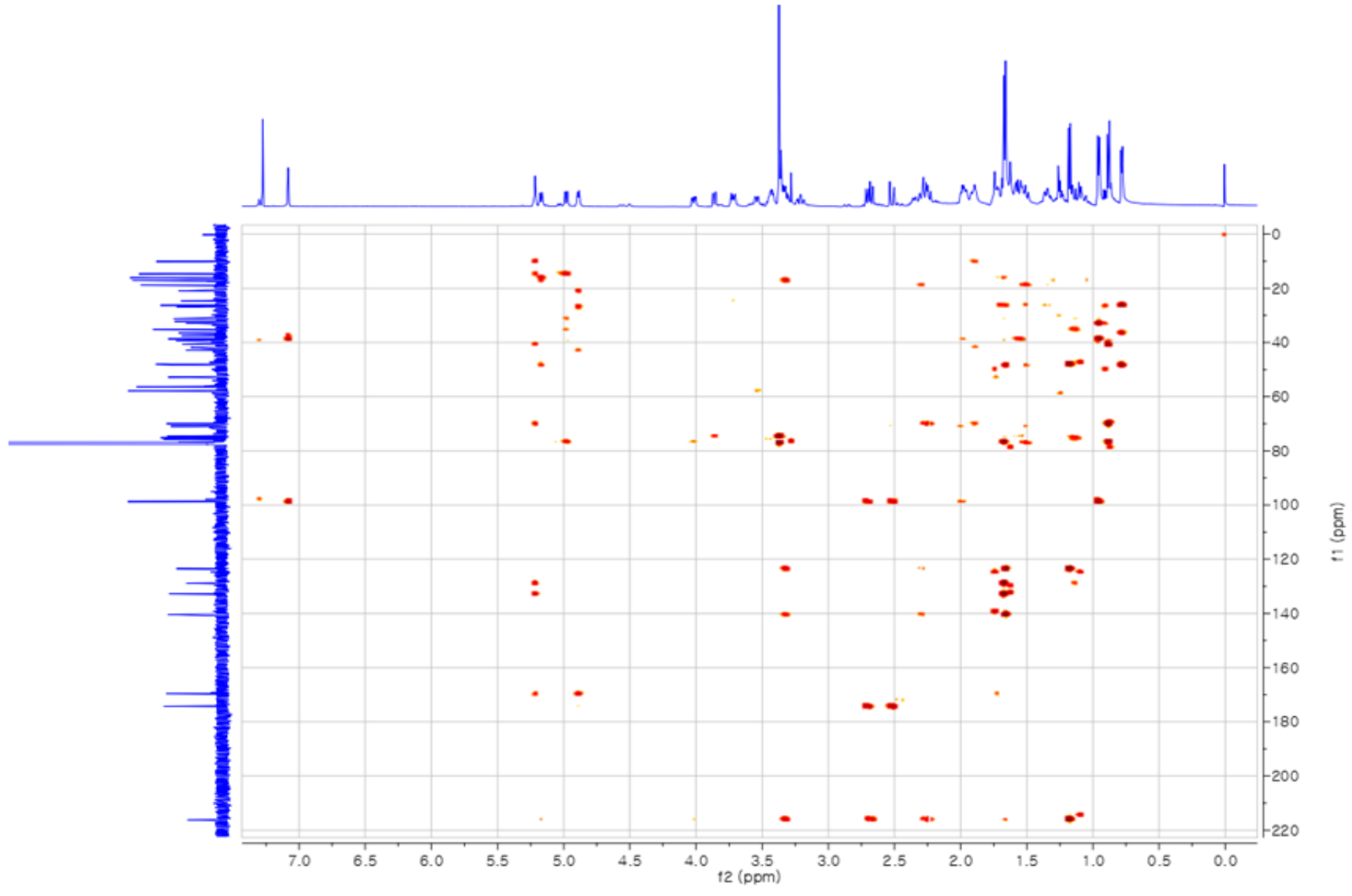

Figure S22. The structural determination of 9-deoxo-31-O-demethylFK523 (14). (a) ${ }^{1} \mathrm{H}(500 \mathrm{MHz})$, (b) ${ }^{13} \mathrm{C}$ (125 MHz), (c) ${ }^{1} \mathrm{H}_{-}{ }^{1} \mathrm{H}$ gCOSY, (d) ${ }^{1} \mathrm{H}_{-}{ }^{13} \mathrm{C}$ gHSQC, and (e) ${ }^{1} \mathrm{H}_{-}{ }^{13} \mathrm{C}$ gHMBC NMR data of 14 in $\mathrm{CDCl}_{3}$ obtained from $\Delta \mathrm{tcsB}-\Delta \mathrm{fkbDM}$ strain. 

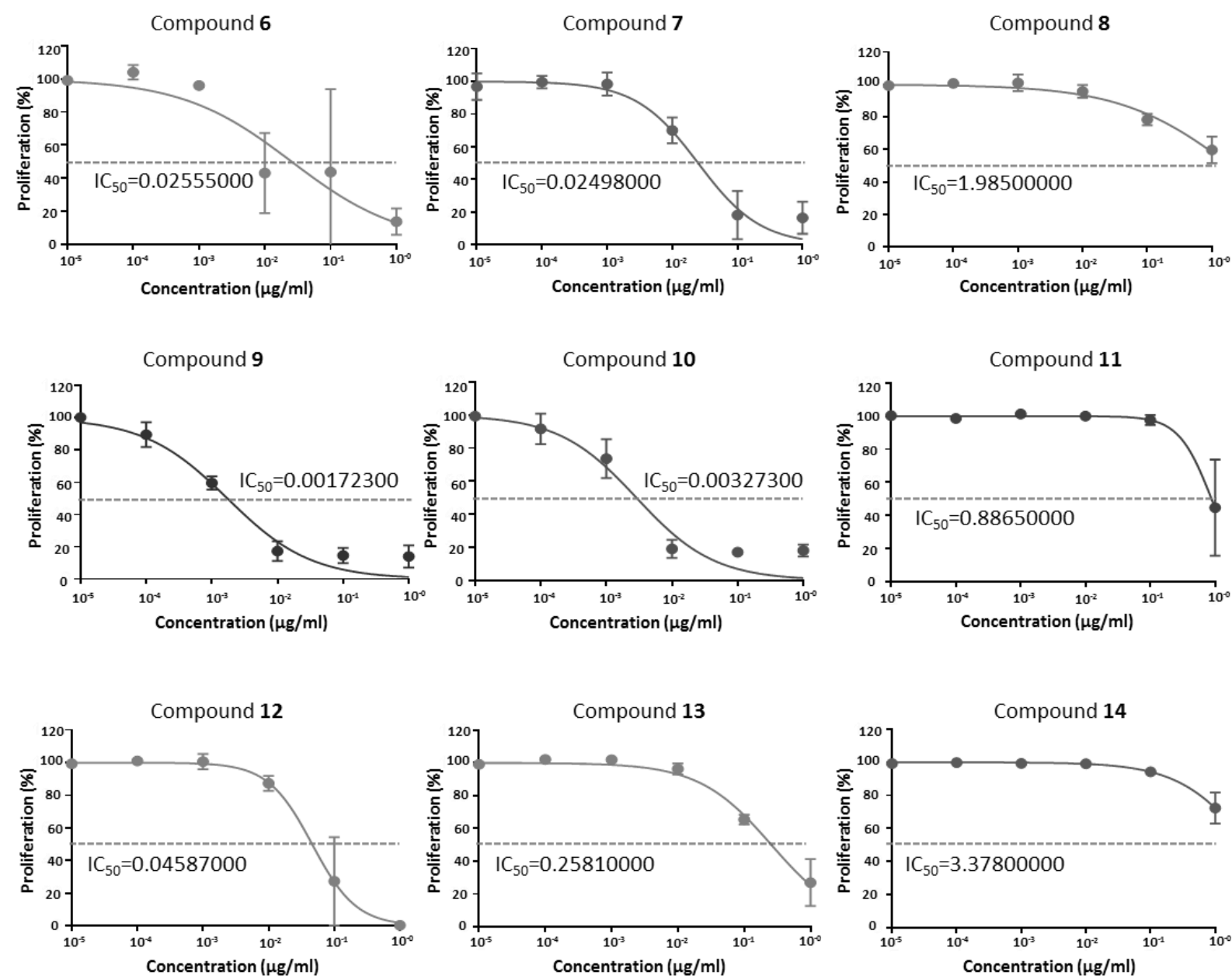

Figure S23. Immunosuppressive activity of FK506 analogues. Data from three independent biological groups were used to calculate the $\mathrm{IC}_{50}$ for each compound using nonlinear regression fit analysis. Curves for all compounds displayed higher $\mathrm{IC}_{50}$ compared with the $\mathrm{IC}_{50}$ of FK506, which indicated a significant reduction in immunosuppressive activity. All data are presented as the mean \pm standard error of the mean (SEM). 
Compound 6

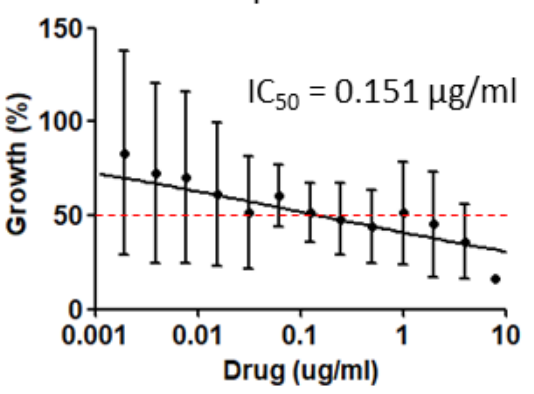

Compound 9

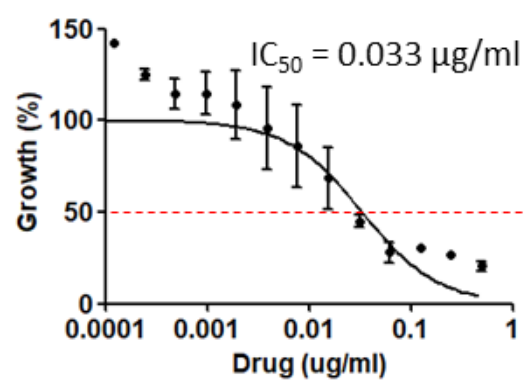

Compound 12

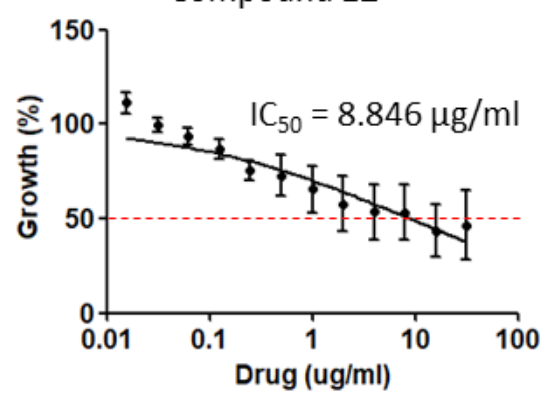

Compound 7

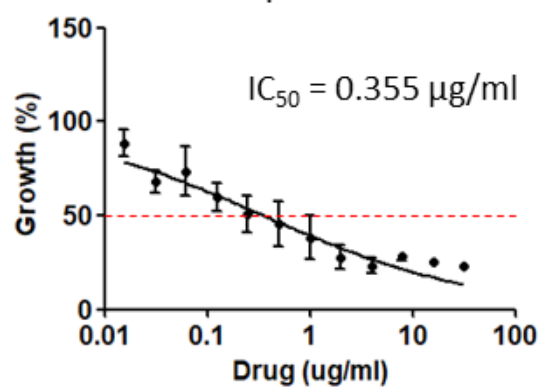

Compound 10

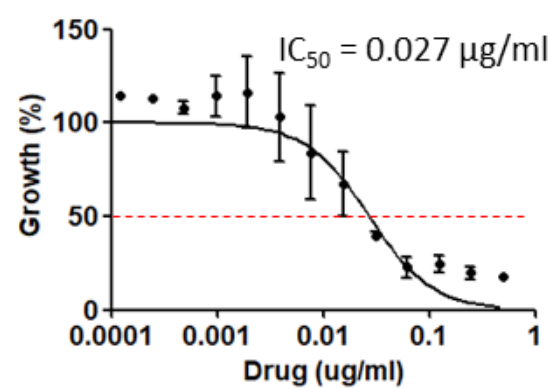

Compound 13

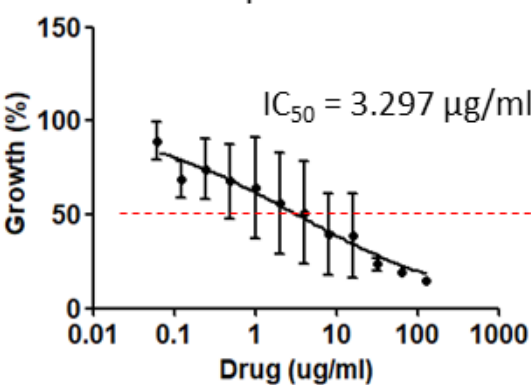

Compound 8

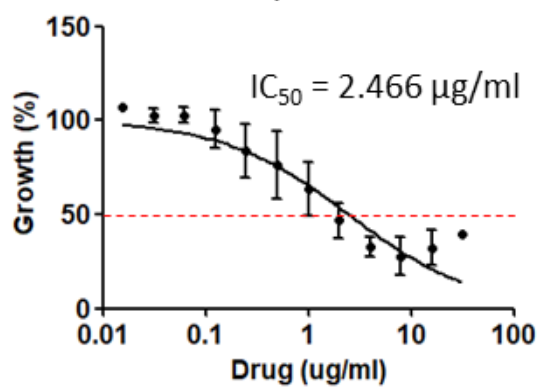

Compound $\mathbf{1 1}$

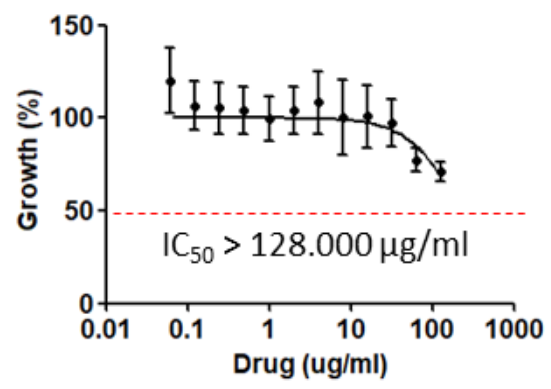

Compound 14

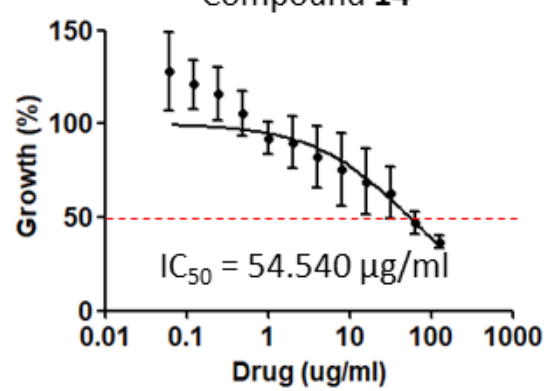

Figure S24. MIC assay of FK506 analogues against Cryptococcus neoformans. Three biological independent assays were performed along with MIC assay by EUCAST guideline. Error bars indicate a standard error of the mean (SEM). 
Compound 6

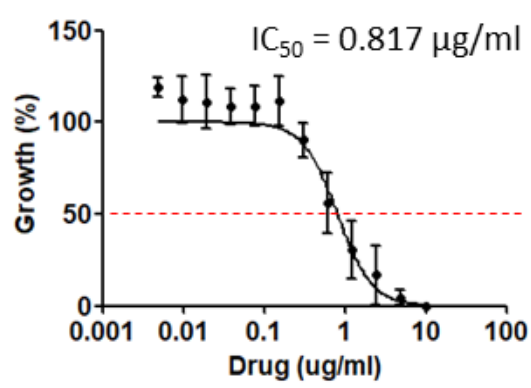

Compound 9

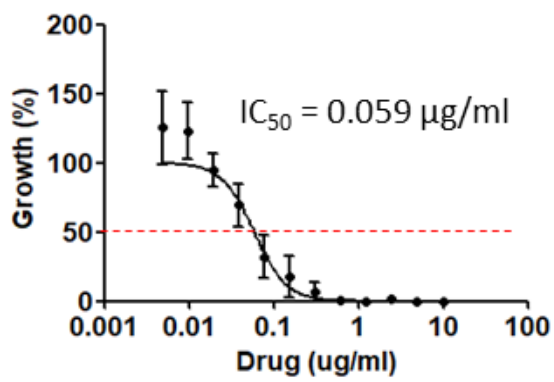

Compound $\mathbf{1 2}$

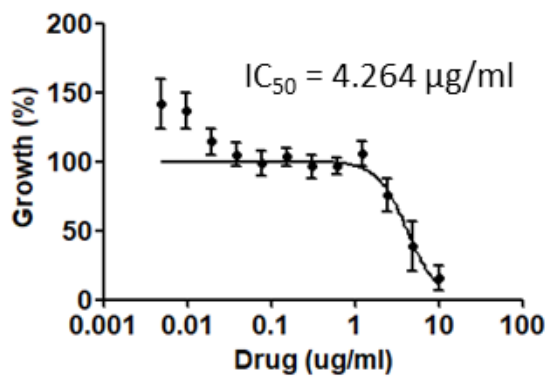

Compound 7

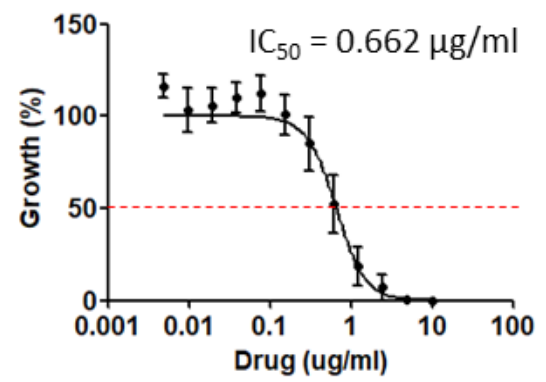

Compound $\mathbf{1 0}$

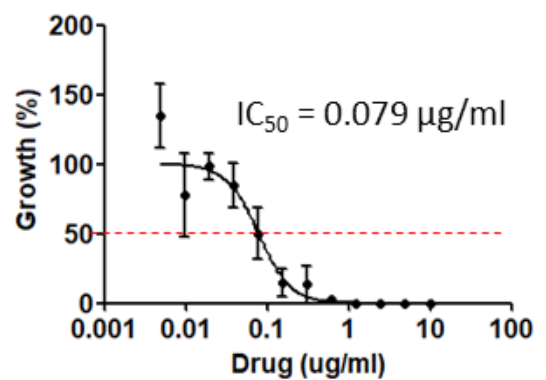

Compound $\mathbf{1 3}$

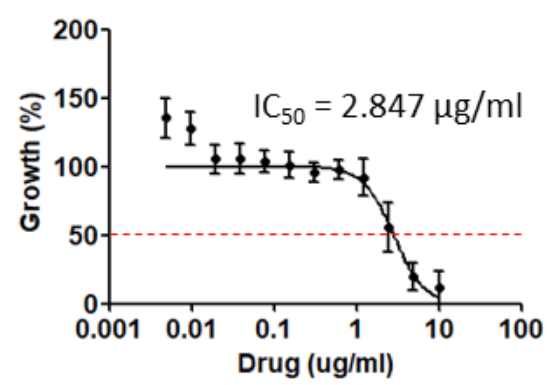

Compound 8

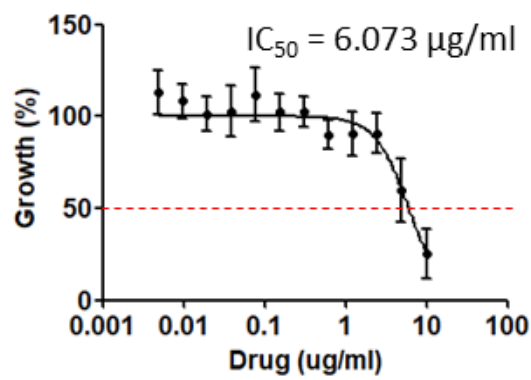

Compound $\mathbf{1 1}$

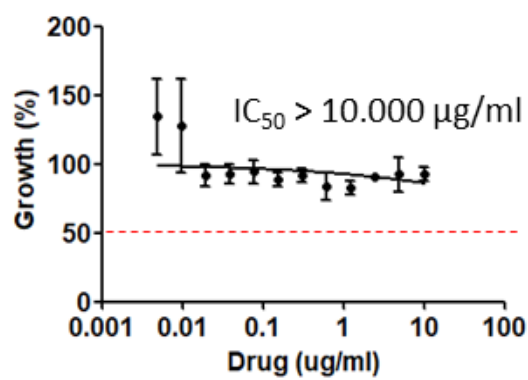

Compound 14

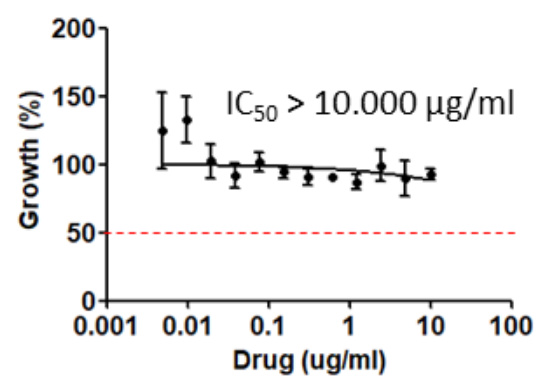

Figure S25. MIC assay of FK506 analogues against Candida albicans. Three biological independent assays were performed along with MIC assay by EUCAST guideline. Error bars indicate a standard error of the mean (SEM). 
(a)

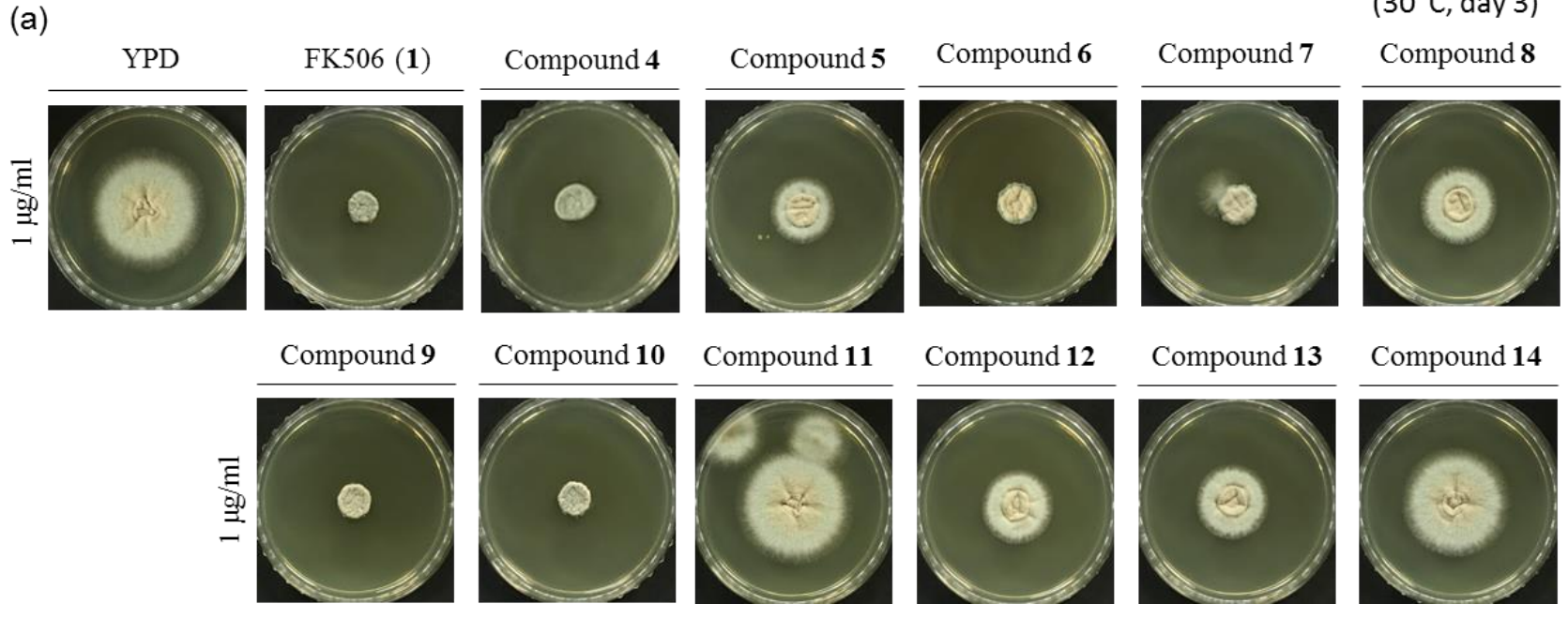

(b)
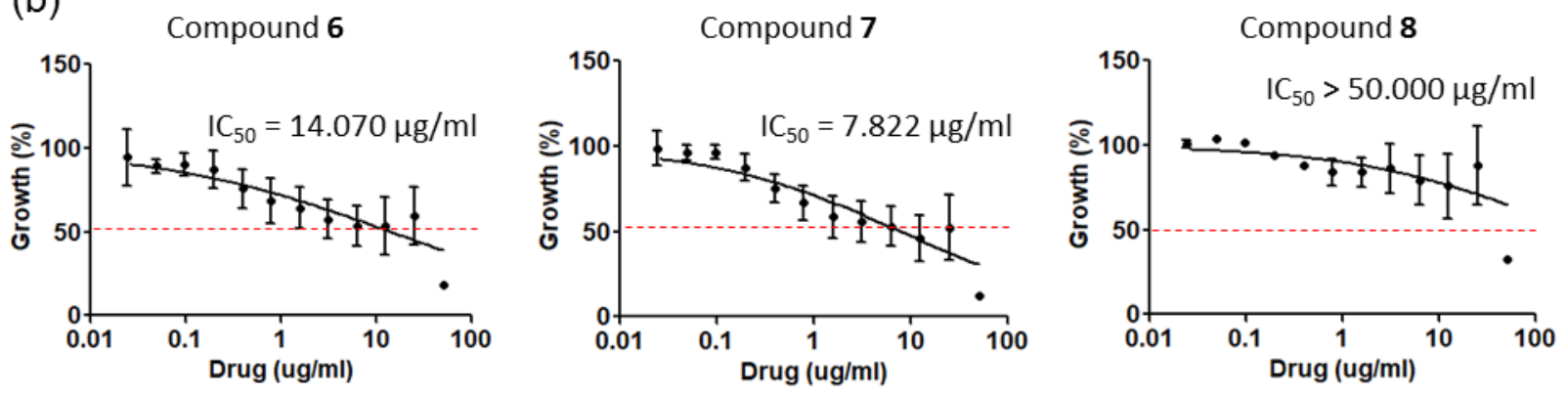

Compound $\mathbf{9}$
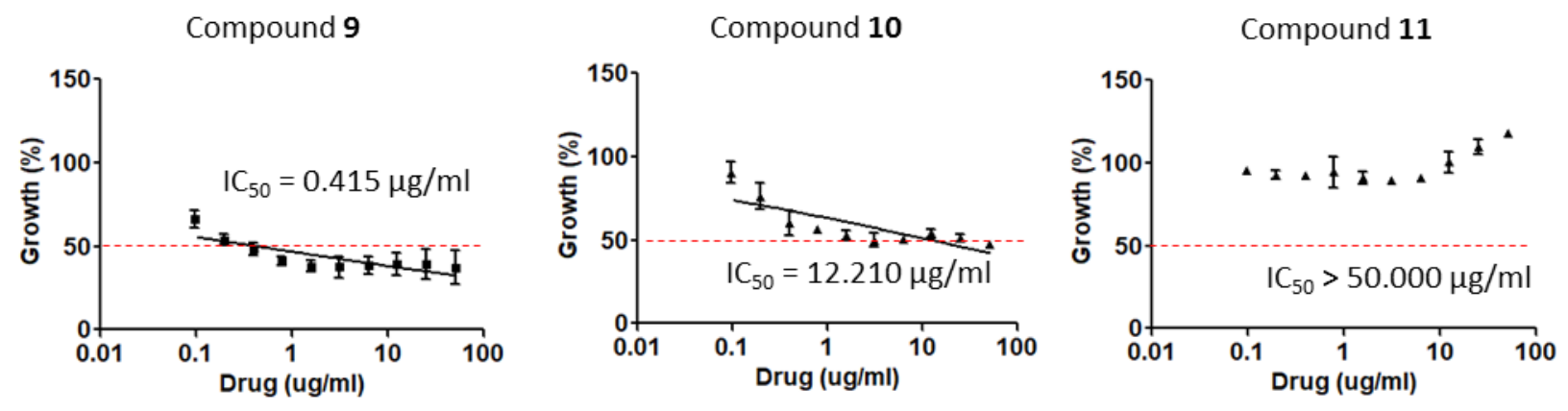

Compound 12
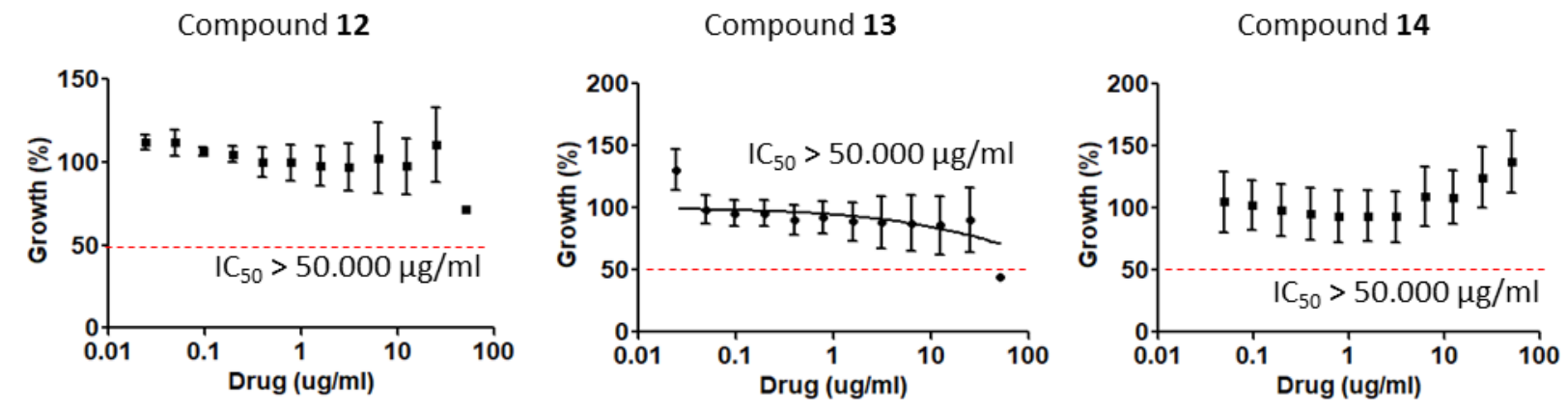

Figure S26. Antifungal activity and MIC assay of FK506 analogues against Aspergillus fumigatus. (a) Growth of $A$. fumigatus $(5,000$ spores $/ 2 \mu \mathrm{L})$ on YPD containing $1 \mu \mathrm{g} / \mathrm{mL}$ of 1 or its analogues at $30{ }^{\circ} \mathrm{C}$ for 3 days. (b) Three biological independent assays were performed along with MIC assay by EUCAST guideline. Error bars indicate a standard error of the mean (SEM). 


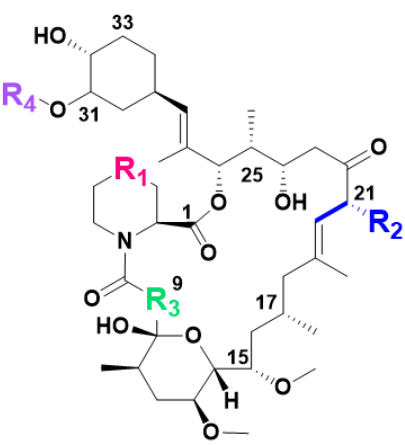

\begin{tabular}{|c|c|c|c|c|c|c|c|c|}
\hline \multirow[b]{2}{*}{ Compound } & \multirow[b]{2}{*}{$R_{1}$} & \multirow[b]{2}{*}{$\mathbf{R}_{\mathbf{2}}$} & \multirow[b]{2}{*}{$\mathbf{R}_{\mathbf{3}}$} & \multirow[b]{2}{*}{$\mathbf{R}_{\mathbf{4}}$} & \multirow{2}{*}{$\begin{array}{c}50 \% \\
\text { Immunosuppression } \\
(\mathrm{ng} / \mathrm{mL})\end{array}$} & \multicolumn{3}{|c|}{$1 C_{50}(\mu \mathrm{g} / \mathrm{mL})$} \\
\hline & & & & & & $\begin{array}{l}\text { Cryptococcus } \\
\text { neoformans }\end{array}$ & $\begin{array}{l}\text { Candida } \\
\text { albicans }\end{array}$ & $\begin{array}{l}\text { Aspergillus } \\
\text { fumigatus }\end{array}$ \\
\hline FK506 (1) & $\mathrm{CH}_{2}$ & $\mathrm{CH}_{2} \mathrm{CH}=\mathrm{CH}_{2}$ & $C=O$ & $\mathrm{CH}_{3}$ & 0.027 & 0.001 & 0.005 & 0.015 \\
\hline 2 & - & $\mathrm{CH}_{2} \mathrm{CH}=\mathrm{CH}_{2}$ & $\mathrm{CH}_{2}$ & $\mathrm{CH}_{3}$ & 268.3 & 6.112 & 322.0 & $>50.0$ \\
\hline 3 & $\mathrm{CH}_{2}$ & $\mathrm{CH}_{2} \mathrm{CH}=\mathrm{CH}_{2}$ & $\mathrm{CH}_{2}$ & $\mathrm{CH}_{3}$ & 0.513 & 0.036 & 0.963 & 24.19 \\
\hline 4 & $\mathrm{CH}_{2}$ & $\mathrm{CH}_{2} \mathrm{CH}=\mathrm{CH}_{2}$ & $C=O$ & $\mathrm{H}$ & 0.246 & 0.005 & 0.106 & 0.165 \\
\hline 5 & $\mathrm{CH}_{2}$ & $\mathrm{CH}_{2} \mathrm{CH}=\mathrm{CH}_{2}$ & $\mathrm{CH}_{2}$ & $\mathrm{H}$ & 15.09 & 0.154 & 2.796 & 29.77 \\
\hline 6 & $\mathrm{CH}_{2}$ & $\mathrm{CH}_{2} \mathrm{CH}_{2} \mathrm{CH}_{3}$ & $\mathrm{CH}_{2}$ & $\mathrm{CH}_{3}$ & 25.55 & 0.151 & 0.817 & 14.07 \\
\hline 7 & $\mathrm{CH}_{2}$ & $\mathrm{CH}_{2} \mathrm{CH}_{3}$ & $\mathrm{CH}_{2}$ & $\mathrm{CH}_{3}$ & 24.98 & 0.355 & 0.662 & 7.822 \\
\hline 8 & $\mathrm{CH}_{2}$ & $\mathrm{CH}_{3}$ & $\mathrm{CH}_{2}$ & $\mathrm{CH}_{3}$ & 1985.0 & 2.466 & 6.073 & 230.4 \\
\hline 9 & $\mathrm{CH}_{2}$ & $\mathrm{CH}_{2} \mathrm{CH}_{2} \mathrm{CH}_{3}$ & $C=O$ & $\mathrm{H}$ & 1.723 & 0.033 & 0.059 & 0.415 \\
\hline 10 & $\mathrm{CH}_{2}$ & $\mathrm{CH}_{2} \mathrm{CH}_{3}$ & $C=O$ & $\mathrm{H}$ & 3.273 & 0.027 & 0.079 & 12.21 \\
\hline 11 & - & $\mathrm{CH}_{2} \mathrm{CH}=\mathrm{CH}_{2}$ & $\mathrm{CH}_{2}$ & $\mathrm{H}$ & 886.5 & 221.1 & 3444.0 & $>50.0$ \\
\hline 12 & $\mathrm{CH}_{2}$ & $\mathrm{CH}_{2} \mathrm{CH}_{2} \mathrm{CH}_{3}$ & $\mathrm{CH}_{2}$ & $\mathrm{H}$ & 45.87 & 8.846 & 4.264 & $>50.0$ \\
\hline 13 & $\mathrm{CH}_{2}$ & $\mathrm{CH}_{2} \mathrm{CH}_{3}$ & $\mathrm{CH}_{2}$ & $\mathrm{H}$ & 258.1 & 3.297 & 2.847 & 306.8 \\
\hline 14 & $\mathrm{CH}_{2}$ & $\mathrm{CH}_{3}$ & $\mathrm{CH}_{2}$ & $\mathrm{H}$ & 3378.0 & 54.54 & 837.1 & $>50.0$ \\
\hline
\end{tabular}

Figure S27. Structures of FK506 and its analogues with theirs bioactivities.

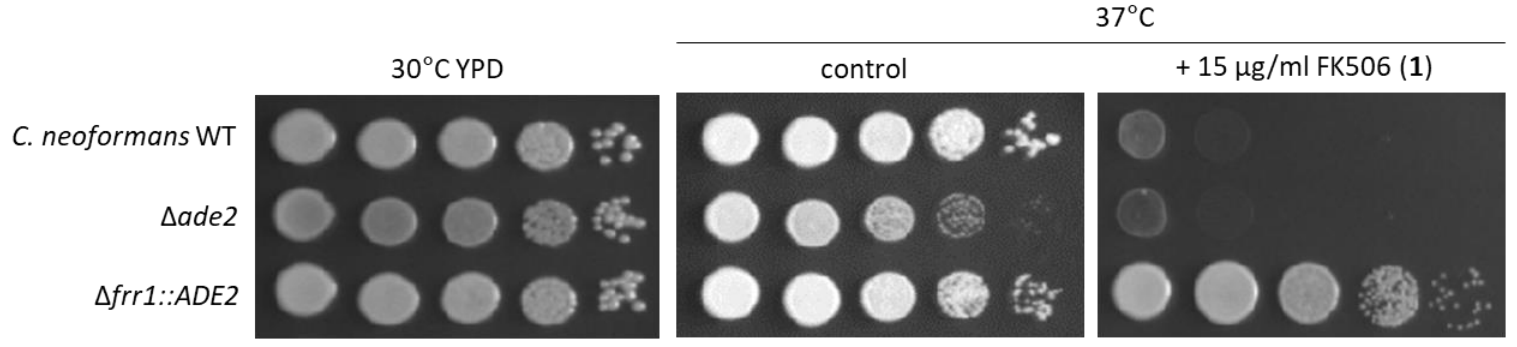

$37^{\circ} \mathrm{C}+30 \mu \mathrm{g} / \mathrm{ml}$ of derivatives

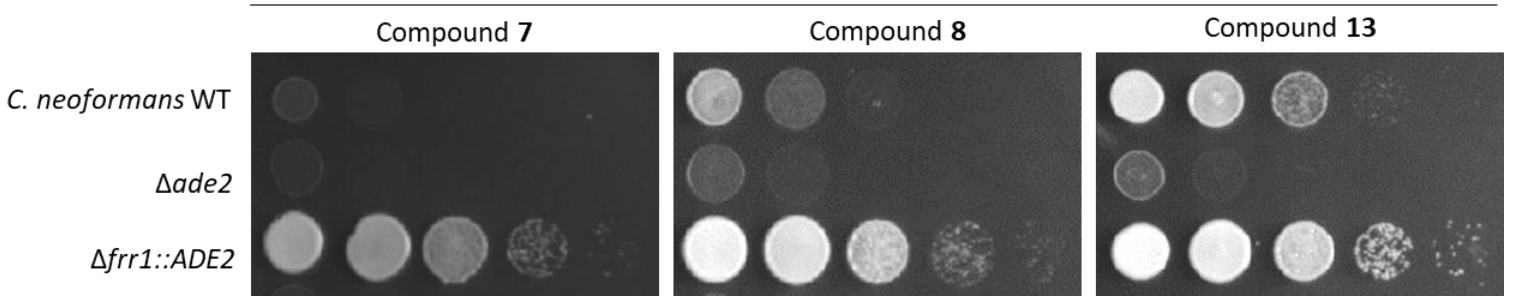

Figure S28. MCC1 ( $\triangle f r r 1:: A D E 2$ mutant) was resistant to FK506 and its analogues in contrast to its background C. neoformans $\Delta$ ade2 (M049) and wild type (WT) H99 strains at $37{ }^{\circ} \mathrm{C}$. This result indicates that the FK506 analogues target FKBP12 in C. neoformans similarly to FK506. 


\section{Supporting References}

(1) Sambrook, J,; Fritsch, E. F.; Maniatis, T. Molecular cloning: A laboratory manual; Cold Spring Harbor Laboratory Press: Cold Spring Harbor, NY, 1989.

(2) MacNeil, D. J.; Gewain, K. M.; Ruby, C. L.; Dezeny, G.; Gibbons, P. H.; MacNeil, T. Gene 1992, 111, 61-68.

(3) Bierman, M.; Logan, R.; O'brien, K.; Seno, E.; Rao, R. N.; Schoner, B. Gene 1992, 116, 43-49.

(4) Andexer, J. N.; Kendrew, S. G.; Nur-e-Alam, M.; Lazos, O.; Foster, T. A.; Zimmermann, A. S.; Warneck, T. D.; Suthar, D.; Coates, N. J.; Koehn, F. E.; Skotnicki, J. S.; Carter, G. T.; Gregory, M. A.; Martin, C. J,; Moss, S. J.; Leadlay, P. F.; Wilkinson, B. Proc. Natl. Acad. Sci. U. S. A. 2011, 108, 4776-4781.

(5) Ban, Y. H.; Shinde, P. B.; Hwang, J. Y.; Song, M. C.; Kim, D. H.; Lim, S. K.; Sohng, J. K.; Yoon, Y. J. J. Nat. Prod. 2013, 76, 1091-1098.

(6) Perfect, J.; Schell, W.; Rinaldi, M. J. Med. Vet. Mycol. 1993, 31, 175-179.

(7) Fonzi, W. A.; Irwin, M. Y. Genetics 199, 134, 717-728.

(8) Nierman, W. C.; Pain, A.; Anderson, M. J.; Wortman, J. R.; Kim, H. S.; Arroyo, J.; Berriman, M.; Abe, K.; Archer, D. B.; Bermejo, C.; Bennett, J.; Bowyer, P.; Chen, D.; Collins, M.; Coulsen, R.; Davies, R.; Dyer, P. S.; Farman, M.; Fedorova, N.; Fedorova, N.; Feldblyum, T. V.; Fischer, R.; Fosker, N.; Fraser, A.; García, J. L.; García, M. J.; Goble, A.; Goldman, G. H.; Gomi, K.; Griffith-Jones, S.; Gwilliam, R.; Haas, B.; Haas, H.; Harris, D.; Horiuchi, H.; Huang, J.; Humphray, S.; Jiménez, J.; Keller, N.; Khouri, H.; Kitamoto, K.; Kobayashi, T.; Konzack, S.; Kulkarni, R.; Kumagai, T.; Lafon, A.; Latgé, J. P.; Li, W.; Lord, A.; Lu, C.; Majoros, W. H.; May, G. S.; Miller, B. L.; Mohamoud, Y.; Molina, M.; Monod, M.; Mouyna, I.; Mulligan, S.; Murphy, L.; O'Neil, S.; Paulsen, I.; Peñalva, M. A.; Pertea, M.; Price, C.; Pritchard, B. L.; Quail, M. A.; Rabbinowitsch, E.; Rawlins, N.; Rajandream, M. A.; Reichard, U.; Renauld, H.; Robson, G. D.; Rodriguez de Córdoba, S.; Rodríguez-Peña, J. M.; Ronning, C. M.; Rutter, S.; Salzberg, S. L.; Sanchez, M.; SánchezFerrero, J. C.; Saunders, D.; Seeger, K.; Squares, R.; Squares, S.; Takeuchi, M.; Tekaia, F.; Turner, G.; Vazquez de Aldana, C. R.; Weidman, J.; White, O.; Woodward, J.; Yu, J. H.; Fraser, C.; Galagan, J. E.; Asai, K.; Machida, M.; Hall, N.; Barrell, B.; Denning, D. W. Nature 2005, 438, 1151-1156. 
(9) Mo, S.; Kim, D. H.; Lee, J. H.; Park, J. W.; Basnet, D. B.; Ban, Y. H.; Yoo, Y. J.; Chen, S. W.; Park, S. R.; Choi, E. A.; Kim, E.; Jin, Y. Y.; Lee, S. K.; Park, J. Y.; Liu, Y.; Lee, M. O.; Lee, K. S.; Kim, S. J.; Kim, D.; Park, B. C.; Lee, S. G.; Kwon, H. J.; Suh, J. W.; Moore, B. S.; Lim, S. K.; Yoon, Y. J. J. Am. Chem. Soc. 2010, 133, 976-985. 